\title{
ipen
}

Autarquia associada à Universidade de São Paulo

\section{Análise da influência dos gases de proteção nas propriedades da solda a laser da liga Ti6AI4V}

Douglas Ramos da Silva

Dissertação apresentada como parte dos requisitos para obtenção do Grau de Mestre em Ciências na área de Tecnologia Nuclear - Materiais.

Orientador:

Dr. Wagner de Rossi

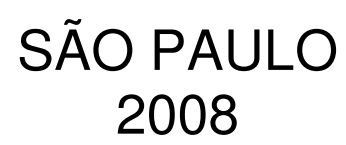




\section{ipen}

Autarquia associada à Universidade de São Paulo

\section{Análise da influência dos gases de proteção nas propriedades da solda a laser da liga Ti6AI4V}

Douglas Ramos da Silva

Dissertação apresentada como parte dos requisitos para obtenção do Grau de Mestre em Ciências na área de Tecnologia Nuclear - Materiais.

Orientador:

Dr. Wagner de Rossi

SÃO PAULO

2008 


\section{DEDICATÓRIA}

Dedico este trabalho em memória de minha mãe, por tudo que ela me ensinou e por fazer parte da pessoa que sou hoje. 


\section{AGRADECIMENTOS}

À Deus acima de tudo, por ter me dado a oportunidade de chegar até aqui.

Ao meu orientador, Dr. Wagner de Rossi, por toda a ajuda dada no trabalho, mostrando-me caminhos e oportunidades e pela orientação sempre presente.

Ao Dr. Milton Sérgio Fernandes de Lima, por disponibilizar as instalações do IEAv e por ajudar na interpretação dos resultados.

Ao IPEN e ao IEAv por ceder as instalações para a realização deste trabalho.

À FAPESP, à CAPES e ao IFM por todo apoio financeiro concedido.

Aos meus colegas de laboratório Dr. José Roberto Berreta, Dr. Ivan Alves de Almeida e Leandro Mattiolli Machado pela ajuda, sugestões e pela amizade.

Ao Laboratório de Fenômenos de superfície da Escola Politécnica da USP e aos seus técnicos Jovanio e Leandro, por ceder o equipamento para os ensaios de microdureza.

À Dra. Sonia Licia Baldochi e Dra. Izilda Márcia Ranieri por ceder o microscópio óptico e a câmera digital.

Ao Dr. Maurício David M. das Neves pelo empréstimo do dispositivo para o ensaio de flexão.

Ao Dr. Luiz Vicente Gomes Tarelho, Dr. Anderson Zanardi de Freitas, Dr. Nilson Dias Vieira Jr., Dra. Lília Coronato Courrol e à Dra. Ana Maria do Espírito Santo por todo apoio e confiança cedida desde a iniciação científica. Devo muito a vocês, obrigado.

Aos técnicos Marcos e Paulo do Centro de Lasers e Aplicações e aos técnicos do Centro de Ciências e Tecnologia dos Materiais por todo o apoio e instruções oferecidas.

Aos meus colegas e amigos do Centro de Lasers e Aplicações, Fernando, Thiago, Jair, Horácio, Marcello, Ivanildo, Daniel, Eduardo, 
Jonas e Fabíola, pelo apoio nas horas de estudo, pelas risadas e principalmente pelas inesquecíveis pausas para o café.

Ao meu pai, Ramos, e ao meu irmão, Danilo, por estarem juntos comigo nesta batalha da vida, que apesar de ter sido injusta conosco, nos uniu mais ainda. À Adriana por nos fazer perder a paciência e por ajudar a equilibrar nossas vidas.

À minha companheira, conselheira e namorada, Daiane, por toda a atenção, o incentivo, os conselhos e principalmente os puxões de orelha que foram dados desde antes do início deste trabalho.

Aos meus amigos Danilo, Paula, Rildo, Clarisse, Douglas, Diogo, Henrique e Priscila por todo apoio que tive, por me ajudar a esfriar a cabeça e por me incentivar neste difícil caminho.

Àqueles não citados, por favor, culpem minha memória, mas não o coração. 


\title{
ANÁLISE DA INFLUÊNCIA DOS GASES DE PROTEÇÃO NAS PROPRIEDADES DA SOLDA A LASER DA LIGA TI6AL4V
}

\author{
Douglas Ramos da Silva
}

\section{RESUMO}

O titânio é um material leve e resistente que possui aplicações em várias áreas, das quais podemos destacar a área médica, a aeronáutica e a nuclear. Porém, devido à sua alta reatividade a altas temperaturas com o oxigênio e outros elementos químicos presentes no ar, a soldagem deste material pode ser muito difícil. O uso de fontes de energia de alta intensidade como o laser, produz uma menor zona afetada pelo calor, diminuindo a área oxidada.

Porém, mesmo assim há a necessidade do uso de uma atmosfera de proteção neutra, formada por hélio, argônio ou misturas destes gases. Esta atmosfera interage com o processo através de mudanças na formação de plasma, modificando as características da solda, como a largura do cordão e a penetração, podendo também provocar o aparecimento de porosidades nestes cordões.

Neste trabalho foi verificada a influência do uso de argônio, hélio e misturas destes gases na soldagem com laser pulsado da liga Ti6Al4V. Também foi feito um estudo verificando a necessidade do uso de diferentes fluxos e dispositivos de proteção na soldagem. Foi verificado que as características físicas e mecânicas do cordão d solda não são modificadas significativamente pelos gases, e que apesar de haver um aumento na dureza pela falta de uma proteção de raiz, esta também não causa efeitos negativos na resistência da solda.

$\mathrm{Na}$ soldagem do mesmo material com laser contínuo foram estudadas as influências dos parâmetros de soldagem, comparando-os com simulações matemáticas. Os resultados mostraram que a simulação pode ser utilizada para prever a largura do cordão de solda e das zonas afetadas pelo calor e oxidadas. 


\title{
ANALISIS OF GAS SHIELDING INFLUENCE IN THE PROPERTIES OF TI6AL4V LASER WELDING
}

\author{
Douglas Ramos da Silva
}

\begin{abstract}
Titanium is a light and resistant material that has applications in many areas, such as medical, aeronautic and nuclear. However, due to its high temperature reactivity with oxygen and other air elements, welding of this material may be very difficult. The use of high intensity energy sources such as the laser, generates a smaller heat affected zone, reducing the oxided area.

Nevertheless, there is still the need of the use of a neutral gas protection, of helium, argon or both. This protection interacts with the process through changes in plasma formation, modifying characteristics of the weld, as the weld width and penetration, or even the appearance of porosity.

In this work it was verified the influence of the use of argon, helium or mixtures of these gases in Ti6Al4V pulsed laser welding. It was also done a study verifying the need of the use of different gas fluxes and welding protection devices. It was verified that the mechanical and physical characteristics of the weld are not significantly modified by the gases, and that although there is a raise in the weld hardness if no backshielding is used, there is not a change in the tensile strength of the weld.

In the welding of the same material with a continuous wave laser, the influences of the welding parameters were studied, comparing them with mathematical simulations. The results showed that the simulation may be used to predict the weld width, heat affected and oxided zones.
\end{abstract}




\section{SUMÁRIO}

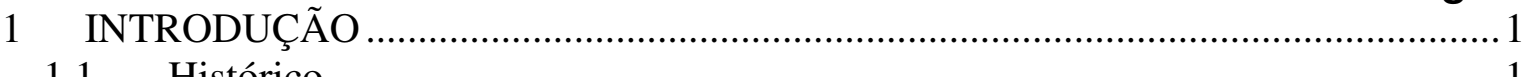

Página

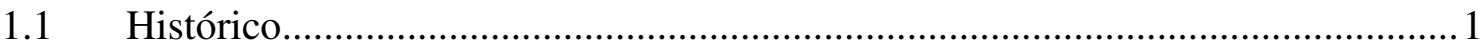

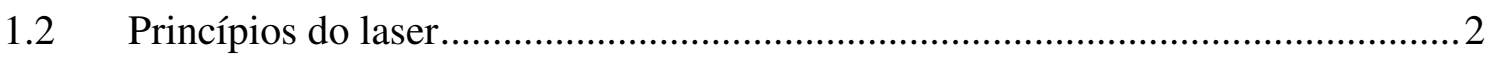

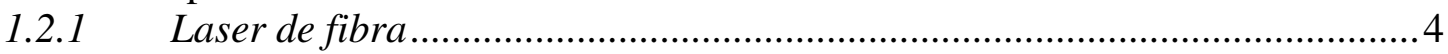

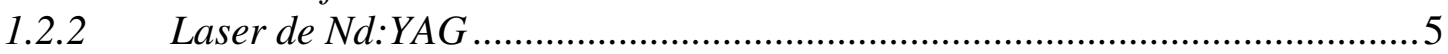

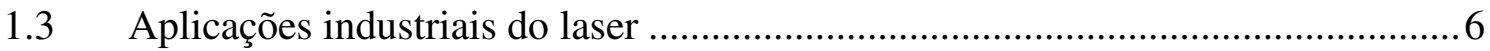

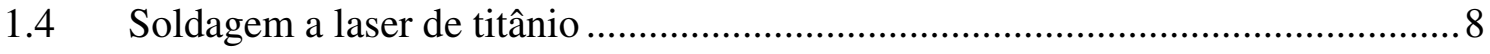

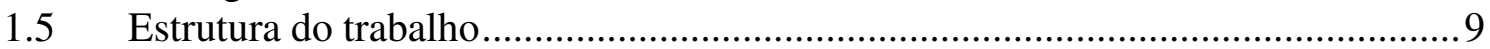

2 INTERAÇÃO LASER-MATÉRIA E AQUECIMENTO DE MATERIAIS ............... 11

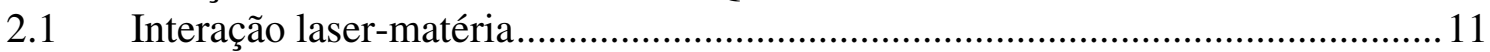

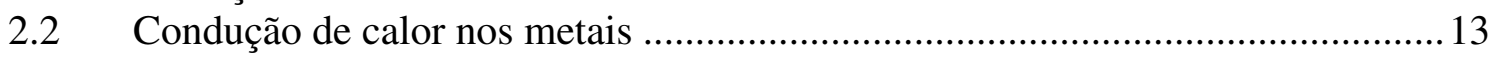

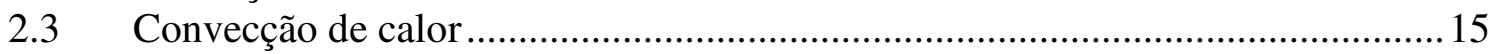

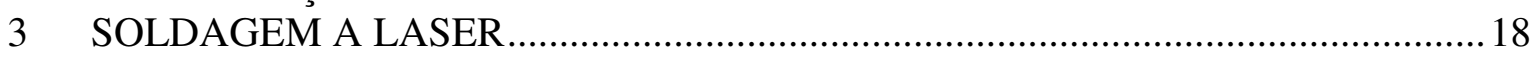

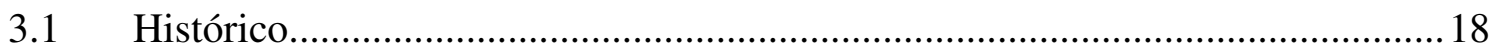

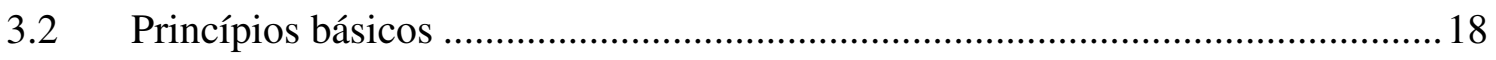

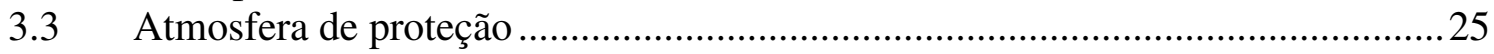

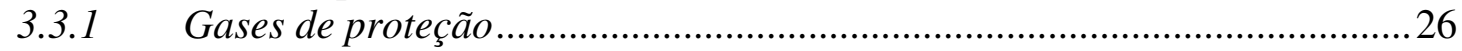

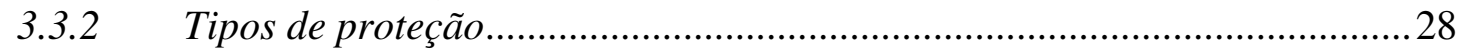

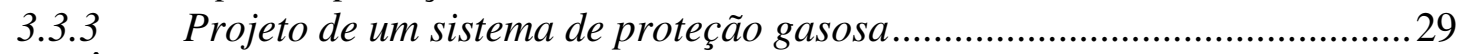

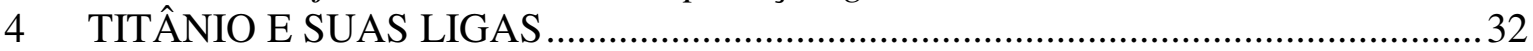

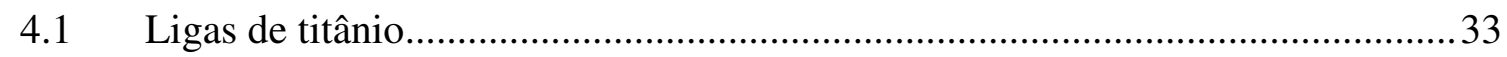

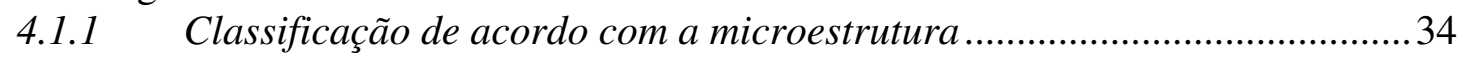

4.1.2 Classificação de acordo com a linha de transformação martensítica ..........35

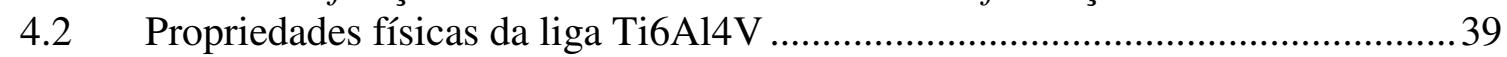

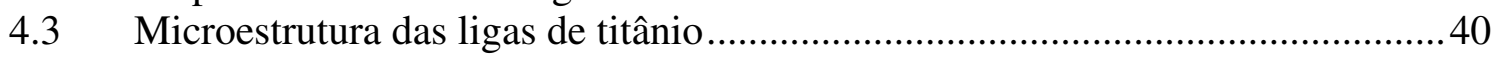

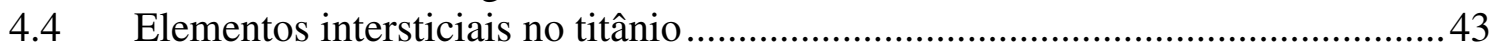

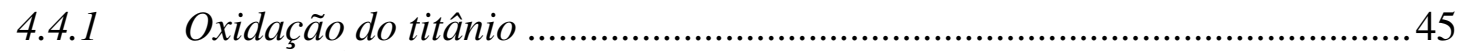

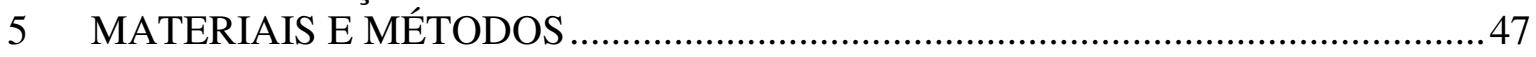

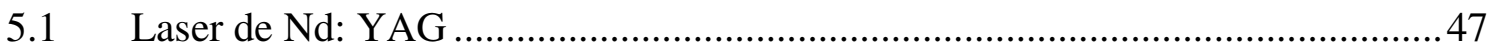

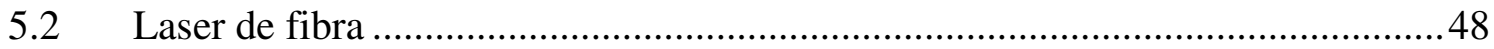

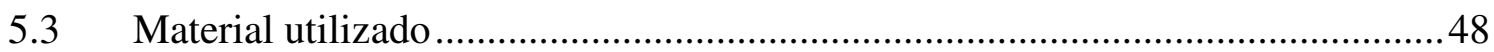

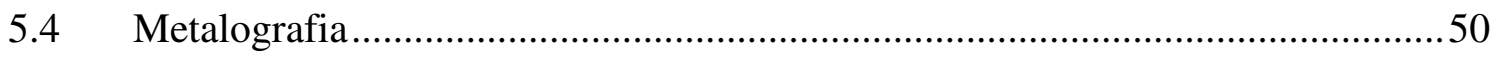

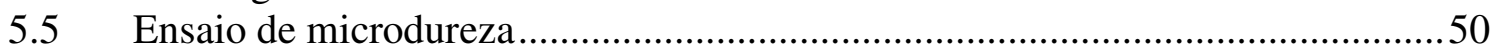

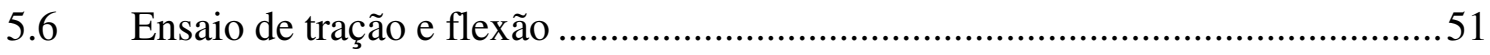

5.7 Microscopia eletrônica de varredura e espectroscopia por energia dispersiva ....54

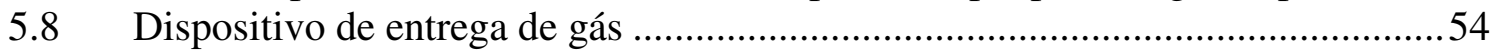

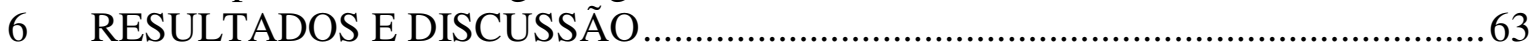

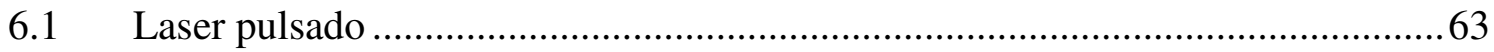

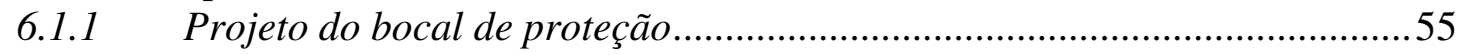

6.1.2 Análise dos parâmetros iniciais na soldagem com o laser pulsado .............63

6.1.3 Influência dos gases de proteção na soldagem com laser pulsado ...............72

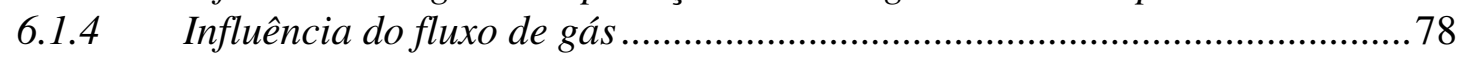

6.1.5 Verificação da influência da proteção de raiz.............................................79

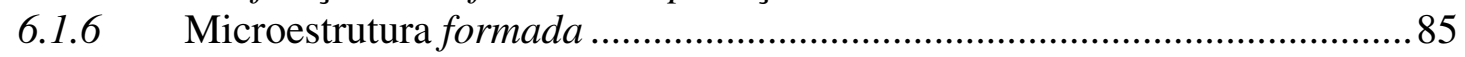

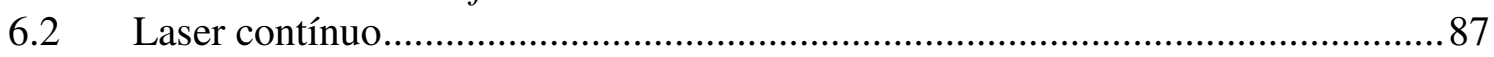

6.2.1 Análise dos parâmetros iniciais na soldagem com o laser contínuo............87 87

6.2.2 Simulações Matemáticas........................................................................... 92 


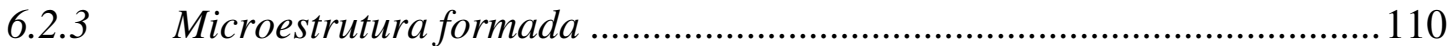

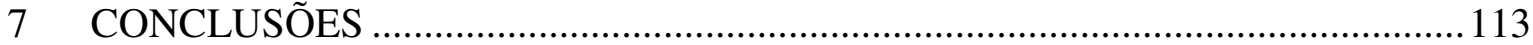

8 APÊNDICE - MODELO DE ROSENTHAL COM PERDAS DE CALOR POR

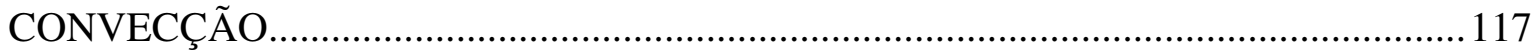

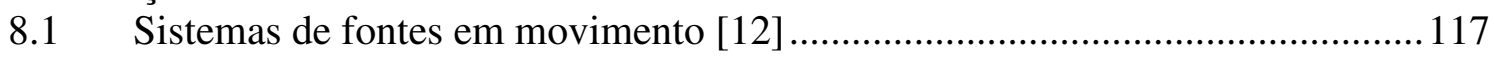

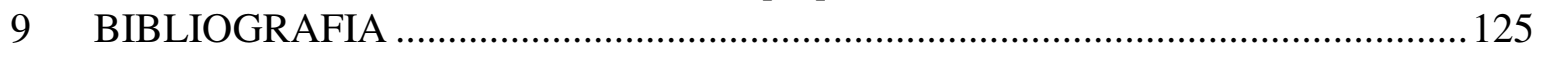




\section{LISTA DE TABELAS}

Tabela 1-1- Histórico dos principais tipos de lasers [2] ......................................

Tabela 3-1 - Propriedades físicas do hélio e argônio [28] ..................................27

Tabela 4-1 - Elementos de liga do titânio [16] ................................................34

Tabela 4-2 - Propriedades mecânicas da liga Ti6AI4V [50].................................39

Tabela 4-3 - Propriedades térmicas da liga Ti6Al4V [50] .................................40

Tabela 4-4 - Efeito dos elementos intersticiais no titânio puro [16] ......................44

Tabela 5-1 - Composição química da chapa Ti6Al4V [57] .................................49

Tabela 5-2 - Composição da chapa utilizada determinada por fluorescência de

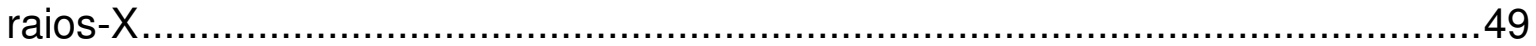

Tabela 6-1 - Primeiras condições de soldagem utilizadas no laser de Nd:YAG...63 Tabela 6-2- Valores da extensão da zona afetada pelo calor, cavidade formada pela solda e profundidade da poça fundida em micrometros.

Tabela 6-3 - Condições utilizadas para verificação da influência dos gases de proteção

Tabela 6-4 - Condições utilizadas para verificar a influência do tipo de gás na soldagem com laser pulsado..............................................................................74

Tabela 6-5 - Média dos valores obtidos ........................................................75

Tabela 6-6 - Valores médios de dureza para diferentes condições de proteção da

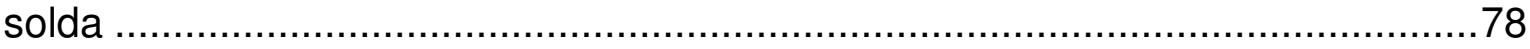

Tabela 6-7 - Valores da largura do cordão de solda para diferentes fluxos ..........79

Tabela 6-8 - Condições utilizadas nas soldas dos ensaios mecânicos ..................80

Tabela 6-9 - Resultados obtidos no ensaio de tração das soldas com laser

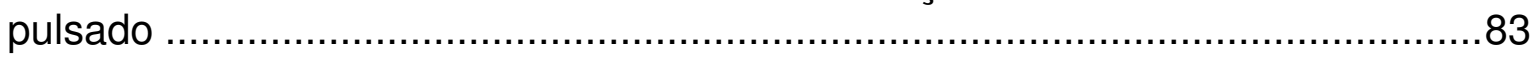

Tabela 6-10 - Parâmetros utilizados para o laser desfocalizado $(\mathrm{d}=1,9 \mathrm{~mm}) \ldots . . .87$

Tabela 6-11 - Parâmetros utilizados para soldagem com o laser focalizado na superfície

Tabela 6-12 - Comparação dos melhores parâmetros para o laser contínuo e o

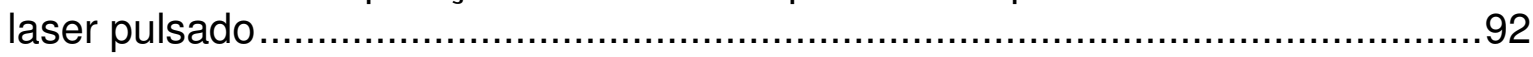

Tabela 6-13 - Valores utilizados para comparação dos dois modelos ..................93

Tabela 6-14 - Variação vertical e horizontal entre as duas simulações..................97

Tabela 6-15 - Variáveis do problema proposto..................................................99

Tabela 6-16 - Projeto da análise ..............................................................100

Tabela 6-17 - SNR para cada combinação utilizada .......................................101

Tabela 6-18 - Valor da SNR para os níveis 1 e 2 dos parâmetros utilizados .....102

Tabela 6-19 - Resultados obtidos a partir de simulações matemáticas .............107

Tabela 6-20 - Valor da largura da isoterma de 600드 para as amostras 1 e $8 \ldots 110$ 


\section{LISTA DE FIGURAS}

Figura 1-1- Esquema simplificado de uma cavidade laser...................................

Figura 1-2 - Laser de fibra ...................................................................

Figura 1-3 - Esquema dos principais processos industriais a laser [2] ..................

Figura 2-1 - Feixe incidente, fração refletida e absorvida por uma superfície

metálica .............................................................................................

Figura 2-2 - Convecção do ar em uma parede aquecida ...................................16

Figura 3-1 - Soldagem a laser por condução [2] ……...................................20

Figura 3-2 - Soldagem a laser de penetração [2] ……………………….......21

Figura 3-3 - Múltiplas reflexões que ocorrem na parede do keyhole ...................22

Figura 3-4 - Processo de instabilidade do keyhole; a) início da formação da cavidade; b) profundidade máxima alcançada; c) fechamento do keyhole pelo material fundido da superfície. ..................................................................23

Figura $3-5$ - Trem de pulsos quadrados .................................................24

Figura 3-6 - Padrão obtido na soldagem com laser pulsado [21] .......................25

Figura 3-7 - Sistemas de proteção gasosa na soldagem a laser..........................28

Figura 4-1 - Principais redes bravais encontradas no titânio; a) célula cúbica de corpo centrado; b) célula hexagonal compacta; c) célula ortorrômbica simples. ..33 Figura 4-2 - Seção esquemática para ligas de titânio contendo estabilizadores $\alpha$ e

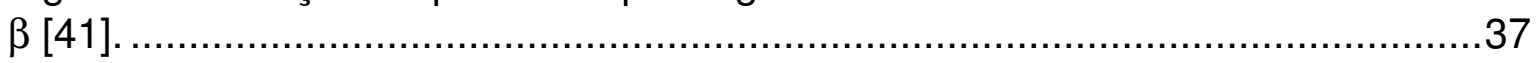

Figura 4-3 - Formação da estrutura Widmanstäten na liga Ti6Al4V; a fase $\alpha$ é representada pela parte clara e a fase $\beta$ pela parte escura [49] . ........................42 Figura 4-4 - Diferentes fases formadas na liga Ti6AI4V dependendo da temperatura de têmpera [49] ....................................................................43

Figura 5-1 - Central de Processamento de Materiais a Laser (CPML) .................48

Figura 5-2 - Máquina universal de ensaios mecânicos. .......................................51

Figura 5-3 - Esquema do ensaio de flexão...............................................52

Figura 5-4 - Esforços submetidos na amostra durante o ensaio de flexão............52

Figura 5-5 - Dispositivo e amostras do ensaio de flexão.....................................53

Figura 5-6 - Corpo de prova utilizado no ensaio de tração..................................53

Figura 5-7 -Dispositivo de proteção com câmara inferior. ....................................55

Figura 6-1 - Fluxo limite para o argônio........................................................56

Figura 6-2 - Fluxo limite para o hélio ..........................................................56

Figura 6-3 - Aproximação para cálculo do número de Reynolds na saída bico-

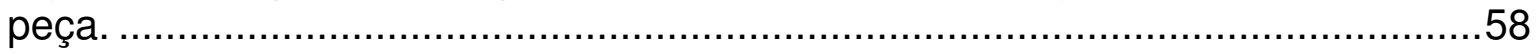

Figura 6-4 - Modificações na pressão provocadas pelo gás de proteção. ............60

Figura 6-5 - Variáveis do projeto do bocal........................................................61

Figura 6-6 - Projeto do bocal utilizado nas soldas.........................................62

Figura 6-7 - Aspecto da parte superior da chapa de Ti6Al4V após os testes.......64

Figura 6-8 - Aspecto do verso da chapa de Ti6Al4V após os testes....................64

Figura 6-9 - Microscopia óptica da secção transversal das soldas realizadas. ....66

Figura 6-10 - Resultados do ensaio de microdureza da amostra 2: a) pontos

analisados; b) Gráfico com os valores medidos...............................................67

Figura 6-11- Resultados do ensaio de microdureza da amostra 4: a) pontos

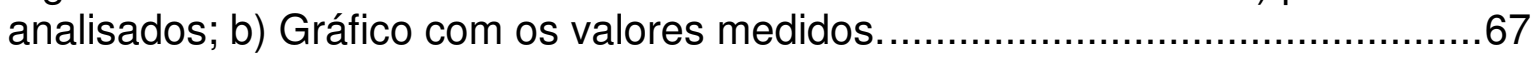

Figura 6-12 - Microscopia óptica da amostra 6 mostrando duas fases distintas na região soldada. 
Figura 6-13 - Estruturas formadas nas soldas 3: a) pontos observados na amostra; b) próximo à superfície; c) próximo à divisória entre a zona afetada pelo

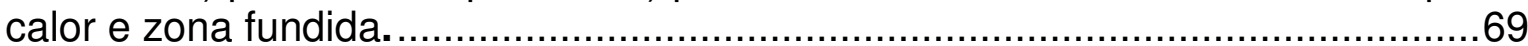

Figura 6-14 - Análises por EDS realizadas no centro dos cordões de solda........70 Figura 6-15 - Análises de EDS da amostra 3; a) Material base; b) $5 \mu \mathrm{m}$ de profundidade; c) $15 \mu \mathrm{m}$ de profundidade.

Figura 6-16 - Análises de EDS da raiz de solda da amostra 4; a) $5 \mu \mathrm{m}$ de profundidade; b) $10 \mu \mathrm{m}$ de profundidade; c) $20 \mu \mathrm{m}$ de profundidade; d) material base.

Figura 6-17 - Aspecto da chapa irradiada, mostrando as amostras de 1 a 5, conforme Tabela 6-4.

Figura 6-18 - Cordão de solda protegido com hélio axialmente e argônio na raiz.

Figura 6-19 - Padrão de microdureza da solda da Figura 6-18 .........................76

Figura 6-20 - Cordão de solda protegido com argônio axialmente e na raiz..........77

Figura 6-21 - Padrão de microdureza obtido para a solda da Figura 6-20 ...........77

Figura 6-22 - Ensaio de flexão das soldas com laser pulsado com a carga aplicada no topo.

Figura 6-23 - Ensaio de flexão das soldas com laser pulsado com a carga

aplicada na raiz.

Figura 6-24 - Ensaio de tração de amostra protegida axialmente com argônio ...82 Figura 6-25 - Algumas amostras após o ensaio de tração; a) protegida axialmente com argônio; b) sem proteção de raiz; c) protegida axialmente com hélio ............83 Figura 6-26 - Fratografia de uma das amostras rompidas na zona fundida.........84 Figura 6-27 - Fratografia revelando a presença de dimples................................85 Figura 6-28 - Estruturas formadas na soldagem com laser pulsado; a) amostra 1

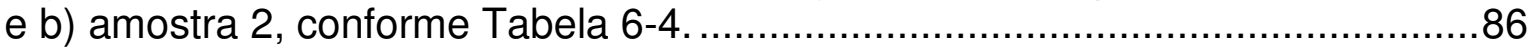
Figura 6-29 - Variação da largura do cordão de solda para o laser contínuo........89 Figura 6-30 - Variação da profundidade da poça de fusão para o laser contínuo.

Figura 6-31 - Alguns cordões de solda realizados com o laser contínuo; a) frente;

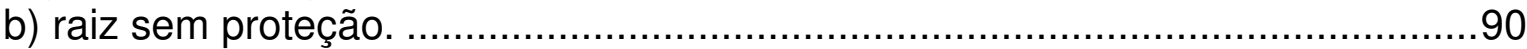

Figura 6-32 - Raízes protegidas com atmosfera neutra ...................................90

Figura 6-33 - Simulação 1, comparando os modelos de Rosenthal com e sem perdas de calor por convecção

Figura 6-34 - Simulação 2, comparando os modelos de Rosenthal com e sem perdas de calor por convecção

Figura 6-35 - Cálculo da variação dos campos de temperatura nos dois modelos de Rosenthal.

Figura 6-36 - Análise de Taguchi para a divergência de temperatura na vertical

Figura 6-37 - Análise de Taguchi para a divergência de temperatura na horizontal

Figura 6-38 - Simulação das isotermas da amostra 2 ..................................106

Figura 6-39 - Zonas pressentes na superfície dos cordões de solda .................107

Figura 6-40 - Comparação dos resultados obtidos em simulação com o real....108

Figura 6-41 - Microestrutura formada nas soldas com penetração total ............111

Figura 6-42 - Comparação do tamanho do grão de alfa equixial formado entre a soldagem com laser pulsado (a) e com o laser contínuo (b)...............................111 
Figura 8-1- Sistema de coordenadas duplo para fontes de calor em movimento ( $\xi$ $=\mathrm{x}-\mathrm{v} \cdot \mathrm{t})$. 117

Figura 8-2- Ordens zero e um das funções modificadas de Bessel de primeiro e segundo tipo 123 


\section{LISTA DE SÍMBOLOS E ABREVIAÇÕES}

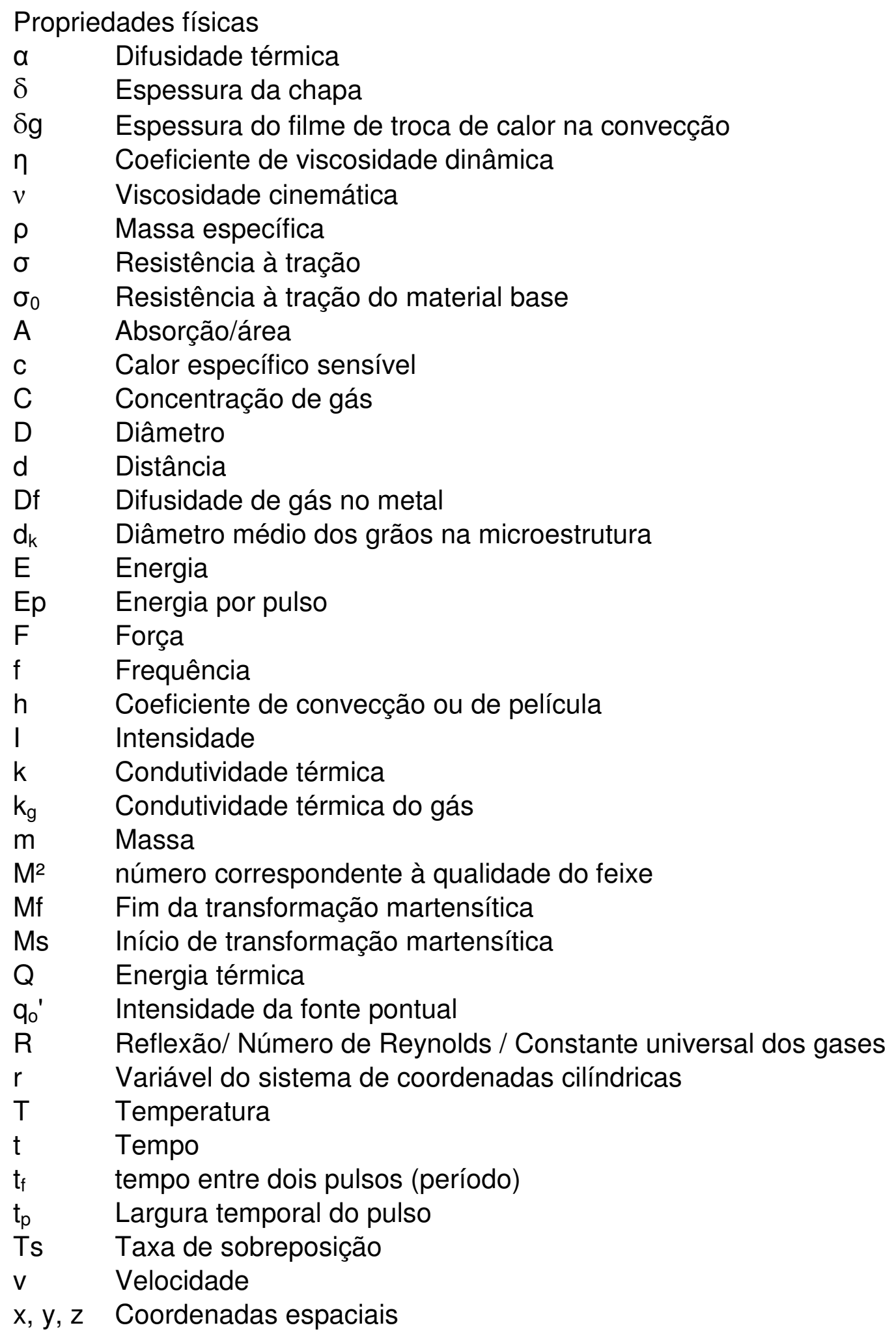


Funções de Bessel

$J_{n} \quad$ Função de Bessel de primeiro tipo e ordem $n$

$I_{n} \quad$ Função de Bessel de segundo tipo e ordem $n$

$\mathrm{Y}_{\mathrm{n}} \quad$ Função de Bessel modificada de primeiro tipo e ordem $\mathrm{n}$

$\mathrm{K}_{\mathrm{n}} \quad$ Função de Bessel modificada de segundo tipo e ordem $\mathrm{n}$

Elementos químicos

$\begin{array}{llll}\text { Al } & \text { Alumínio } & \mathrm{O} & \text { Oxigênio } \\ \mathrm{Ar} & \text { Argônio } & \mathrm{Si} & \text { Silício } \\ \mathrm{C} & \text { Carbono } & \mathrm{Sn} & \text { Estanho } \\ \mathrm{Fe} & \text { Ferro } & \mathrm{Ta} & \text { Tântalo } \\ \mathrm{H} & \text { Hidrogênio } & \mathrm{Ti} & \text { Titânio } \\ \mathrm{He} & \text { Hélio } & \mathrm{V} & \text { Vanádio } \\ \mathrm{Mo} & \text { Molibidênio } & \mathrm{W} & \text { Tungstênio } \\ \mathrm{Nb} & \text { Nióbio } & \mathrm{Yb} & \text { Itérbio } \\ \mathrm{Nd} & \text { Neodímio } & \mathrm{Zr} & \text { Zircônio }\end{array}$

Estrutura do titânio e metalurgia

a Estrutura do titânio à temperatura ambiente (célula unitária hexagonal compacta)

$\beta \quad$ Estrutura do titânio após temperatura de transformação alotrópica (célula unitária cúbica de corpo centrado)

$\alpha^{\prime} \quad$ Martensita do titânio (célula unitária hexagonal compacta)

a" Martensita do titânio (célula unitária ortorrômbica)

ccc Célula unitária cúbica de corpo centrado

hcp Célula unitária hexagonal compacta

Abreviações

ABNT Associação Brasileira de Normas técnicas

AT Aporte térmico

CNC Computer Numerical Control - Controle numérico computadorizado

EBW Electron beam welding - Soldagem com feixe de elétrons

EDS Energy Dispersive Spectroscopy - Espectroscopia por Energia

Dispersiva

HV Hardness Vickers - Dureza Vickers

LBW Laser beam welding - Soldagem a laser

MB Material Base

PPF Profundidade da poça fundida

SNR Signal/Noise Ratio - Razão entre sinal e ruído

SDOE Statistical Design Of Experiments - Projeto Estatístico de Experimentos

ZAC Zona Afetada pelo calor

ZF Zona Fundida

ZO Zona Oxidada 


\section{INTRODUÇÃO}

\subsection{Histórico}

A palavra LASER é um acrônimo para Light Amplification by Stimulated Emission of Radiation. O laser é uma fonte de luz monocromática, colimada e coerente.

Os fundamentos para a teoria do laser foram feitos por Einstein, que formulou os princípios básicos de absorção, emissão espontânea e emissão estimulada de um material [1, 2]. Após isto, Kopfermann e Ladenburg apresentaram as primeiras confirmações experimentais das previsões de Einstein. Em 1960, Maiman desenvolveu o primeiro laser de rubi, trabalho que foi seguido por outros pesquisadores de forma que em 1968, os lasers mais importantes (lasers de semicondutores, $\mathrm{CO}_{2}, \mathrm{Nd}$ : YAG, corantes, etc) já tinham sido fabricados [2]. A Tabela 1-1 mostra um resumo dos avanços ocorridos naquela época.

Os anos posteriores a 1969 foram dedicados ao melhoramento dos lasers já existentes, como o aumento da eficiência, confiabilidade e durabilidade. Com estes avanços, os lasers se tornaram, no meio da década de 70 , mais apropriados para as aplicações industriais como corte, soldagem, furação e marcação. Na década de 80 e início da década de 90 houve várias pesquisas para a área de aplicações na engenharia de superfície [2]. 
Tabela 1-1- Histórico dos principais tipos de lasers [2]

\begin{tabular}{|c|c|c|}
\hline Laser & Surgimento & Algumas aplicações \\
\hline Rubi & 1960 & $\begin{array}{l}\text { Metrologia, Aplicações médicas, } \\
\text { processamento de material inorgânico, } \\
\text { furação. }\end{array}$ \\
\hline Nd: vidro & 1961 & $\begin{array}{l}\text { Medidas de velocidade e comprimento, } \\
\text { furação. }\end{array}$ \\
\hline Diodo & 1962 & $\begin{array}{l}\text { Processamento de semicondutores, } \\
\text { aplicações biomédicas, soldagem, } \\
\text { telecomunicações. }\end{array}$ \\
\hline $\mathrm{He}-\mathrm{Ne}$ & 1962 & $\begin{array}{l}\text { Medidas de velocidade e comprimento, } \\
\text { sistemas de alinhamento. }\end{array}$ \\
\hline $\mathrm{CO}_{2}$ & 1964 & $\begin{array}{l}\text { Processamento de materiais - corte e } \\
\text { soldagem, fusão atômica. }\end{array}$ \\
\hline Nd: YAG & 1964 & $\begin{array}{l}\text { Processamento de materiais, soldagem, } \\
\text { técnicas analíticas. }\end{array}$ \\
\hline Íon de argônio & 1964 & Aplicações médicas. \\
\hline Corante & 1966 & $\begin{array}{l}\text { Detecção de poluição, separação } \\
\text { isotópica. }\end{array}$ \\
\hline Vapor de cobre & 1966 & Separação isotópica. \\
\hline Excímero & 1975 & $\begin{array}{l}\text { Aplicações médicas, processamento de } \\
\text { materiais, coloração. }\end{array}$ \\
\hline
\end{tabular}

\subsection{Princípios do laser}

O laser baseia-se basicamente no processo de emissão estimulada [1]. Este processo depende de uma inversão de população, ou seja, depende de que os estados de maior energia estejam com uma grande concentração de população, maior do que normalmente ocorre. Como isto não é uma condição de equilíbrio encontrada na natureza, ela tem que ser forçada através de uma energia externa. 
Para provocar esta inversão de população há várias maneiras que dependem da característica do meio ativo, dentre as quais podemos citar:

- $\quad$ Bombeamento por lâmpada (luz);

- $\quad$ Aplicação de uma diferença de potencial;

- $\quad$ Bombeamento por outro laser (luz).

O meio ativo do laser é onde ocorre a inversão de população e a emissão estimulada que provoca a amplificação. Ele pode ser sólido (Nd:YAG, Nd: YLF, Ruby, Ti:Safira, Yb: vidro, etc), líquido (lasers de corante) ou gasoso $\left(\mathrm{CO}_{2} \mathrm{e}\right.$ $\mathrm{HeNe}$ ). As diferenças entre os meios ativos são o comprimento de onda emitido pelo laser, a potência máxima que pode ser atingida e sua facilidade de manuseio $[1,2]$.

O laser consiste basicamente de uma cavidade ressonante com o meio ativo no seu interior sendo bombeado pela fonte externa. A cavidade mais simples é constituída por dois espelhos planos, um que reflete totalmente e outro que reflete parcialmente a luz incidida, como mostrado na figura abaixo:

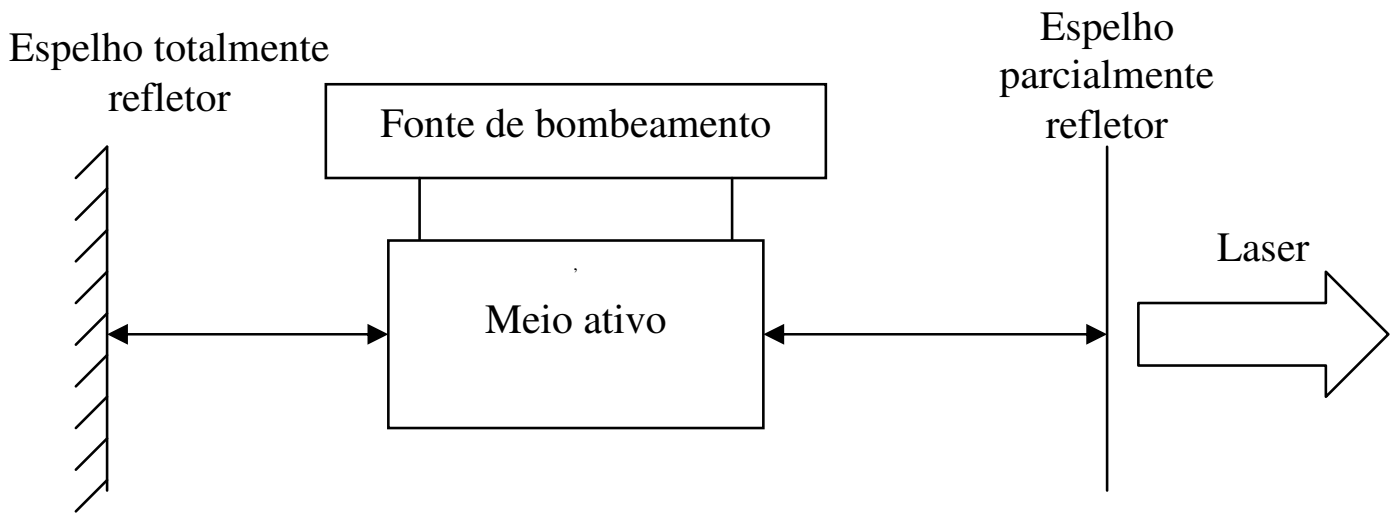

Figura 1-1- Esquema simplificado de uma cavidade laser.

Ao ser bombeado, o meio ativo passa por uma inversão de população. Os elétrons (ou moléculas) excitados para o nível de energia superior decaem para um estado chamado de metaestável [1]. Este estado possui um tempo de 
decaimento muito longo $\left(\sim 10^{-4}\right.$ a $\left.10^{-6} \mathrm{~s}\right)$ e acumula os elétrons. Quando um destes elétrons decai para o nível fundamental, produz um fóton que pode estimular o decaimento dos outros elétrons, produzindo uma avalanche de fótons com a mesma direção, frequência, polarização e fase do fóton original.

Estes fótons produzidos vão em direção ao espelho parcialmente refletor e parte deles saem da cavidade. Outra parte volta para o meio ativo e estimula outros fótons com os elétrons que já foram bombeados para o estado metaestável, criando novos fótons e assim por diante, até que se alcance um equilíbrio.

\subsubsection{Laser de fibra}

O primeiro uso de lasers de fibra data para o início dos anos 60 , quando lasers de baixa potência eram usados em amplificadores ópticos [3]. No ano 2000, o primeiro laser de fibra de $100 \mathrm{~W}$ foi produzido para processamento de materiais [4].

A tecnologia empregada mais recentemente para lasers de fibra permite potências de $17 \mathrm{~kW}$ para os lasers de fibra comerciais, com perspectivas de aumento para os próximos anos [3]. Maiores potências são atingidas combinando as saídas de vários lasers de fibras [5].

Eles possuem uma alta eficiência e boa qualidade de feixe (com $\mathrm{M}^{2}$ variando de 7 a 10) e são mais compactos que os lasers de $\mathrm{Nd} Y \mathrm{YAG}$ e $\mathrm{CO}_{2}$, e prometem um custo de manutenção menor quando comparado com os outros lasers [3]. Além disto, por se tratar de uma fibra óptica, seu posicionamento e consequentemente sua automação é mais simples que os demais lasers. 
O meio ativo da fibra é o seu próprio núcleo dopado com um íon de terra rara. O feixe de bombeamento é disparado longitudinalmente ao longo do comprimento da fibra e pode ser guiado tanto pelo próprio núcleo, como ocorre para lasers de "modo simples" ou pelo "cladding" interno ao redor do núcleo, como mostrado na figura abaixo.
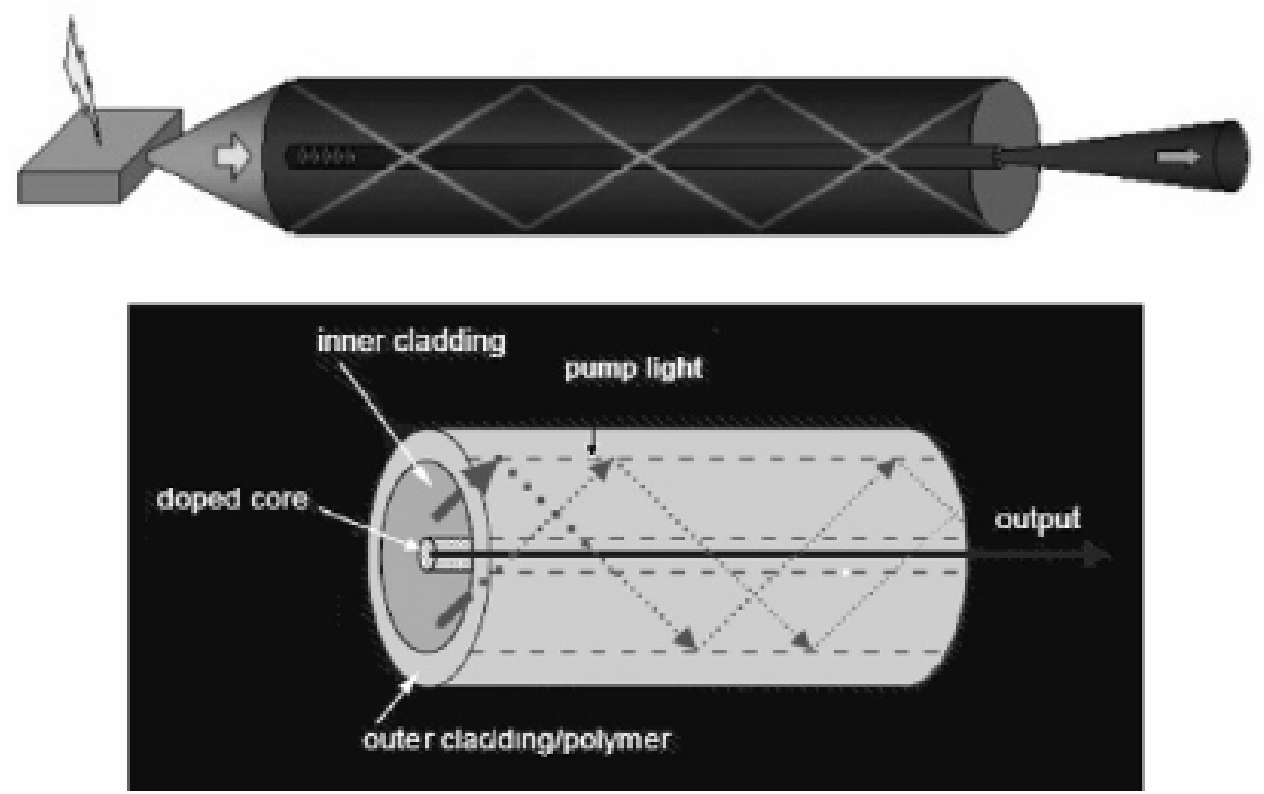

Figura 1-2 - Laser de fibra [6]

\subsubsection{Laser de Nd:YAG}

O meio ativo no laser de Nd:YAG é um monocristal de estrutura cúbica e fórmula química $\mathrm{Y}_{3} \mathrm{Al}_{5} \mathrm{O}_{12}$ dopado com íons de neodímio $\mathrm{Nd}^{3+}$, os quais participam de maneira substitucional aos íons de ítrio na matriz cristalina. A concentração dos íons de neodímio é em torno de $1 \%$, onde a concentração otimizada é de 0,8\% para uma operação contínua e de 1,2\% para operação pulsada. A maior vantagem do YAG em comparação com os outros cristais hospedeiros é sua boa estabilidade térmica. A inversão de população é geralmente obtida por luz de uma lâmpada ou por lasers semicondutores. 
Grande parte da energia elétrica consumida é dissipada em forma de calor tanto na lâmpada quanto no bastão laser. Assim, algum tipo de regrigeração forçada se faz necessária; resfriamento por ar é utilizado em unidades de baixa potência, enquanto que em lasers de maior potência um fluxo de água deionizada é utilizado para refrigeração tanto do bastão laser quanto da lâmpada.

Os lasers de estado sólido de Nd:YAG são os mais utilizados por produzirem altas energias por pulso em curtos intervalos de tempo. A largura temporal do pulso é dada pela eletrônica e controle da lâmpada, e tipicamente se estende de 0,1 a $10 \mathrm{~ms}$.

Como os lasers de Nd:YAG podem ser operados tanto em modo contínuo quanto no pulsado, eles possuem flexibilidade para um vasto campo de aplicações em processamento de materiais. A potência que pode ser disponibilizada nestes lasers os faz competir com os lasers de $\mathrm{CO}_{2}$ em uma variedade de aplicações em soldagem. A possibilidade de entrega do feixe através de fibras ópticas aumenta o campo de aplicações para o processamento de materiais em geometrias complexas [7].

\subsection{Aplicações industriais do laser}

As primeiras aplicações do laser foram baseadas em suas características únicas (coerência espacial e temporal, estabilidade, monocromatilidade e baixa divergência). e incluiam espectroscopia e metrologia. Com o aumento da potência disponibilizada pelos lasers, sua potencialidade para o processamento de materiais começou a ser estudada [7].

Com suas várias vantagens no processamento de materiais como a alta produtividade, a facilidade de automação, os processos sem contato com o 
material, a eliminação da operação de acabamento, o custo reduzido do processo, a melhor qualidade do produto, a melhor utilização do material e a mínima zona afetada pelo calor, o aumento na demanda deste processo aumentou com o passar dos anos [2].

Dentre as várias aplicações industriais existentes podemos citar as aplicações de usinagem (corte, furação, marcação), de junção de materiais (soldagem, brazagem), de engenharia de superfície (aumento de dureza), metrologia (medição de velocidade, rugosidade, deslocamento), etc. Cada uma destas aplicações está ligada a uma intensidade do feixe laser na superfície do material.

A figura a seguir resume alguns destes seguimentos:

\begin{tabular}{ccc} 
& \multicolumn{2}{c}{ Aplicações industriais do laser } \\
Conformação & União de materiais & Usinagem \\
•Dobra/alinhamento & $\bullet$ Soldagem & •Corte \\
•Manufatura rápida & $\bullet$ Brazagem & •Furação \\
& $\bullet$ Sinterização & •Marcação \\
Engenharia de superfície & Metrologia \\
$\bullet$ Endurecimento de superfície & •Posicionamento \\
$\bullet$ Coloração de superfície & $\bullet$ Medidas de velocidade, \\
& distância, fluxo, vibrações, \\
& rugosidade
\end{tabular}

Figura 1-3 - Esquema dos principais processos industriais a laser [2]

Dentre os lasers mais utilizados para a área industrial podemos destacar o laser de Nd: YAG, o laser de $\mathrm{CO}_{2}$ e a tecnologia mais recente do laser de fibra. 


\subsection{Soldagem a laser de titânio}

O titânio é um material leve e resistente e junto com suas ligas possui um grande campo de aplicações que varrem a área nuclear, biomédica, marinha e aeronáutica. Ele passa por uma transformação alotrópica no aquecimento a aproximadamente $900^{\circ} \mathrm{C}$ passando de uma fase alfa com estrutura hexagonal compacta para uma beta com estrutura cúbica de corpo centrado, podendo possuir, dependendo da composição da liga e do tratamento térmico aplicado, a formação de estruturas martensíticas tanto hexagonais quanto ortorrômbicas e a formação de placas Widmanstäten.

$\mathrm{Na}$ soldagem a laser, o titânio passa por aquecimento e resfriamento rápidos comparados com os outros processos de soldagem, formando estruturas que dependem também da atmosfera de proteção na qual se realizou o processo. Elementos como o oxigênio, nitrogênio, carbono e o hidrogênio são possíveis impurezas que são encontradas no material. Por possuírem um pequeno raio atômico estes elementos se acomodam nos interstícios da estrutura cristalina do titânio, dificultando o movimento de imperfeições, aumentando significativamente a dureza, porém fragilisando o cordão de solda [8]. Assim, o titânio deve ser devidamente coberto com uma atmosfera de proteção neutra, como o argônio ou o hélio para que possa ser soldado devidamente.

A literatura mostra [9] que dentre estes gases, as soldas realizadas com o hélio apresentam maior penetração do que aquelas realizadas com o argônio, que apresentam uma largura de cordão maior.

Entretanto, não há na literatura estudos que apontam qual é a atmosfera de proteção ideal, tanto com relação ao gás utilizado nem com relação aos dispositivos necessários, e este trabalho vem de encontro a esta necessidade. 0 
uso de um fluxo de gás excessivo bem como o uso de dispositivos desnecessários pode aumentar consideravelmente o custo final da soldagem, inviabilizando o processo.

\subsection{Objetivos}

\section{Objetivos primários}

Estudar a influência do uso do argônio ou do hélio e do uso ou não de alguns dispositivos de entrega de gás na proteção à oxidação, formato do cordão e propriedades mecânicas da soldagem a laser da liga de Ti6Al4V (titânio grau 5).

\section{Objetivos secundários}

- Análise dos parâmetros de soldagem e sua influência nas características da solda;

- Otimização dos parâmetros, de forma a se obter um cordão de solda com penetração total e mínimas perdas;

- Aplicação de modelo matemático para simular a soldagem do material com um laser contínuo;

- Verificação da validade deste modelo matemático;

- Comparação da microestrutura obtida na solda com os diferentes lasers (pulsado e contínuo).

\subsection{Estrutura do trabalho}

Este trabalho se divide na seguinte forma: no capítulo 2 são apresentados alguns métodos de determinação da temperatura alcançada durante o processo de soldagem. A importância desta parte é a relação direta da oxidação do titânio 
com a temperatura. Sabendo-se como é a distribuição da temperatura na superfície durante o processo ajuda a entender melhor o processo de oxidação.

No capítulo 3 é realizada uma breve abordagem das principais características da soldagem a laser.

O capítulo 4 se dedicará à apresentação do titânio e suas ligas, mostrando propriedades mecânicas, tipos de ligas existentes e suas aplicações, microestruturas formadas e os efeitos do elementos intersticiais.

Os materiais e métodos utilizados neste trabalho serão apresentados no capítulo 5 e os resultados alcançados e discussões no capítulo 6.

O último capítulo concluirá o trabalho, destacando os principais resultados obtidos. 


\section{INTERAÇÃO LASER-MATÉRIA E AQUECIMENTO DE MATERIAIS}

O estudo dos processos de aquecimento dos materiais é importante para que se possa prever o comportamento do material durante o processamento e para se compreender melhor o papel e a importância de cada uma das variáveis envolvidas.

Nos itens a seguir serão abordados os conceitos básicos e alguns dos modelos matemáticos utilizados para prever as temperaturas dos materiais durante os processos a laser.

\subsection{Interação laser-matéria}

Segundo um modelo proposto por Drude [10] e descrito por Prokhorov [11], a absorção da energia absorvida por metais procede através do intermédio dos elétrons livres, que transmitem, através de colisões, esta energia para a rede cristalina.

Porém, nem toda a energia emitida pelo laser é absorvida pelo material, sendo uma parte dela refletida. A porcentagem de luz refletida é dada pelo coeficiente de reflexão $(R)$ e a porcentagem de luz absorvida pelo coeficiente de absorção do material (A). A figura abaixo mostra um feixe laser atingindo uma superfície. 


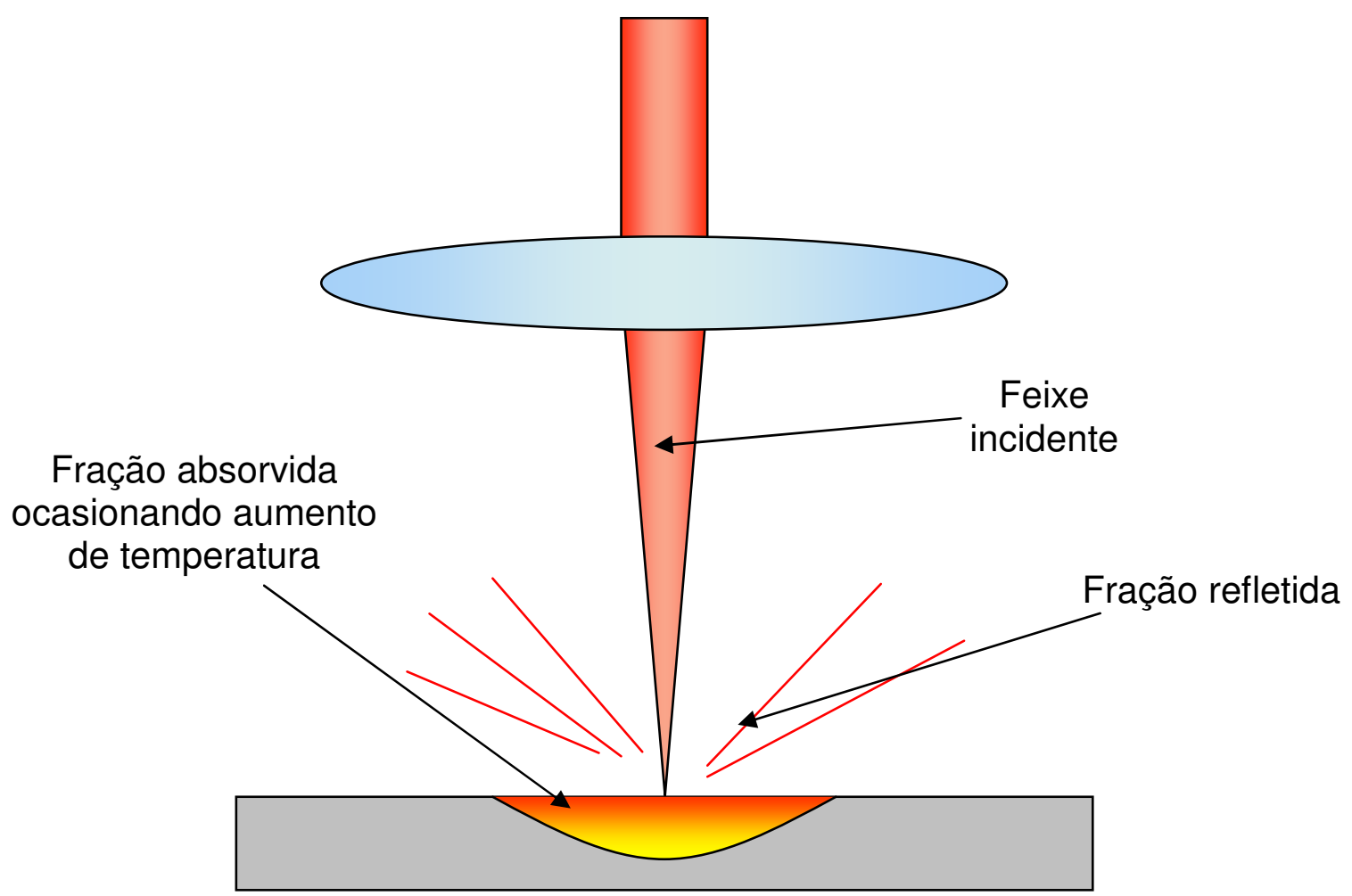

Figura 2-1 - Feixe incidente, fração refletida e absorvida por uma superfície metálica

O coeficiente de absorção depende de vários fatores, entre os quais podemos citar $[7,12]$ :

- A temperatura em que se encontra o material - como regra geral, quanto maior a temperatura, mais um material irá absorver.

- O comprimento de onda utilizado - no caso específico dos metais, quanto maior o comprimento de onda, menor será a absorção.

- O estado físico em que se encontra o material - sólidos, líquidos e gases absorvem de maneira diferente o feixe laser.

- Rugosidades ou impurezas na superfície

Assim, percebe-se que é difícil estipular um valor para o coeficiente de absorção, e mesmo que se tenha tal valor, seria até mesmo inviável verificar 
como que ele varia com as mudanças de temperatura e de fase que ocorrem durante o processamento de materiais a laser.

\subsection{Condução de calor nos metais}

O fenômeno de condução de calor em sólidos é normalmente interpretado com uma simples troca intermolecular de energia cinética, através de vibrações das moléculas e, no caso dos metais, também através de colisões dos elétrons livres [13].

Os estudos de condução de calor podem ser separados em estados estacionários e estados transientes. A condução transiente ocorre quando a temperatura aparece como função do tempo e de uma coordenada de espaço, enquanto que a condução estacionária ocorre quando a temperatura é dependente apenas de uma ou mais coordenadas de espaço.

Antes de prosseguir para um estudo mais aprofundado do fenômeno da condução de calor, é necessário compreender algumas das variáveis envolvidas na condução de calor e no caso específico de uma fonte laser.

Condutividade térmica $(k)$ : A condutividade térmica é uma propriedade do material definida como a quantidade de calor conduzido através de uma unidade de área normal ao fluxo em unidade de tempo e por unidade de gradiente de temperatura ao longo do fluxo. A condutividade é o inverso da resistência ao fluxo de calor. A unidade da condutividade térmica no SI é $\left[\mathrm{J}^{-1} \mathrm{~S}^{-1} \mathrm{~K}^{-1}\right]$.

Calor específico sensível (c): O calor específico sensível de um material define a quantidade de energia necessária para aquecer uma unidade de massa deste material em uma unidade de temperatura, ou seja: 


$$
\mathrm{c}=\frac{\mathrm{Q}}{\mathrm{m} \cdot \Delta \mathrm{T}}
$$

A unidade do calor específico sensível no SI é dada por [ $\left[\mathrm{kg}^{-1} \mathrm{~K}^{-1}\right]$.

Difusidade térmica ( $\alpha$ ): No processo de aquecimento transiente, o calor específico sensível representa a quantidade de calor absorvida e a condutividade térmica com que taxa este calor é transmitido. O recíproco da difusidade térmica $\alpha^{-1}$, mede o tempo necessário para aquecer este material para uma determinada temperatura.

A difusidade térmica do material pode ser calculada por [13]:

$$
\alpha=\frac{\mathrm{k}}{\rho \cdot \mathrm{c}}
$$

Onde $\rho$ é a massa específica do material.

A unidade de difusidade térmica no SI é dada por $\left[\mathrm{m}^{2} \cdot \mathrm{s}^{-1}\right]$.

Os fenômenos de condução de calor em sólidos foram estudados por Fourrier, que formulou a equação de condução de calor geral [12]:

$$
\frac{\partial^{2} T}{\partial x^{2}}+\frac{\partial^{2} T}{\partial y^{2}}+\frac{\partial^{2} T}{\partial z^{2}}=\frac{1}{\alpha} \frac{\partial T}{\partial t}
$$

Onde $\mathrm{T}$ é a temperatura, $\mathrm{t}$ é o tempo e $\mathrm{x}, \mathrm{y}$ e $\mathrm{z}$ são as coordenadas espaciais.

Esta equação descreve um sistema em que a condutividade térmica do material, $k\left(J \cdot s^{-1} \cdot m^{-1} \cdot K^{-1}\right)$, é homogênea e não muda com o tempo e que no material não há fontes ou perdas de energia. A partir desta equação é possível elaborar uma série de soluções analíticas para problemas de condução de calor. 
Uma destas soluções foi proposta por Rosenthal, que estudou sistemas de fontes pontuais em movimento em um material semi-infinito. A solução proposta por ele ficou conhecida como equação de Rosenthal e é mostrada a seguir [14]:

$$
\mathrm{T}=\mathrm{Ti}+\frac{\mathrm{q}_{0}{ }^{\prime}}{2 \pi \cdot \mathrm{k}} \cdot \mathrm{e}^{-(\mathrm{v} / 2 \alpha) \cdot(x-v \cdot t)} \mathrm{K}_{0}\left(\frac{\mathrm{v}}{2 \alpha} \cdot \sqrt{(\mathrm{x}-\mathrm{v} \cdot \mathrm{t})^{2}+\mathrm{y}^{2}}\right)
$$

Onde $\mathrm{T}$ é a temperatura do material na superfície, Ti é a temperatura inicial, qo' é a intensidade linear da fonte (ou seja, em unidades de energia por unidades de comprimento), $k$ é a condutividade térmica, $v$ é a velocidade da fonte, $\alpha$ é a difusidade térmica, $t$ é o tempo e $K_{0}$ é uma função de Bessel modificada de ordem zero e segundo tipo. O termo qo' aparece por que a fonte é considerada por um ponto, ou seja, não tem uma área.

A Equação 4 já foi usada em outros trabalhos [15,16] com razoável sucesso, apesar de não levar em conta que as propriedades térmicas do material mudam com o tempo e ter o inconveniente da temperatura ir para infinito no ponto em que se encontra a fonte.

\subsection{Convecção de calor}

Na convecção a energia térmica é transmitida através de um transporte de massa. Esta convecção pode ser forçada, quando o fluido é forçado a passar pela superfície ou natural, quando o movimento do fluido se dá apenas por diferença de temperatura e densidade.

Considere o caso de uma parede aquecida perdendo calor para o ar ao seu redor por convecção natural ou forçada. Em um plano normal à parede a temperatura do gás varia do valor da temperatura da parede $(T p)$ para o valor da temperatura do gas $(\mathrm{Tg})$. Este exemplo é ilustrado abaixo: 

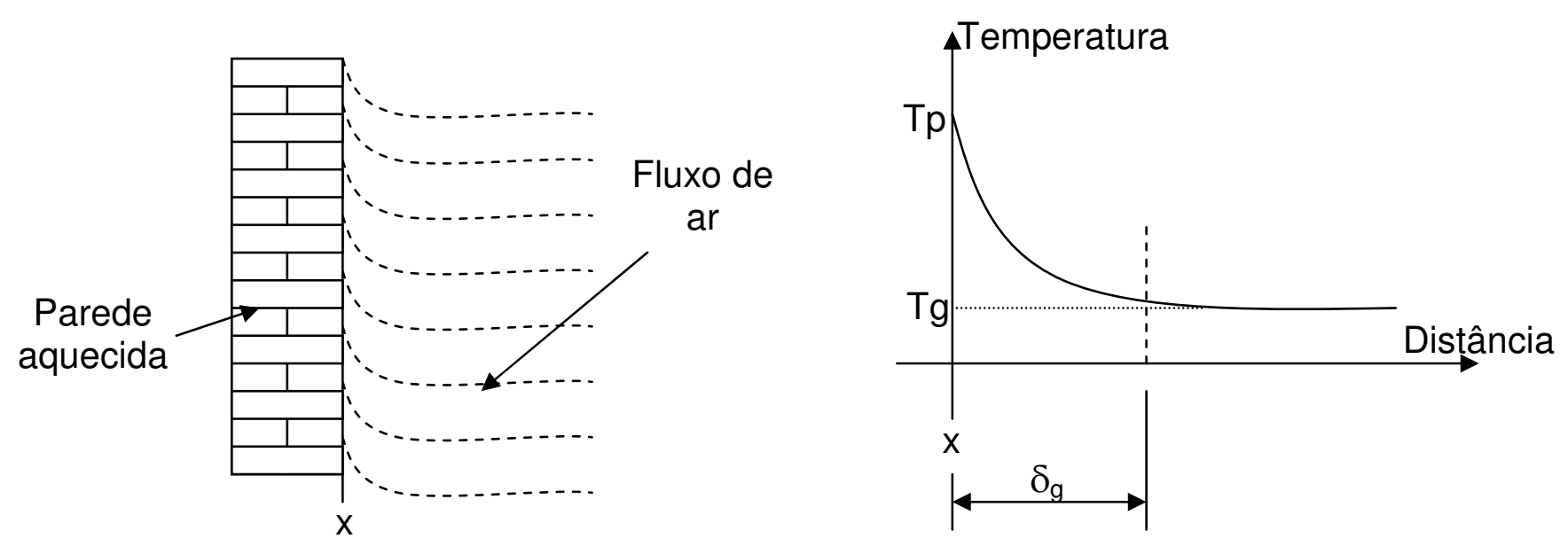

Figura 2-2 - Convecção do ar em uma parede aquecida

Há um gradiente de temperatura entre a parede e o ar, cuja temperatura se torna estável a uma certa distância da superfície. De acordo com o conceito de filme de Langmuir, toda a resistência à troca de calor entre a parede e o gás é concentrada neste filme estático de gás próximo à superfície do sólido, que inclui a região de queda de temperatura [13].

Aproximando este gradiente de temperatura entre a superfície do sólido e o gás como sendo constante em toda a espessura $\delta_{g}$ do filme, o calor conduzido através deste filme pode ser dado por [13]:

$$
q=\frac{k_{g}}{\delta_{g}} \cdot A \cdot(T p-T g)
$$

Onde q é a potência irradiada pelo sistema parede e gás, $k_{g}$ é a condutividade térmica do gás e A é a área da superfície.

Devido à dificuldade de interpretar e medir de maneira efetiva a espessura deste filme, é comum combinar o quociente $\mathrm{k}_{\mathrm{g}} / \delta_{\mathrm{g}}$ em uma única propriedade $\mathrm{h}$, e expressar a troca de calor na superfície como sendo simplesmente

$$
q=h \cdot A \cdot\left(T_{1}-T_{2}\right)
$$


Apesar de possuir uma variedade de nomes, o coeficiente h é geralmente chamado de coeficiente de convecção.

A unidade de $\mathrm{h}$ no sistema internacional é $\left[\mathrm{J} \cdot \mathrm{s}^{-1} \cdot \mathrm{m}^{-2} \cdot \mathrm{K}^{-1}\right]$.

Assim, também é possível levar em conta as perdas de calor por convecção na superfície de um material submetido a uma fonte de calor pontual em movimento, acrescentando um termo de perda de calor na equação de Fourrier [13]:

$$
\frac{\partial^{2} \mathrm{~T}}{\partial \mathrm{x}^{2}}+\frac{\partial^{2} \mathrm{~T}}{\partial \mathrm{y}^{2}}-\left(\frac{\mathrm{h}_{1}+\mathrm{h}_{2}}{\mathrm{k} \cdot \delta}\right) \cdot \mathrm{T}=\frac{1}{\alpha} \frac{\partial \mathrm{T}}{\partial \mathrm{t}}
$$

Onde $h_{1}$ e $h_{2}$ são respectivamente as condutividades das superfícies superior e inferior e $\delta$ é a espessura do material. A solução desta equação é mostrada no Apêndice A e é dada por:

$$
\mathrm{T}=\mathrm{Ti}+\frac{\mathrm{q}_{0}{ }^{\prime}}{2 \pi \mathrm{k}} \cdot \mathrm{e}^{-\left(\frac{\mathrm{v}}{2 \alpha}\right) \cdot(x-v \cdot t)} \mathrm{K}_{0}\left(\sqrt{\left[\frac{(\mathrm{h} 1+\mathrm{h} 2)}{\mathrm{k} . \delta}+\left(\frac{\mathrm{V}}{2 \alpha}\right)^{2}\right]} \cdot r\right)
$$

Onde r é a variável no sistema de coordenadas cilíndricas e é dado por:

$$
r=\sqrt{(x-v t)^{2}+y^{2}}
$$

Uma comparação mais detalhada dos dois modelos de Rosenthal é mostrada na seção de resultados. 


\section{SOLDAGEM A LASER}

\subsection{Histórico}

A soldagem a laser destaca-se como um dos principais processos de materiais a laser devido ao grande número de trabalhos realizados e principalmente aos avanços ocorridos nos últimos anos [2].

Entretanto, até a década de 70 , a soldagem a laser era restrita a materiais relativamente finos e à baixas velocidades de soldagem por causa da limitada potência disponível. Já em 1965, vários sistemas de lasers foram desenvolvidos para fazer microsoldas em placas de circuitos eletrônicos dentro de câmaras de vácuo e em outras aplicações especializadas onde a tecnologia convencional não estava apta a disponibilizar uma junta de solda confiável. A soldagem a laser deu um salto com o aparecimento dos lasers de $\mathrm{CO}_{2}$ e de $\mathrm{Nd}$ : YAG, que devido à alta potência disponível acabou com as limitações deste processo existentes até então [17].

\subsection{Princípios básicos}

O processo consiste na focalização de um feixe laser sobre a junta de duas placas, que são aquecidas até seus pontos de fusão e, em seguida, resfriadas após a saída do feixe. A soldagem a laser (LBW) é um processo com alta densidade de energia, assim como a soldagem por feixe de elétrons (EBW), chegando a intensidades da ordem de $10^{6} \mathrm{~W} / \mathrm{cm}^{2}$. A alta intensidade na soldagem a laser é um dos fatores que contribuem para a alta qualidade atingida 
e a possibilidade de soldar materiais que não podem ser soldados por outros processos, inclusive materiais dissimilares $[18,19,20]$.

Além disto, outras vantagens da soldagem a laser devem ser levadas em consideração [18,19,21]:

- Na soldagem a laser não há a necessidade de câmaras de vácuo;

- $\quad$ Não são necessários eletrodos ou materiais de preenchimento;

- Baixa distorção da peça soldada;

- $\quad$ Pequena zona afetada pelo calor;

- $\quad$ Facilidade de automação e, consequentemente, maior precisão no posicionamento do feixe na superfície;

- A luz não é desviada por um campo magnético externo, como acontece na soldagem com feixe de elétrons.

Apesar de todas estas vantagens, vale ressaltar que a maior desvantagem de qualquer processo a laser é o alto custo inicial e de manutenção.

Vários parâmetros devem ser levados em conta na soldagem a laser, entre eles podemos destacar a velocidade de soldagem, a largura temporal do pulso, a frequência destes pulsos, a taxa de sobreposição (que depende dos 3 fatores anteriores), o gás de proteção, o fluxo do gás de proteção, o bocal de distribuição do gás, a distância do bocal até a superfície e a posição do foco em relação à superfície das amostras a serem soldadas [22].

Ao atingir uma superfície metálica, a maior parte da energia advinda do laser é refletida e apenas uma pequena fração da energia é convertida em calor. Contudo, o aumento da temperatura é acompanhado por um aumento da absorção do material, aumentando o rendimento do processo [18]. 
Dependendo da intensidade do feixe laser, a soldagem pode ser dividida em soldagem por condução e soldagem por penetração (keyhole).

$\mathrm{Na}$ soldagem por condução o material é aquecido até fundir e a energia absorvida não é suficiente para elevar sua temperatura até seu ponto de ebulição [2]. O calor é transmitido para o resto do material por convecção de calor na poça fundida e condução desta para o material base. A Figura 3-1 mostra como isto ocorre.

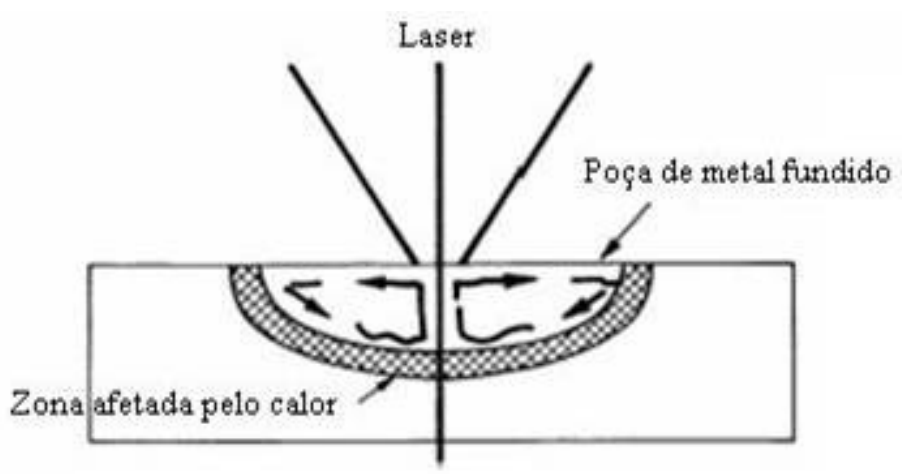

Figura 3-1 - Soldagem a laser por condução [2]

Devido a este modo de transferência de calor ser lento, acarreta em uma grande largura de cordão e uma pequena profundidade alcançada, o que pode prejudicar as propriedades mecânicas da solda. Geralmente esta penetração não ultrapassa o valor de um quarto da largura do cordão de solda obtido [23].

Com o aumento da intensidade do feixe na superfície, a temperatura aumenta mais rapidamente, chegando cada vez mais próxima do ponto de evaporação do material. Para muitos metais, a pressão de vapor cresce exponencialmente com a temperatura e torna-se de intensidade considerável quando o material chega à temperaturas de aproximadamente $80 \%$ da temperatura de ebulição [19]. Quando a temperatura da superfície alcança este 
valor (geralmente no centro da poça), o líquido da superfície abaixo do feixe sofre um deslocamento e uma depressão é formada [19, 24].

Esta depressão facilita a entrada do feixe laser no material, aumentando consideravelmente a razão de aspecto da soldagem (razão entre a largura do cordão de solda e a profundidade alcançada) e é chamada de keyhole, um canal formado por vapor e plasma (do gás de proteção e do metal) que aumenta a profundidade alcançada pela soldagem a laser.

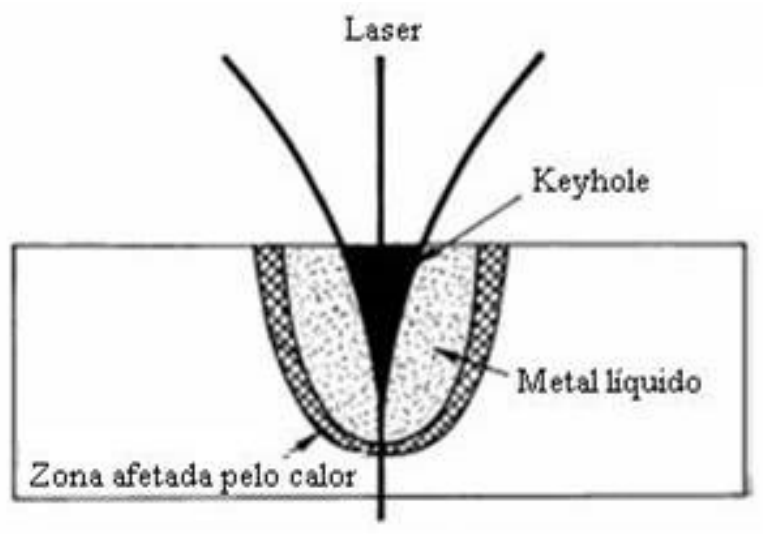

Figura 3-2 - Soldagem a laser de penetração [2]

Segundo Ho e Wen [21], a distribuição da intensidade no keyhole depende, dentre outras coisas, da distribuição de energia do pulso, comprimento de onda e polarização do feixe laser, além do índice de refração do material. Porém, mesmo variando com a polarização do feixe incidido, Beyer e colaboradores [25] descobriram que só há uma ligação da polarização com a profundidade da poça fundida para velocidades de soldagem maiores que $3000 \mathrm{~mm} / \mathrm{min}$.

O aumento da absorção da energia do laser quando se abre o keyhole é devido às múltiplas reflexões ocorridas na parede deste canal [21]. 


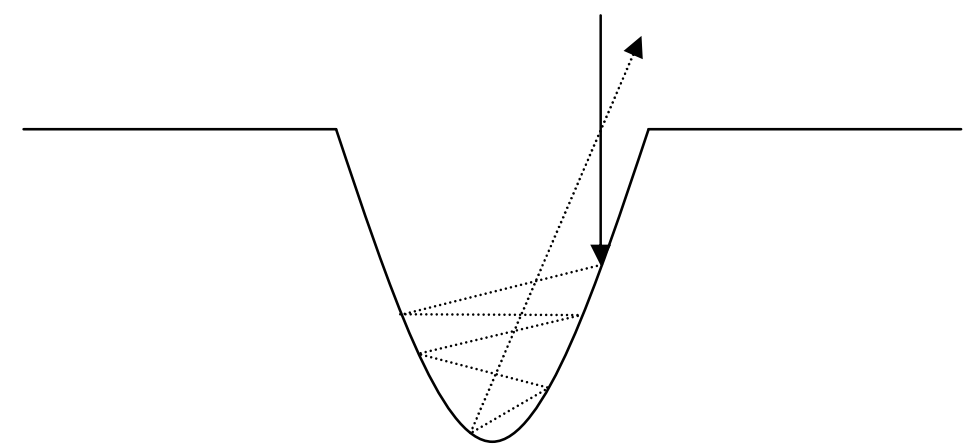

Figura 3-3 - Múltiplas reflexões que ocorrem na parede do keyhole

Assim, um feixe que incidir na parede do keyhole terá uma parte absorvida, que dependerá do coeficiente de absorção do material $(A)$ e uma parte refletida novamente para o keyhole, onde uma outra parte será absorvida e outra refletida.

Enquanto a energia laser for aplicada, o keyhole é mantido aberto pela pressão do vapor, o que previne as paredes fundidas de fecharem o canal. Se o laser é operado em modo pulsado, o material fundido irá cair no centro do keyhole e solidificar no final do pulso, deixando às vezes algumas porosidades devido à presença do gás de proteção que ficou preso no material e à evaporação do metal [18].

Já para o laser contínuo, o keyhole é levado junto com o movimento do feixe laser através da junta. O material fundido na parte frontal do keyhole produz uma pequena onda que é suportada por tensão superficial. À medida que o feixe avança, a onda se reorienta nas bordas do keyhole e se junta atrás dele, solidificando-se.

Além deste fluxo de material fundido ao redor do keyhole na superfície, há também um fluxo que causa instabilidade nele mostrado pelas variações da profundidade alcançada ao longo da solda. A estabilidade do keyhole depende basicamente de dois fatores: a pressão de vapor que faz com que o canal permaneça aberto e a tensão superficial, que tenta fechar o canal. Ambos são 
funções da temperatura, sendo que a pressão de vapor cresce com o aumento da temperatura enquanto que a tensão superficial decresce [19].

Assim, o keyhole é estável na parte baixa, onde a temperatura é maior e a pressão de vapor é maior que a tensão superficial. Porém, próximo da superfície, onde a temperatura é menor, a tensão superficial é maior que a pressão de vapor, fazendo com que exista uma tendência por parte do material fundido de ser empurrado pela tensão superficial para dentro do keyhole, fechando-o [19].

Esta sequência de eventos foi registrada por Mara e colaboradores em fotos de raios-X [26] e esquematizada por Tong and Giedt [27] de forma similar à Figura 3-4.
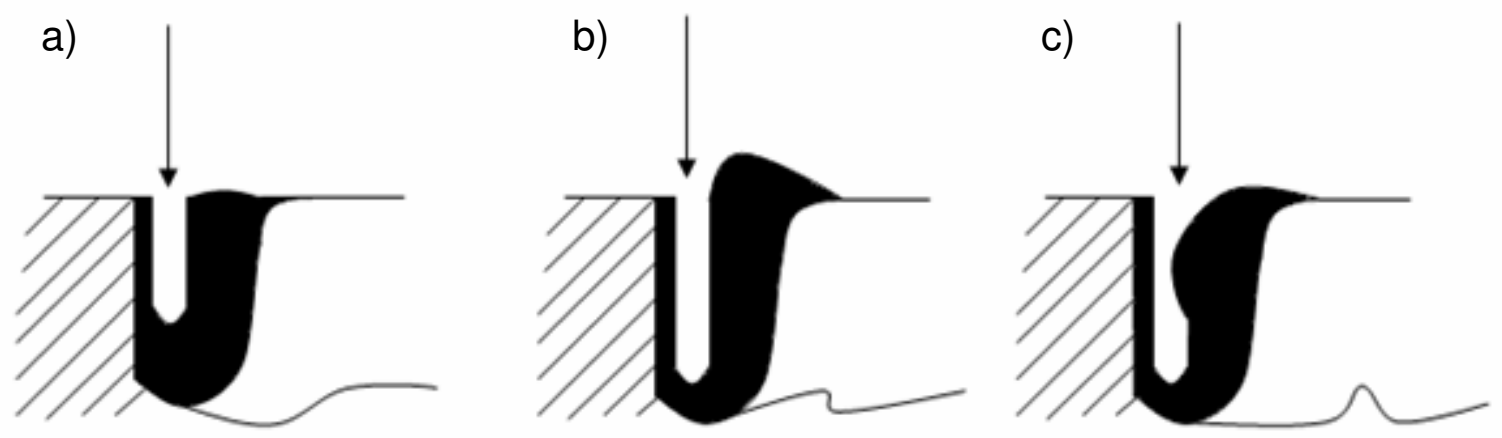

Figura 3-4 - Processo de instabilidade do keyhole; a) início da formação da cavidade; b) profundidade máxima alcançada; c) fechamento do keyhole pelo material fundido da superfície.

Na Figura 3-4-a há o início da formação do keyhole, que com o aumento da temperatura devido às múltiplas reflexões em suas paredes é acompanhado por um aumento da pressão de vapor e, consequentemente, um aumento da cavidade. Este aumento também é acompanhado por um acúmulo de material fundido na parte superior do keyhole devido à tensão superficial (Figura 3-4-b). 
Após uma certa quantidade de material acumulado, parte dela cai no canal e fecha parte da cavidade (Figura 3-4-c), fazendo com que volte para a mesma condição que a Figura 3-4-a.

$\mathrm{Na}$ soldagem com lasers pulsados é necessário que a poça fundida produzida por um pulso sobreponha com aquela produzida pelo pulso anterior. Esta sobreposição está relacionada com a largura temporal do pulso, diâmetro do feixe, taxa de repetição e velocidade de soldagem do laser [22].

Considere um laser pulsado como o mostrado na figura abaixo, onde temos a largura temporal do pulso $\left(t_{p}\right)$ e o tempo entre dois pulsos consecutivos $\left(\mathrm{t}_{\mathrm{f}}\right)$.

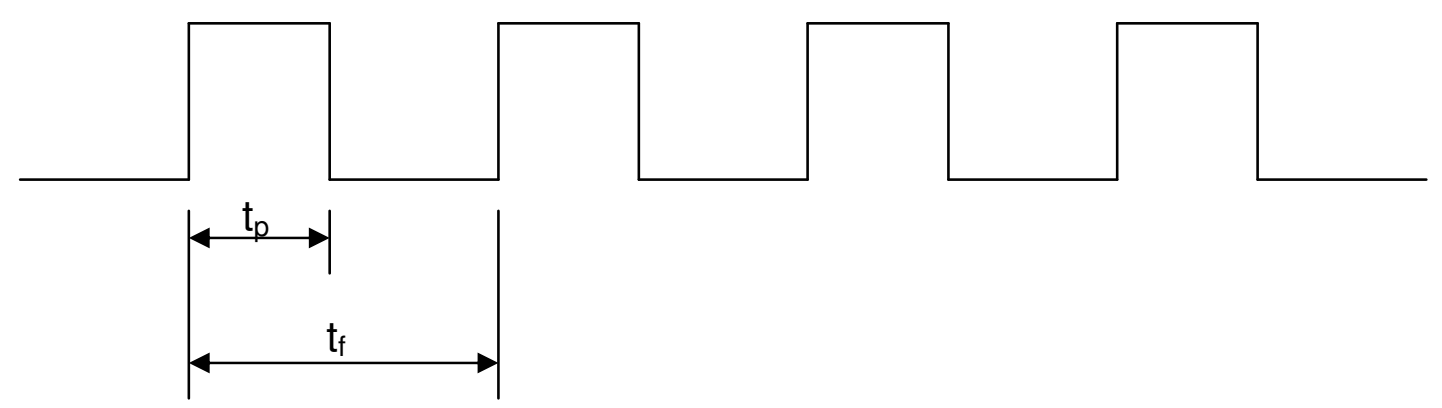

Figura 3-5 - Trem de pulsos quadrados

Ao incidir este feixe laser na superfície a uma velocidade de soldagem $\mathrm{v}, \mathrm{o}$ diâmetro menor da elipse obtida será W. Na aplicação de vários pulsos onde pelo menos uma parte deles se sobreponha será dada a relação conforme a figura a seguir: 


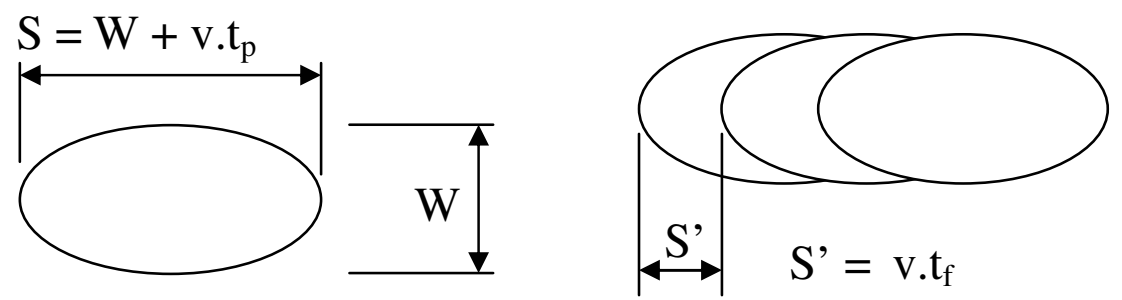

Figura 3-6 - Padrão obtido na soldagem com laser pulsado [22]

A taxa de sobreposição dos pulsos será dada por:

$$
\mathrm{Ts}=\frac{\mathrm{S}-\mathrm{S}^{\prime}}{\mathrm{S}}=\left[1-\frac{\mathrm{v} \cdot \mathrm{t}_{\mathrm{f}}}{\mathrm{W}+\mathrm{v} \cdot \mathrm{t}_{\mathrm{P}}}\right]
$$

A partir desta taxa de sobreposição é possível estipular valores máximos e mínimos para a velocidade de soldagem. Para uma taxa de sobreposição igual a 1, um pulso está sobrepondo $100 \%$ sobre o outro, então a velocidade de soldagem é zero.

Para uma taxa de sobreposição igual a zero, temos:

$$
\begin{aligned}
& {\left[1-\frac{\mathrm{v} \cdot \mathrm{t}_{\mathrm{f}}}{\mathrm{W}+\mathrm{v} \cdot \mathrm{t}_{\mathrm{P}}}\right]=0} \\
& \mathrm{v}=\frac{\mathrm{W}}{\mathrm{t}_{\mathrm{f}}-\mathrm{t}_{\mathrm{p}}}
\end{aligned}
$$

Assim, temos que a velocidade de soldagem para um laser pulsado tem valores mínimos e máximos estipulados a partir da taxa de sobreposição:

$$
0<\mathrm{v}<\frac{\mathrm{W}}{\mathrm{t}_{\mathrm{f}}-\mathrm{t}_{\mathrm{p}}}
$$

\subsection{Atmosfera de proteção}

$\mathrm{Na}$ soldagem a laser, a atmosfera de proteção gasosa é dita por alguns autores como o fator mais importante do processo [28,29], alterando as 
características da solda como penetração, largura do cordão e zona afetada pelo calor. Trabalhos realizados em outros tipos de soldas e materiais mostraram que uma pequena diferença na atmosfera de proteção é suficiente para causar uma grande mudança na solda $[30,31,32]$.

O principal objetivo da atmosfera de proteção é evitar que o material soldado sofra oxidação e, por conseqüência, tenha suas características mecânicas prejudicadas. A escolha do tipo de gás utilizado depende principalmente das características do material que será soldado, devendo-se levar em conta processos químicos e metalúrgicos que podem ocorrer entre o material e a atmosfera de proteção [28]. Os gases de proteção mais utilizados são o gás carbônico, o nitrogênio, o oxigênio, o argônio, o hélio e misturas destes gases, sendo que dentre eles, os mais utilizados são o hélio, o argônio e o gás carbônico, tendo às vezes pequenas adições de oxigênio.

\subsubsection{Gases de proteção}

Na soldagem a laser há a formação de um plasma um pouco acima da superfície do material soldado, devido à alta intensidade do laser naquele ponto. Este plasma é decorrente de duas fontes. A primeira é do vapor do próprio material, o qual também devemos levar em conta suas impurezas, e a segunda é da atmosfera de proteção [33]. A intensidade deste plasma será maior quanto menor for o potencial de ionização do gás utilizado.

O potencial de ionização é a energia, expressa em elétrons volts (eV), necessária para remover um elétron de um átomo de gás, tornando-o um íon. Mantendo-se todos os outros fatores constantes, o potencial de ionização diminui com o aumento do peso molecular. Portanto, quanto maior o potencial de 
ionização, mais energia é necessária para que o átomo do gás torne-se um íon e menos plasma é formado.

Uma vez formado, este plasma absorverá e espalhará parte da energia cedida pelo laser, podendo prejudicar o processo de soldagem [34].

A seguir tem-se uma tabela com as propriedades de alguns gases de proteção utilizados:

Tabela 3-1 - Propriedades físicas do hélio e argônio [29,35,36]

\begin{tabular}{|c|c|c|}
\hline Gás & Hélio & Argônio \\
\hline Condutividade térmica $\left(\mathrm{mW} . \mathrm{cm}^{\mathrm{K}} \mathrm{K}^{-1}\right)$ & 3,63 & 0,427 \\
\hline Potencial de ionização $(\mathrm{eV})$ & 24,5 & 15,67 \\
\hline Número de Reynolds crítico & 3220 & 2950 \\
\hline Viscosidade cinemática $\left(10^{-6} \mathrm{~m}^{2} / \mathrm{s}\right)$ & 114 & 13,0 \\
\hline Massa específica $(\mathrm{g} / \mathrm{l})$ & 0,1368 & 1,38 \\
\hline
\end{tabular}

Destes gases, o hélio é dito pela literatura como o que resulta em uma maior penetração de soldagem, enquanto que o argônio permanece mais tempo sobre a superfície do material [17]. Esta maior penetração é devida à menor quantidade de plasma formado pelo hélio, que possui um maior potencial de ionização e é mais leve que o ar, fazendo com que tenha poucas moléculas de hélio acima da superfície da amostra para serem ionizadas.

Além disto, como o argônio produz maior quantidade de plasma, é de se esperar que os cordões de solda formados com o argônio sejam relativamente mais largos que os formados com o hélio, devido à energia transferida deste plasma para a superfície do metal.

Uma mistura destes pode ser utilizada quando se necessita das características de ambos, mas na solda de titânio pelo menos uma quantia de 
$25 \%$ de cada um deles deve ser utilizada para que haja um efeito significativo [17].

\subsubsection{Tipos de proteção}

Quanto ao tipo de sistema de proteção, podemos dividi-los em primário, secundário e auxiliar [17]. A proteção primária é aquela fornecida axialmente com o feixe do laser, através de um bocal de solda.

A proteção secundária tem a função de proteger o material após a passagem do feixe, para que não ocorra oxidação do material recém solidificado. A proteção auxiliar ou de raiz tem a função de proteger a raiz da solda contra oxidações. Estes dois últimos tipos de proteções nem sempre são utilizados. Para muitos materiais, apenas a proteção primária é necessária, como no caso da soldagem de aços [20].

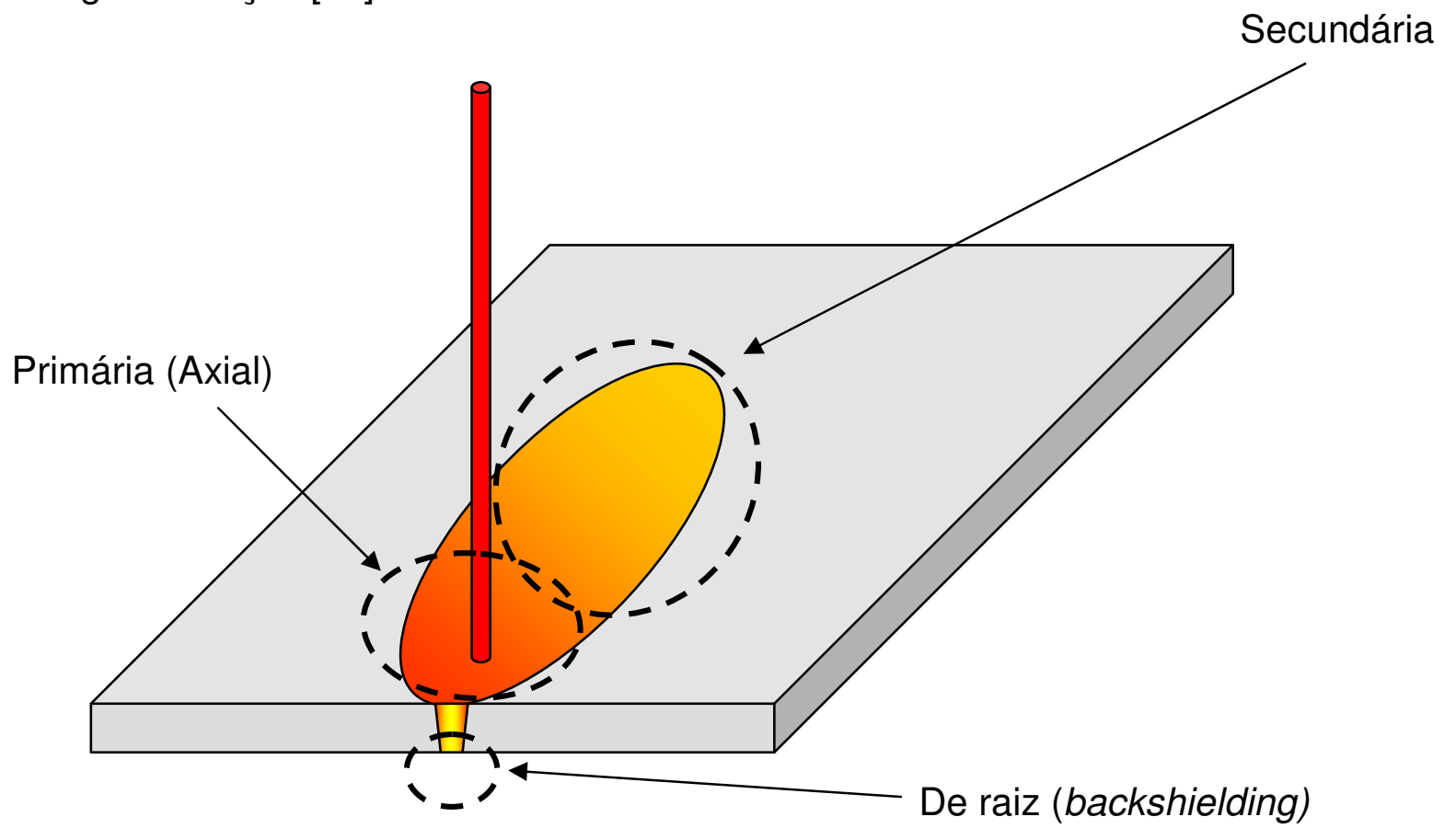

Figura 3-7 - Sistemas de proteção gasosa na soldagem a laser 


\subsubsection{Projeto de um sistema de proteção gasosa}

Além da natureza da atmosfera de proteção, é necessário também levar em conta o sistema de entrega do gás, que inclui as dimensões do bocal de proteção, a distância deste para a superfície da amostra, o fluxo do gás e verificar se há a necessidade de uma proteção na raiz da solda. Todos estes parâmetros variam de acordo com os parâmetros escolhidos para soldar o material.

Alguns aspectos devem ser levados em conta na hora de projetar o sistema de proteção gasosa, dentre eles podem ser citados:

- Concentração de gás - o gás neutro utilizado deve estar bem concentrado na região que se pretende proteger. Como a simulação matemática do comportamento de um gás é complexa e exige o uso de softwares específicos, cabe bom senso de se utilizar valores de fluxo já utilizados na literatura ou adquiridos por experiência;

- Fluxo de gás - o fluxo de gás deve ser grande o suficiente para evitar a contaminação do material e o menor possível para minimizar custos. Além disto, uma melhor proteção é atingida quando é utilizado um fluxo laminar para a atmosfera de proteção, pois a turbulência na região pode causar inclusão de ar na atmosfera neutra e prejudicar o cordão de solda [17];

- Pressão do gás na superfície - a dinâmica do gás ao sair do bocal e atingir a superfície do metal pode provocar o aumento ou diminuição da pressão. Uma pressão menor que a pressão atmosférica "arrastaria" o ar para esta área, fazendo com que haja oxidação. Este fenômeno já foi estudado na literatura [28] e os resultados podem ser usados como guia para outros projetos. 
Para um melhor entendimento do projeto do bocal de proteção, que será tratado mais adiante no trabalho, é necessário conhecer o número de Reynolds.

\section{Número de Reynolds}

Na mecânica dos fluidos, o número de Reynolds é a razão das forças de inércia e das forças viscosas e, conseqüentemente, quantifica a importância relativa destes dois tipos de forças para dadas condições de fluxos. Assim, o número de Reynolds é utilizado para identificar diferentes regimes de fluxo, como fluxo laminar ou turbulento.

O escoamento laminar é caracterizado pelo fluxo do fluido em camadas paralelas, não havendo cruzamento entre estas camadas. Já no escoamento turbulento, o fluido possui um movimento caótico, ou seja, não há padrões de movimento detectáveis dentro dele.

O número de Reynolds é calculado a partir da seguinte equação [37]:

$$
\mathrm{R}=\frac{\mathrm{v} \cdot \mathrm{D}}{v}
$$

Onde v é a velocidade do fluido, D é o diâmetro do tubo por onde passa este fluido e $v$ é a viscosidade cinemática do fluido, que também pode ser escrito da forma:

$$
v=\frac{\eta}{\rho}
$$

Onde $\eta$ é o coeficiente de viscosidade dinâmica e $\rho$ é a massa específica do fluido.

Lembrando que a velocidade de um fluído pode ser escrita da forma: 


$$
\mathrm{v}=\frac{\phi}{\mathrm{A}}=\frac{4 \cdot \phi}{\pi \cdot \mathrm{D}^{2}}
$$

Onde $\phi$ é fluxo do fluido, A é a área da tubulação pela qual o fluido passa e D é o diâmetro desta tubulação.

Podemos substituir (15) na (17) e obter:

$$
\mathrm{R}=\frac{4 . \phi}{\pi \cdot \mathrm{D} \cdot v}
$$

Que nos dá uma relação direta do número de Reynolds com o diâmetro do bocal, fluxo e viscosidade cinética do gás.

Um fluido que possua em uma certa situação um número de Reynolds menor que um certo valor crítico está em um regime laminar. A partir deste valor crítico o fluido está em um regime intermediário, onde ele pode ter tanto características laminares quanto turbulentas. Com um acréscimo do número de Reynolds, o fluído entrará em um regime turbulento. 


\section{TITÂNIO E SUAS LIGAS}

Mesmo sendo considerado um elemento raro, o titânio é o 9e elemento e o 4- metal mais abundante da crosta terrestre, tendo o rutilo $\left(\mathrm{TiO}_{2}\right)$ e o ilmenito $\left(\mathrm{FeTiO}_{3}\right)$ como suas principais fontes de extração. A dificuldade de se encontrar o metal se dá por falta de jazidas economicamente viáveis de titânio, pois ele se encontra quase que uniformemente distribuído pela crosta terrestre [38].

A primeira identificação do titânio como material metálico foi em 1791 na Ingleterra, por W. Gregor, que concedeu ao novo metal o nome de "menacanita". Anos mais tarde, na Alemanha, M. H. Klaproth descobriu um novo metal que se podia extrair do rutilo e the concedeu o nome de titânio. Anos mais tarde, descobriu-se que se tratava do mesmo material e o nome titânio foi conservado, pois já havia sido adotado internacionalmente $[39,40]$.

O início das aplicações industriais do titânio foi na década de 50, com o desenvolvimento da indústria aeronáutica e espacial, onde o titânio foi utilizado na substituição do alumínio a temperaturas elevadas [40]. Hoje, o titânio e suas ligas encontram aplicações também na biomedicina, por algumas de suas ligas serem biocompatíveis [7,41], na indústria petroquímica, pois resiste à maior parte dos ácidos minerais e cloretos, na indústria de papel e celulose, devido à sua resistência ao cloro e seus compostos que são utilizados no branqueamento e em outras áreas como na construção de reatores de fusão $[42,43]$.

À temperatura ambiente, o titânio apresenta uma estrutura hexagonal compacta (hcp) denominada alfa $(\alpha)$. Quando atinge uma temperatura de 
aproximadamente $880^{\circ} \mathrm{C}$ (para o titânio puro [44]) o titânio passa por uma transformação alotrópica, passando a ter uma estrutura cúbica de corpo centrado (ccc) denominada beta $(\beta)$. Quando resfriado rapidamente, algumas ligas de titânio apresentam formações martensíticas do tipo $\alpha$, que possui estrutura hexagonal compacta ou $\alpha "$, que possui estrutura ortorrômbica.
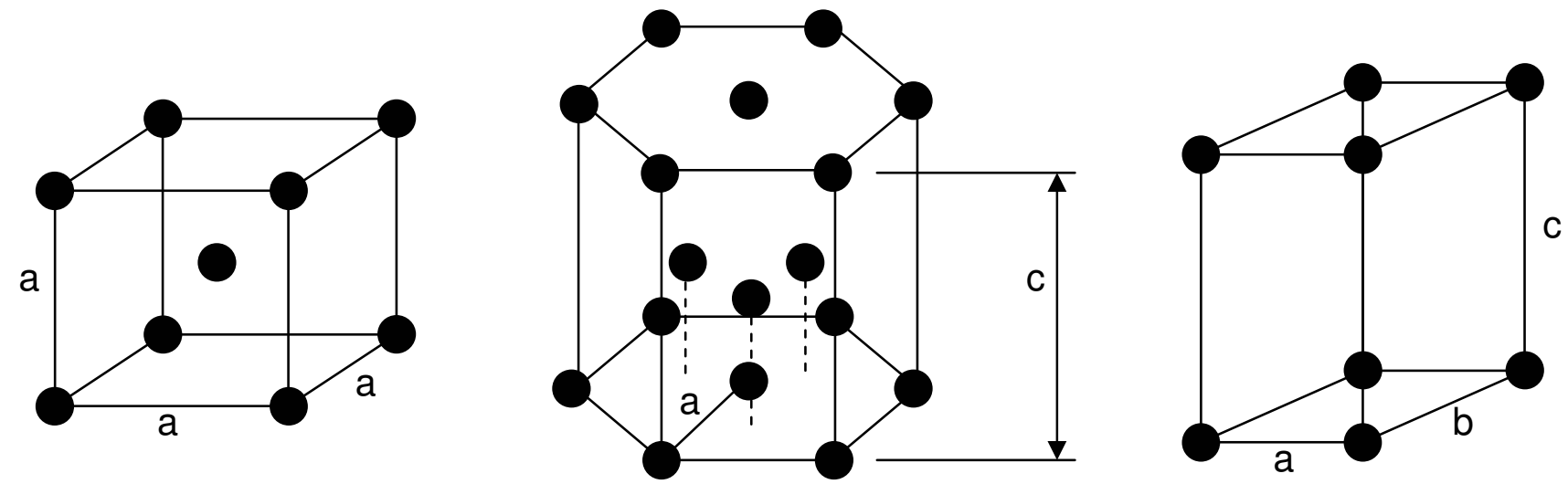

Figura 4-1 - Principais redes bravais encontradas no titânio; a) célula cúbica de corpo centrado; b) célula hexagonal compacta; c) célula ortorrômbica simples.

\subsection{Ligas de titânio}

É possível classificar os elementos de liga do titânio em duas categorias: os elementos que estabilizam a fase $\alpha$, alfagênicos, e os que estabilizam a fase $\beta$, ou betagênicos. Eles agem mudando o equilíbrio termodinâmico das fases $\alpha$ e $\beta$, aumentando ou diminuindo a temperatura em que ocorre a transformação alotrópica.

Estes elementos podem interagir com a matriz de titânio substituindo um dos átomos de titânio na matriz cristalina (elementos substitucionais) ou se acomodando nos espaços presentes dentro das células unitárias (elementos intersticiais). A tabela Tabela 4-1 mostra alguns dos elementos alfagênicos e 
betagênicos, classificando-os em substitucionais ou intersticiais. Percebe-se que a maioria dos elementos são betagênicos.

A classificação das ligas de titânio pode ser feita de acordo com a microestrutura encontrada, onde temos as ligas $\alpha$, ligas $\alpha+\beta$ e ligas $\beta$, de acordo com a linha de transformação martensítica, onde temos ligas $\alpha$, ligas quase $\alpha$, ligas $\alpha+\beta$ e ligas quase $\beta$ e ligas $\beta$, ou de forma mais abrangente, separando as ligas em ligas resistentes à corrosão e ligas estruturais.

Tabela 4-1 - Elementos de liga do titânio [17]

\begin{tabular}{|c|c|c|c|}
\hline \multicolumn{2}{|c|}{ Estabilizadores alfa } & \multicolumn{2}{|c|}{ Estabilizadores beta } \\
\hline Intersticiais & Substitucionais & Intersticiais & Substitucionais \\
\hline $\begin{array}{l}\text { Oxigênio, } \\
\text { nitrogênio, } \\
\text { carbono. }\end{array}$ & $\begin{array}{l}\text { Alumínio, chumbo, } \\
\text { índio. }\end{array}$ & Hidrogênio. & $\begin{array}{l}\text { Prata, } \\
\text { cromo, cobalto, } \\
\text { cobre, ferro, } \\
\text { manganês, } \\
\text { molibidênio, } \\
\text { níquel, paládio, } \\
\text { platina, tântalo, } \\
\text { tungstênio, } \\
\text { vanádio, zircônio. }\end{array}$ \\
\hline
\end{tabular}

\subsubsection{Classificação de acordo com a microestrutura}

Ligas $\alpha$ - Estão nesta categoria o titânio puro e as ligas com estabilizadores alfa. Na temperatura ambiente elas apresentam apenas a fase $\alpha$. Possuem níveis satisfatórios de resistência mecânica, tenacidade e soldabilidade. 
Além disto, estas ligas são apropriadas para aplicações criogênicas por não apresentarem uma transformação dúctil-frágil, fenômeno típico de estruturas cristalinas do tipo cúbica de corpo centrada $[40,45]$. As ligas $\alpha$ são utilizadas quando há necessidade de resistência à fadiga em temperaturas elevadas (entre $600^{\circ} \mathrm{C}$ e $800^{\circ} \mathrm{C}$ ), como em motores de turbinas de combustão interna [44].

Ligas $\alpha+\beta$ - A principal representante desta categoria é a liga Ti6Al4V. Nesta categoria há a coexistência das fases $\alpha$ e $\beta$ na temperatura ambiente, pois ela apresenta quantidades moderadas tanto de estabilizadores alfa quanto beta. Elas possuem alta resistência a temperatura ambiente e moderada resistência em altas temperaturas.

Ligas $\beta$ - Dentre as ligas $\beta$ comerciais de maior interesse destaca-se a Ti11,5Mo-6Zr-4,5Sn, que é facilmente conformada. Nesta categoria há a presença de grandes quantidades de estabilizadores beta, fazendo com que a fase $\beta$ seja a principal fase na temperatura ambiente. São impróprias para aplicações em baixas temperaturas, pois a fase $\beta$ é do tipo cúbica do corpo centrado, que apresenta transição dúctil-frágil. Entretanto, são ligas para trabalho a frio, com alta conformabilidade e endurecem por tratamento [38].

\subsubsection{Classificação de acordo com a linha de transformação martensítica}

Esta classificação faz referência de acordo com as linhas de transformação martensítica inicial e final, que em geral são muito próximas ou quase coincidentes, analisando a quantidade de fases $\alpha$ ou $\beta$ retidas na temperatura ambiente após resfriamento. A Figura 4-2 esquematiza melhor esta classificação, mostrando a quantidade de fase $\alpha$ e $\beta$ que é retida após um resfriamento rápido em cada uma das ligas. 
Ligas $\alpha$ - As ligas $\alpha$ são aquelas que após resfriamento não exibem retenção da fase $\beta$, mesmo na forma metaestável [38]. Analisando a Figura 4-2, é possível verificar que mesmo que a liga seja resfriada do campo $\beta$, ao atingir a temperatura ambiente terá toda fase $\beta$ transformada em $\alpha$ devido a instabilidade termodinâmica. Estas ligas $\alpha$ não possuem transformação martensítica e, portanto, não são tratáveis termicamente, sendo possível alterar suas características mecânicas apenas através de mudança na quantidade de estabilizadores $\alpha$, que causam endurecimento por solução sólida [38]. Quanto às propriedades mecânicas destacam-se a boa resistência mecânica, tenacidade, resistência à fluência e soldabilidade, porém são ligas de difícil conformabilidade. $\mathrm{Na}$ microestrutura, apresentam grãos equiaxiais de $\alpha$ quando resfriadas a partir do campo $\alpha$ e grãos muito grandes de $\alpha$ (que é a fase $\beta$ que não conseguiu se manter estável) quando resfriadas do campo $\beta$. Exemplos são o titânio puro e a liga Ti-5Al-2,5Sn. 


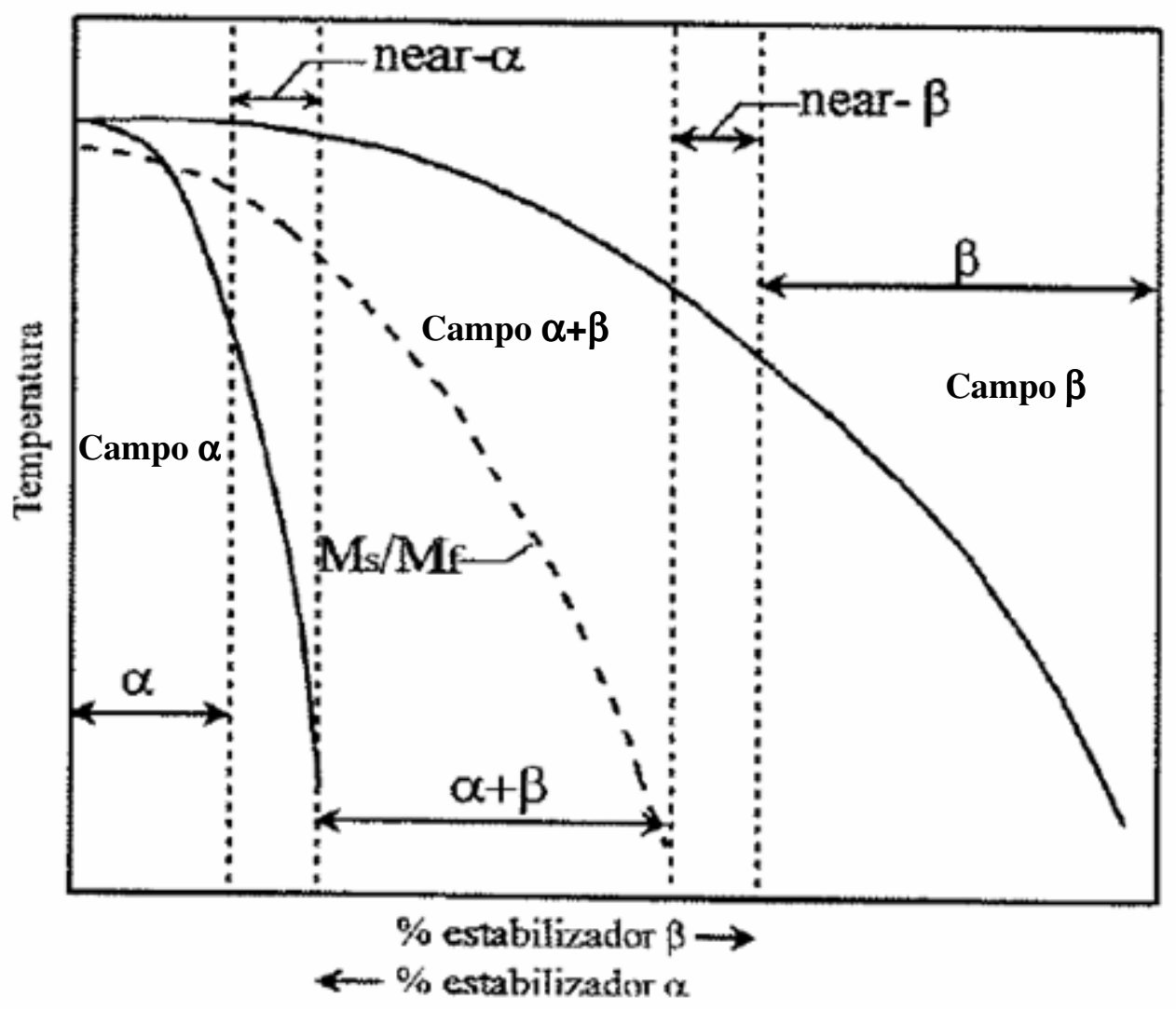

Figura 4-2 - Seção esquemática para ligas de titânio contendo estabilizadores $\alpha$ e $\beta$ [42].

Ligas quase $\alpha$ - Estas ligas possuem pequena quantidade de estabilizadores $\beta$, se diferenciando pelas ligas $\alpha$ por poder possuir uma pequena quantidade de fase $\beta$ (metaestável) nos contornos de grão da fase $\alpha$ quando resfriada do campo $\beta$. Ela se diferencia também pela ocorrência da transformação martensítica de $\beta$ em $\alpha$ ' (que é a martensita do titânio com estrurura hexagonal) que aparece nos contornos de grão da fase $\alpha$. Elas possuem propriedades mecânicas ligeiramente superiores às ligas $\alpha$, destacando-se a resistência à fluência e a soldabilidade, além disto apresentam razoável facilidade de forjamento e são empregadas na produção de componentes para motores aeronáuticos e automotivos [46]. São indicadas para componentes empregados 
em temperaturas muito elevadas (acima de 600ㄷ) [38]. Como exemplos destas ligas cita-se o Ti-6Al-2Sn-4Zr-2Mo/Si (Ti - 6242) e o Ti-5,5Al-3,5Zr-3Sn-1Nb0,25Mo-0,3Si (IMI 829).

Ligas $\alpha+\beta$ - Nestas ligas, o campo de estabilidade $\alpha+\beta$ se estende até a temperatura ambiente. Na temperatura ambiente a faixa de composição de $\beta$ para a qual ocorre a retenção de $\beta$ e de estruturas martensíticas $\alpha^{m}$ ( $\alpha^{\prime}$ e $\alpha^{\prime \prime}$ ) é muito pequena. No resfriamento rápido, a fase $\beta$ pode tanto se transformar em uma das estruturas martensíticas ou ficar retida na forma metaestável, onde pode formar o precipitado $\omega$, formado atermicamente. Estas ligas possuem uma variedade muito grande de microestruturas. Possuem boa resistência mecânica em qualquer faixa de temperatura acima da ambiente, boas condições de conformabilidade e usinabilidade, razoável soldabilidade, ótima relação resistência/peso, além da boa resistência à corrosão [45]. A principal representante deste grupo é a liga Ti6Al4V, que possui aplicação na aeronáutica e em próteses ortopédicas.

Ligas quase $\beta$ - Elas possuem uma quantidade de estabilizadores $\beta$ suficiente para que as linhas de transformação martensítica passem abaixo da temperatura ambiente. Caso seja submetida à deformação, a temperatura de transformação martensítica passará a ocorrer acima da ambiente, possibilitando o aparecimento da estrutura martensítica por trabalho mecânico. Como microestrutura comum há o precipitamento de grãos de $\alpha$ nos contornos de grãos de $\beta$ caso não sejam temperadas. Estas ligas apresentam os maiores níveis de resistência mecânica, boa conformabilidade e baixa soldabilidade, sendo frágeis em temperaturas criogênicas e não indicadas para trabalhos em temperaturas acima de $350^{\circ} \mathrm{C}$. Uma de suas ligas, a Ti-10V-2Fe-3Al (Ti-10-2-3) é utilizada na fabricação de componentes estruturais forjados no Boeing 757 e 737-300 [38]. 
Ligas $\beta$ - Estas ligas apresentam apenas a fase $\beta$ em equilíbrio termodinâmico na temperatura ambiente. Elas possuem boa resistência à corrosão, sendo que algumas delas, como a Ti-Nb-Ta e a Ti-Nb-Ta-Zr, possuem aplicações biomédicas por apresentarem baixo módulo de elasticidade e por seus elementos constituintes serem todos biocompatíveis.

\subsection{Propriedades físicas da liga Ti6Al4V}

A liga Ti6Al4V, como já visto, é uma liga $\alpha+\beta$ para ambas as classificações, e sua temperatura de transformação alotrópica ocorre a $980^{\circ} \mathrm{C}$. Ela possui uma boa combinação de resistência à fadiga e ductilidade, dureza elevada e boa resistência à corrosão $[47,48]$, motivo pelo qual vem sendo utilizada em implantes cirúrgicos desde 1960 [49]. Também possui aplicações na indústria aeroespacial, na produção de vasos de pressão e turbinas de aeronaves [50].

As tabelas a seguir mostram as propriedades mecânicas desta liga.

Tabela 4-2 - Propriedades mecânicas da liga Ti6Al4V [51]

\begin{tabular}{|l|l|l|}
\hline Propriedade & Valor & Unidade \\
\hline Massa específica & 4,43 & $\mathrm{~g} / \mathrm{cm}^{3}$ \\
\hline Dureza & 334 & Brinell \\
\hline Dureza & 363 & Knoop \\
\hline Dureza & 36 & Rockell C \\
\hline Dureza & 349 & Vickers \\
\hline Resistência à tração & 950 & MPa \\
\hline
\end{tabular}




\begin{tabular}{|l|l|l|}
\hline Tensão de escoamento & 880 & $\mathrm{MPa}$ \\
\hline Elongação até a ruptura & 14 & $\%$ \\
\hline Módulo de elasticidade & 113,8 & $\mathrm{GPa}$ \\
\hline Resistência à compressão & 970 & $\mathrm{GPa}$ \\
\hline Resistência ao cisalhamento & 1490 & $\mathrm{Mpa}$ \\
\hline Módulo de Poisson & 0,33 & \\
\hline Resistência ao impacto & 17 & $\mathrm{~J}$ \\
\hline Resistência à fadiga & 75 & $\mathrm{MPa}{ }^{*}$ \\
\hline Módulo de cisalhamento & 44 & $\mathrm{GPa}$ \\
\hline
\end{tabular}

${ }^{*} 1.10^{7}$ ciclos

Tabela 4-3 - Propriedades térmicas da liga Ti6Al4V [51]

\begin{tabular}{|l|l|l|}
\hline Propriedade & Valor & Unidade \\
\hline Calor específico sensível & 0,5263 & $\mathrm{~J} / \mathrm{g}^{\circ} \mathrm{C}$ \\
\hline Condutividade térmica & 6,7 & $\mathrm{~W} / \mathrm{m} . \mathrm{K}$ \\
\hline Ponto de fusão & 1660 & ${ }^{\circ} \mathrm{C}$ \\
\hline
\end{tabular}

\subsection{Microestrutura das ligas de titânio}

No titânio, há dois tipos de fases $\alpha$ : a fase $\alpha$ primária é aquela já existente na temperatura ambiente, permanecendo após o aquecimento e resfriamento do material, enquanto que a fase $\alpha$ secundária (ou $\beta$ transformada) é aquela produzida do resfriamento de uma fase $\beta$ a uma maior temperatura. A morfologia da fase $\alpha$ secundária na maioria das vezes é acicular ou lamelar, podendo também ser em forma de plaquetas ou Widmanstäten [52]. Esta estrutura 
Widmanstäten é formada a partir de resfriamento lento, quando os grãos de $\alpha$ crescem a partir de uma matriz de $\beta$, preferencialmente nos planos $\{110\}$, começando nos contornos de grãos, formando ângulos próximos de 90ํe eles [50]. Um esquema da formação desta estrutura pode ser encontrado na Figura 4-3.

Um resfriamento rápido da liga do campo beta faz com que a fase $\beta$ fique retida à temperatura ambiente ( $\beta$ retida), geralmente formando a matriz da estrutura do material. Além da fase $\beta$, pode ocorrer também a formação de estruturas martensíticas $\alpha$ ou $\alpha$ ". A martensita $\alpha$ é a mais comum e pode apresentar duas morfologias: a martensita massiva e a acicular [53]. A martensita massiva consiste de colônias resolvíveis opticamente, contendo placas de martensitas paralelas.

Com um aumento da concentração de estabilizadores $\beta$ e conseqüentemente uma diminuição da temperatura de transformação martensítica, o tamanho das colônias de martensita massiva diminuem, chegando a degenerar-se totalmente a placas individuais, que possuem uma morfologia acicular. Esta morfologia de martensita $\alpha$ 'é a existente na liga Ti6Al4V.

O segundo tipo de martensita é a $\alpha "$, que aparece em ligas binárias de titânio como Ti-Mo, Ti-Nb, Ti-W e não aparece em outras como o Ti-V. Porém, com adições de $\mathrm{Al}$, ligas que não formam $\alpha$ " como a Ti-V, podem formar a estrutura em um largo campo de composições. Em algumas ligas $\alpha+\beta$, como a TiAl-2Sn-4Zr-6Mo, a formação desta martensita é acompanhada por uma diminuição na ductilidade. 


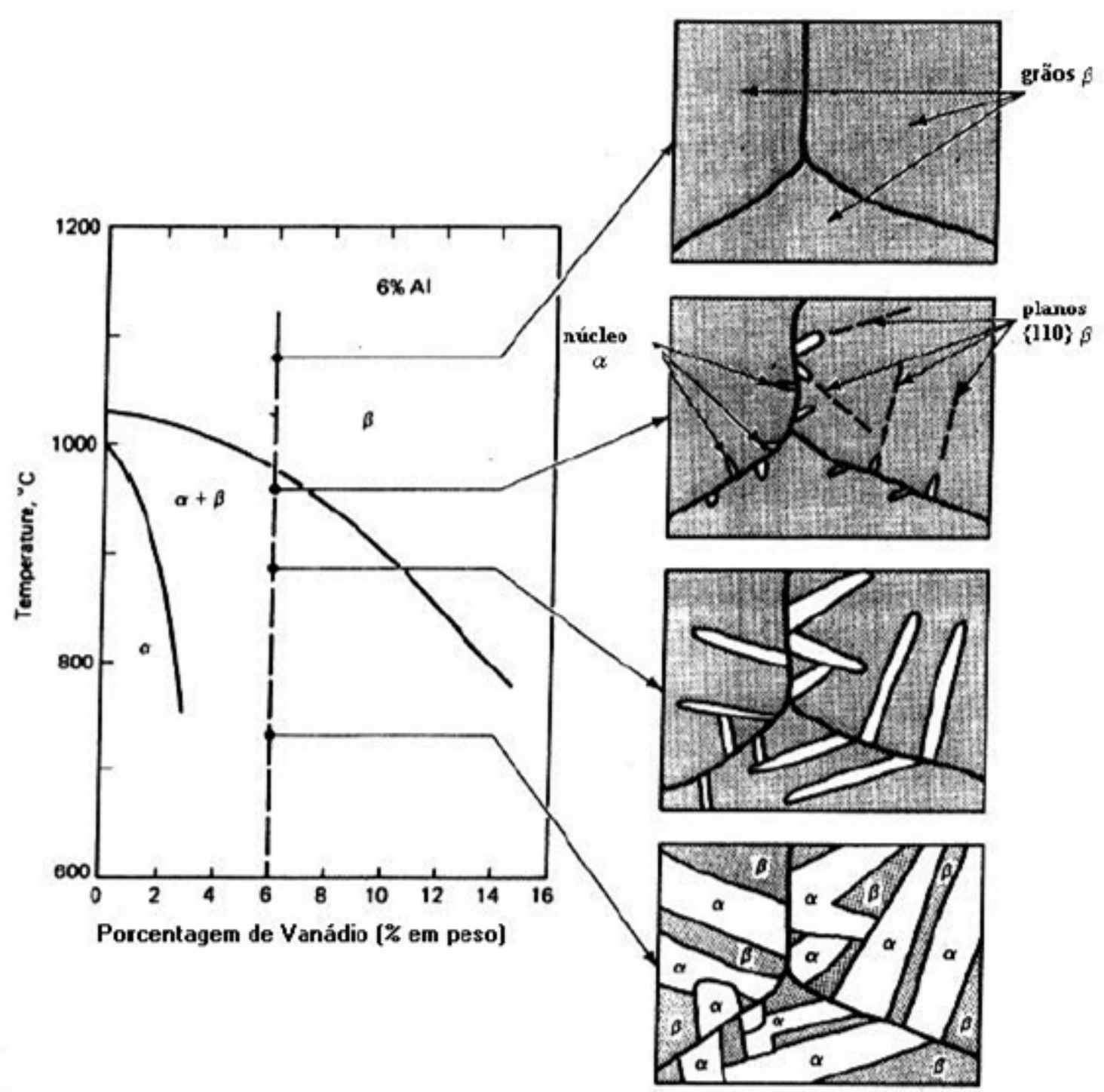

Figura 4-3 - Formação da estrutura Widmanstäten na liga Ti6Al4V; a fase $\alpha$ é representada pela parte clara e a fase $\beta$ pela parte escura [50].

Dependendo da temperatura de têmpera podemos ter uma das martensitas ou ambas, com ou sem a fase $\beta$. A Figura 4-4 mostra as diferentes estruturas que ocorrem na liga Ti6Al4V dependendo da temperatura de têmpera adotada. 

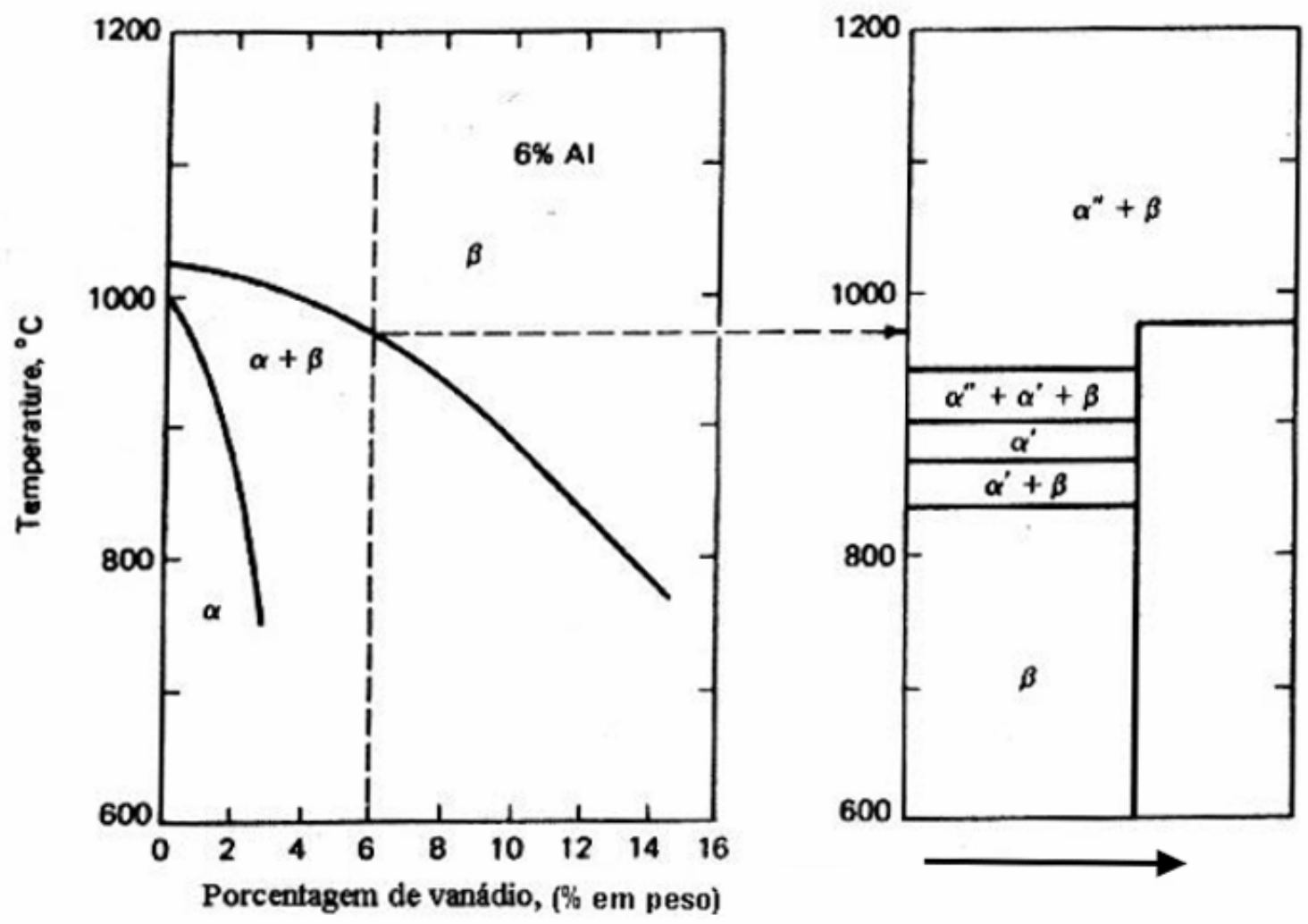

Figura 4-4 - Diferentes fases formadas na liga Ti6Al4V dependendo da temperatura de têmpera [50]

\subsection{Elementos intersticiais no titânio}

Como mostrado na Tabela 4-1, os elementos intersticiais no titânio são o carbono, o nitrogênio, o hidrogênio e o oxigênio, sendo que este último provoca as modificações mais acentuadas no material. Destes, o carbono, o nitrogênio e o oxigênio são solúveis na fase $\alpha$ do titânio, aumentando a temperatura de transformação alotrópica, ao contrário do hidrogênio que é pouco dissolvido na fase $\alpha$, porém pode chegar a até $8 \%$ de solubilidade na fase $\beta$ [17].

Cada um destes elementos tende a formar um outro composto com o titânio após o limite de solubilidade deles ser ultrapassado. Todos estes elementos em excesso diminuirão a ductilidade da solda e aumentarão a sua 
dureza em excesso, podendo criar fissuras provocadas por tensões de encolhimento.

O titânio puro contém até $0,35 \%$ de oxigênio, $0,07 \%$ de nitrogênio, $0,1 \%$ de carbono, $0,015 \%$ de hidrogênio e $0,3 \%$ de ferro [17]. Um aumento das impurezas para valores acima destes limites pode causar um decréscimo significativo na ductilidade da liga.

A Tabela 4-4 mostra o comportamento mecânico do titânio puro com a adição dos elementos de liga intersticiais.

Tabela 4-4 - Efeito dos elementos intersticiais no titânio puro [17]

\begin{tabular}{|c|c|c|c|c|c|c|c|}
\hline \multicolumn{4}{|c|}{ Elementos intersticiais (\%) } & \multirow{2}{*}{$\begin{array}{l}\text { Limite de } \\
\text { resistência } \\
\text { (psi) }\end{array}$} & \multirow{2}{*}{$\begin{array}{c}\text { Tensão de } \\
\text { escoamento } \\
\text { (psi) }\end{array}$} & \multirow{2}{*}{$\begin{array}{c}\text { Elongamento } \\
\text { (\%) }\end{array}$} & \multirow{2}{*}{$\begin{array}{l}\text { Dureza } \\
\text { Vickers }\end{array}$} \\
\hline C & $\mathrm{H}$ & $\mathrm{N}$ & O & & & & \\
\hline * & $\ldots$ & 0,02 & 0,15 & 80.000 & 70.000 & 25 & 200 \\
\hline * & $\ldots$ & 0,07 & 0,41 & 142.000 & 140.000 & 22 & 300 \\
\hline * & $\ldots$ & 0,09 & 0,47 & 153.000 & 150.000 & 12 & 310 \\
\hline * & $\ldots$ & 0,14 & 0,62 & 101.000 & 101.000 & 0 & 360 \\
\hline 0,02 & 0,001 & 0,005 & 0,025 & 36.000 & 18.000 & 75 & 88 \\
\hline * & $\ldots$ & $\cdots$ & 0,1 & 65.000 & 50.000 & 35 & 170 \\
\hline * & $\ldots$ & 0,1 & $\cdots$ & 80.000 & 57.000 & 25 & 190 \\
\hline 0,1 & $\ldots$ & $\ldots$ & $\ldots$ & 55.000 & 36.000 & 40 & 140 \\
\hline
\end{tabular}

*Não determinado 
Percebe-se que ao ultrapassar um certo limite de concentração do oxigênio e do nitrogênio, as propriedades de alongamento e de limite de resistência do titânio são altamente modificadas.

\subsubsection{Oxidação do titânio}

Na temperatura ambiente o titânio não reage com o ar, que possui grandes quantidades de nitrogênio e oxigênio, devido à presença de uma fina camada de óxido protetora [54]. Porém, a partir de uma determinada temperatura (temperatura de oxidação), esta camada de óxido perde suas propriedades de proteção, permitindo que os elementos da atmosfera, principalmente o oxigênio, difundam no titânio e reajam com ele. Na literatura há discordâncias no valor desta temperatura para o titânio, que varia de $300^{\circ} \mathrm{C}$ a $600^{\circ} \mathrm{C}[17,54,56]$.

O oxigênio entra na estrutura cristalina do titânio através de difusão. A equação que rege a difusão de um elemento em outro é dada pela segunda lei de Flick, mostrada a seguir $[54,55]$ :

$$
\frac{\partial \mathrm{C}}{\partial \mathrm{t}}=\mathrm{Df} \cdot \frac{\partial^{2} \mathrm{C}}{\partial \mathrm{x}^{2}}
$$

Onde Df é a difusidade do gás no metal, $C$ é a concentração da espécie que difunde na outra, t é o tempo e x é o caminho percorrido pela espécie que difunde.

A difusidade (Df) é dependente da temperatura, sendo normalmente expressa como [55]:

$$
\mathrm{Df}=\mathrm{Df}_{0} \exp \left(\frac{-\mathrm{Q}}{\mathrm{R} . \mathrm{T}}\right)
$$

Onde $\mathrm{Df}_{0}$ e $\mathrm{Q}$ são constantes, $\mathrm{T}$ é a temperatura e $\mathrm{R}$ é a constante universal dos gases. 
Portanto, a difusão de um gás em um sólido é um fenômeno dependente da temperatura. Quanto maior a temperatura, mais facilmente o gás conseguirá entrar na rede cristalina do sólido, podendo então reagir com ele.

A camada de óxido formada na superfície do material é um fator que conta para a diminuição da difusão do gás no metal, por ser mais um obstáculo que os átomos do gás tem que atravessar para reagir com o metal base.

Porém nem os átomos neutros do metal nem os átomos neutros do oxigênio são solúveis nesta camada de óxido. Para que a oxidação continue ocorrendo, o metal e o oxigênio perdem e ganham elétrons respectivamente para virarem íons e passarem pela camada de óxido [55].

No titânio, a oxidação pode ser dividida em duas partes: quando há predominância da difusão dos íons de oxigênio e quando a difusão dos íons de titânio para a superfície é predominante.

Até aproximadamente $1000^{\circ} \mathrm{C}$, há uma difusão do oxigênio no titânio, formando uma camada de óxido na superfície do material, porém a partir de $1000^{\circ} \mathrm{C}$ o fenômeno que prevalece é a difusão dos íons de titânio para a superfície, passando pela camada de óxido já existente [56].

Esta camada de óxido formado na superfície do titânio é visível, possuindo cores que dependem da concentração de oxigênio existente que vai do roxo até o azul, voltando novamente para o azul e repetindo a seqüência [57]. 


\section{MATERIAIS E MÉTODOS}

\subsection{Laser de Nd: YAG}

O equipamento utilizado para as soldagens dos materiais foi desenvolvido no Instituto de Pesquisas Energéticas e Nucleares (IPEN), denominado de central de processamento de materiais a laser (CPML). Trata-se de um laser de Nd:YAG pulsado em conjunto com uma mesa CNC de três eixos.

O laser produz pulsos temporalmente quadrados que possuem largura temporal controlada de 0,2 a $10 \mathrm{~ms}$, com a energia por pulso podendo chegar até 10J, 100W de potência média, potência pico de $3 \mathrm{~kW}$ e taxa de repetição maior que $300 \mathrm{~Hz}$. O feixe produzido é multimodo, com $\mathrm{M}^{2}=12$. O sistema de guiamento do feixe possui espelhos que o levam desde a saída do ressonador até a superfície da peça onde é focalizado por uma lente de comprimento focal $f=$ 100mm. Um obturador eletrônico e um programa CNC controla o caminho do cordão de solda bem como a taxa de sobreposição dos pulsos; uma câmera ccd acoplada colinearmente ao feixe permite a visualização amplificada da região fundida. 


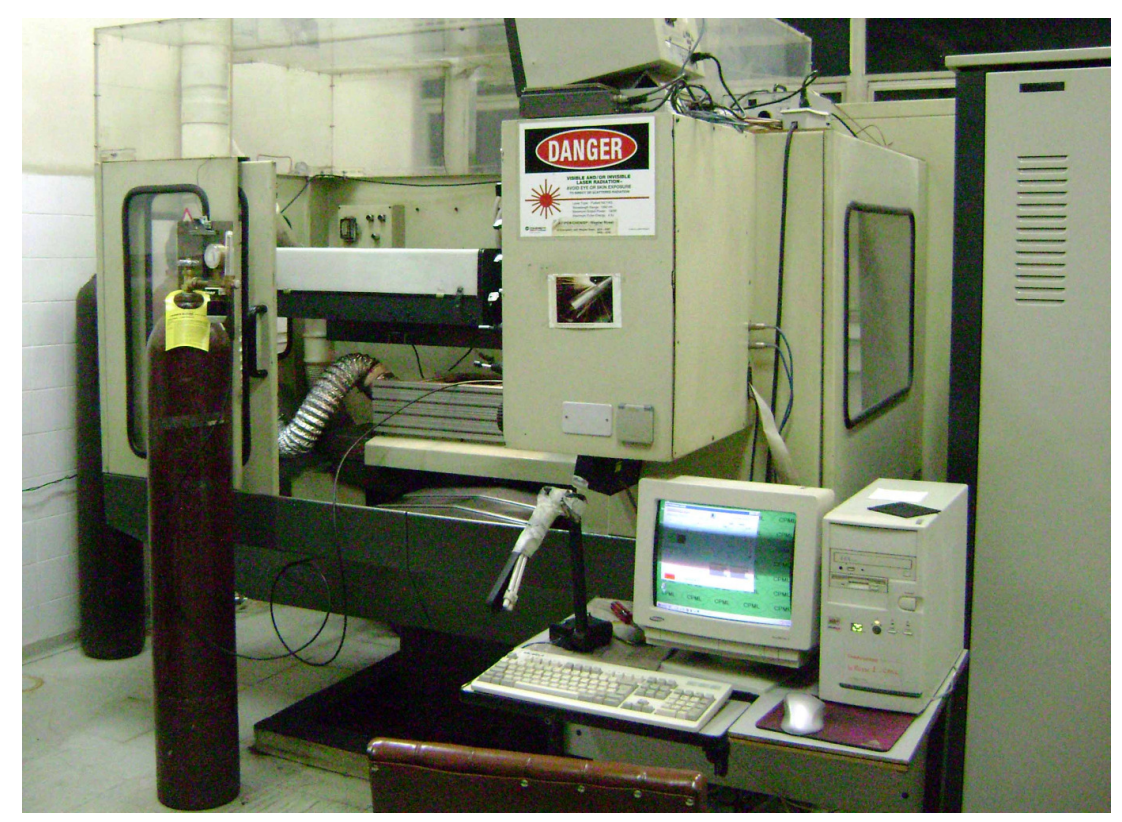

Figura 5-1 - Central de Processamento de Materiais a Laser (CPML).

\subsection{Laser de fibra}

Um outro laser também foi utilizado neste trabalho; trata-se de um laser com emissão contínua, de fibra de vidro pertencente ao Centro Tecnológico da Aeronáutica (CTA) e fabricado pela IPG Photonics. Possui um comprimento de onda entre 1070 e 1080 nm e potência máxima de 2kW.

\subsection{Material utilizado}

Os materiais utilizados foram chapas de Ti6Al4V (titânio grau 5), laminados na espessura nominal de $1,0 \mathrm{~mm}$ e espessura medida de $1,1 \mathrm{~mm}$, adquiridos nas dimensões de $300 \mathrm{~mm} \times 600 \mathrm{~mm}$ da empresa Realum. A composição química fornecida pelo fabricante é mostrada na tabela abaixo. 
Tabela 5-1 - Composição química da chapa Ti6Al4V [58]

\begin{tabular}{|c|c|c|c|c|c|c|c|c|}
\hline \multicolumn{10}{|c|}{ Concentração máxima dos elementos químicos (\%) } \\
\hline & $\mathrm{N}$ & $\mathrm{C}$ & $\mathrm{H}$ & $\mathrm{Fe}$ & $\mathrm{O}$ & $\mathrm{Al}$ & $\mathrm{V}$ & $\mathrm{Ti}$ \\
\hline Ti6Al4V & 0,05 & 0,08 & 0,015 & 0,4 & 0,2 & 5,5 & 3,5 & balanço \\
& & & & & & $\mathrm{a}$ & $\mathrm{a}$ & \\
& & & & & & 6,75 & 4,5 & \\
\hline
\end{tabular}

Uma chapa de Ti6Al4V de $1 \mathrm{~mm}$ de espessura foi utilizada para os testes de soldagem. Uma análise por fluorescência de raios-X foi realizada nos laboratórios do Centro de Química e Meio Ambiente do IPEN, apresentando composição conforme Tabela 5-2.

Tabela 5-2 - Composição da chapa utilizada determinada por fluorescência de raios-X

\begin{tabular}{|c|c|}
\hline Elemento químico & $\%$ \\
\hline $\mathrm{Ti}$ & 89,4 \\
\hline $\mathrm{Al}$ & 6,3 \\
\hline $\mathrm{V}$ & 3,9 \\
\hline $\mathrm{Fe}$ & 0,24 \\
\hline $\mathrm{Si}$ & 0,07 \\
\hline $\mathrm{Na}$ & 0,04 \\
\hline $\mathrm{Ni}$ & 0,02 \\
\hline $\mathrm{S}$ & 0,01 \\
\hline $\mathrm{P}$ & $<0,01$ \\
\hline
\end{tabular}




\subsection{Metalografia}

Após serem irradiadas, as amostras eram cortadas na cortadora Isomet 2000 da Buehler, com carga de 300g e velocidade de 1500 rpm. Foram realizados embutimentos a frio, com o uso de resina, em recipientes de $2 \mathrm{~cm}$ de diâmetro e de altura.

A lapidação das amostras com lixas d'água seguia a seguinte seqüência: 200, 400, 600, 1200 e era realizada em dispositivo encontrado no Centro de Ciências e Tecnologia de Materiais (CCTM) do IPEN.

Não foi possível realizar o polimento das amostras com a pasta de diamante de qualquer granulação, pois após o processo a amostra se encontrava com riscos. Para contornar o problema, o polimento foi realizado com sílica coloidal que apresentou ótimos resultados, com um bom polimento em um curto intervalo de tempo.

$\mathrm{O}$ ataque químico das amostras foi realizado utilizando o reagente de Kroll: $2 \mathrm{ml}$ de $\mathrm{HF}, 6 \mathrm{ml}$ de $\mathrm{HNO}_{3}$ e $88 \mathrm{ml}$ de $\mathrm{H}_{2} \mathrm{O}$, seguindo o exemplo de trabalhos anteriores $[59,9]$.

\subsection{Ensaio de microdureza}

Os ensaios de microdureza foram realizados no Laboratório de Fenômenos de Superfície da Escola Politécnica da Universidade de São Paulo. O objetivo deste ensaio foi tanto de encontrar impurezas, que aumentam a dureza da solda, quanto para a caracterização de microestruturas.

A carga utilizada no ensaio foi de $50 \mathrm{~g}$ e era deixado um espaçamento de $100 \mu m$ entre as marcas do ensaio, para não haver algum tipo de influência. 


\subsection{Ensaio de tração e flexão}

Os ensaios mecânicos de tração e flexão foram realizados na máquina universal de ensaios da INSTRON, modelo 440R, do Centro de Ciências e Tecnologia dos Materiais (CCTM), localizado no IPEN, mostrada na foto abaixo.

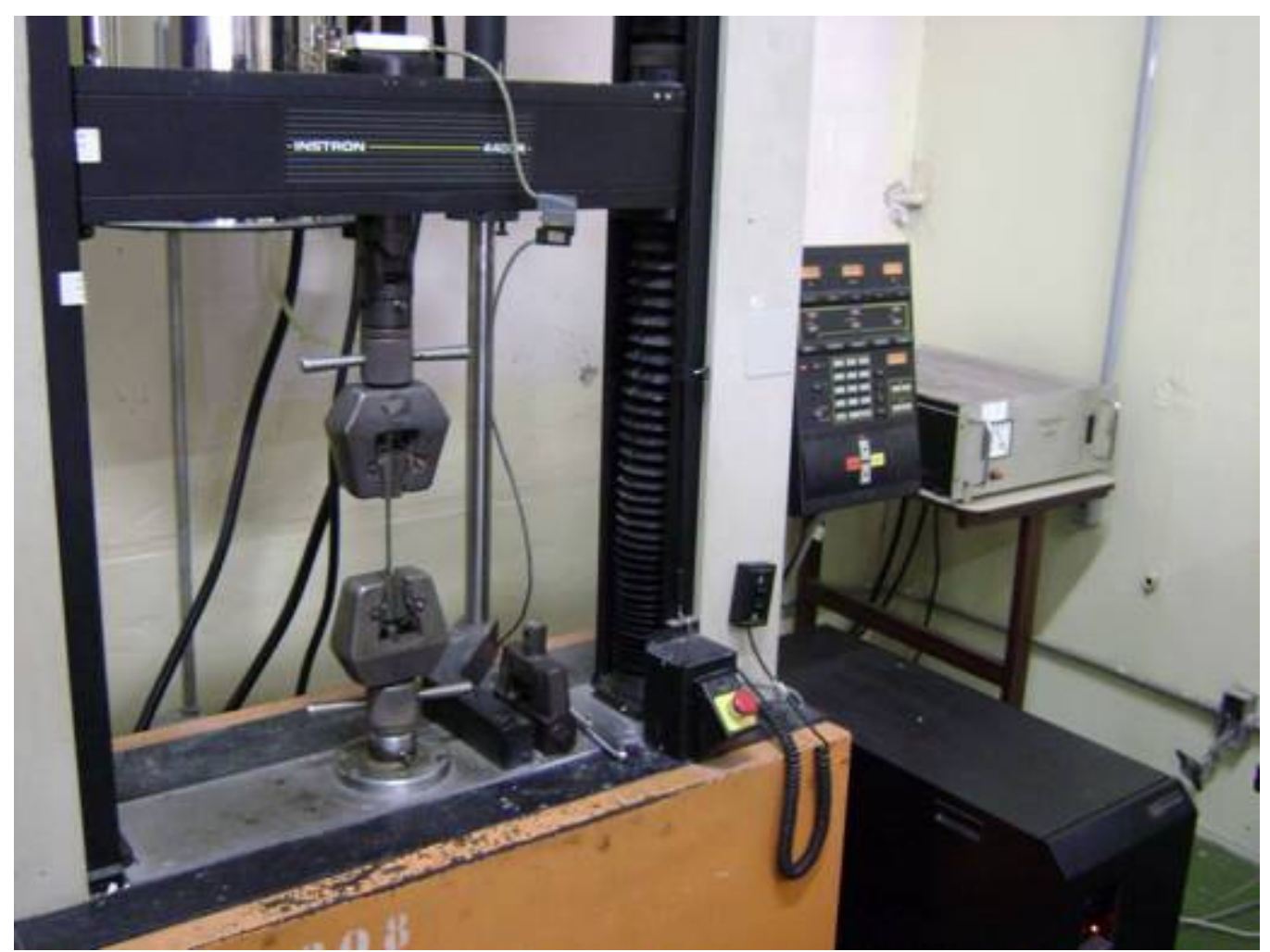

Figura 5-2 - Máquina universal de ensaios mecânicos.

No ensaio de flexão de 3 pontos, as amostras são apoiadas entre dois pontos e um terceiro ponto na distância média entre os outros dois aplica uma carga, flexionando a amostra. A Figura 5-3 e Figura 5-4 mostram respectivamente o esquema do ensaio de flexão e as forças atuantes na amostra no decorrer do ensaio. 


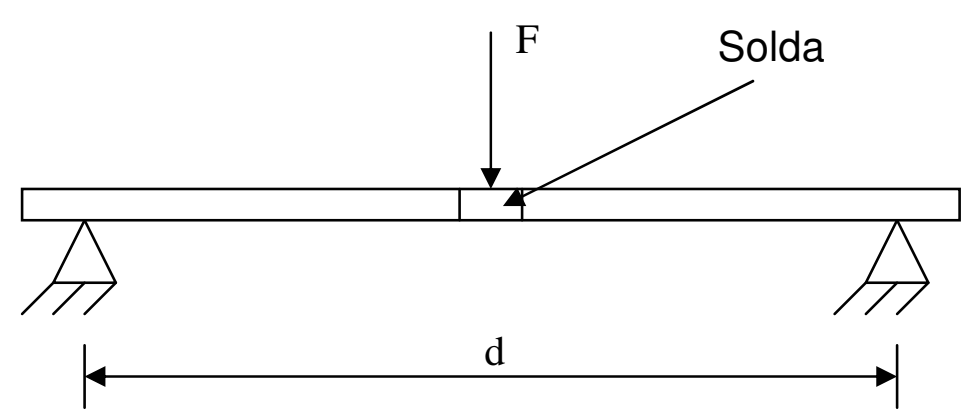

Figura 5-3 - Esquema do ensaio de flexão

No decorrer do ensaio, a parte superior da amostra é comprimida e a parte inferior é tracionada, de forma que há uma divisória entre os dois tipos de tensões pela linha neutra, que é uma linha que se encontra na metade da espessura do material e é onde a aplicação dos esforços de tração e compressão anulam-se.

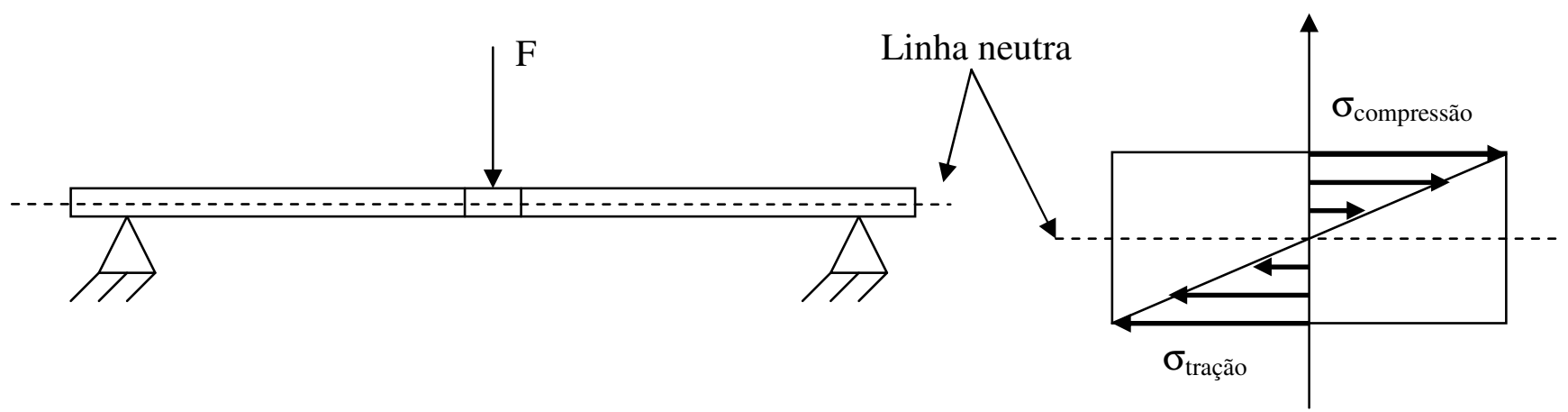

Figura 5-4 - Esforços submetidos na amostra durante o ensaio de flexão

As amostras eram retângulos de $40 \times 5 \times 1 \mathrm{~mm}$, e a distância dos pinos da base era de 1 polegada. A seguir tem-se uma foto de algumas das amostras e do dispositivo utilizado. 


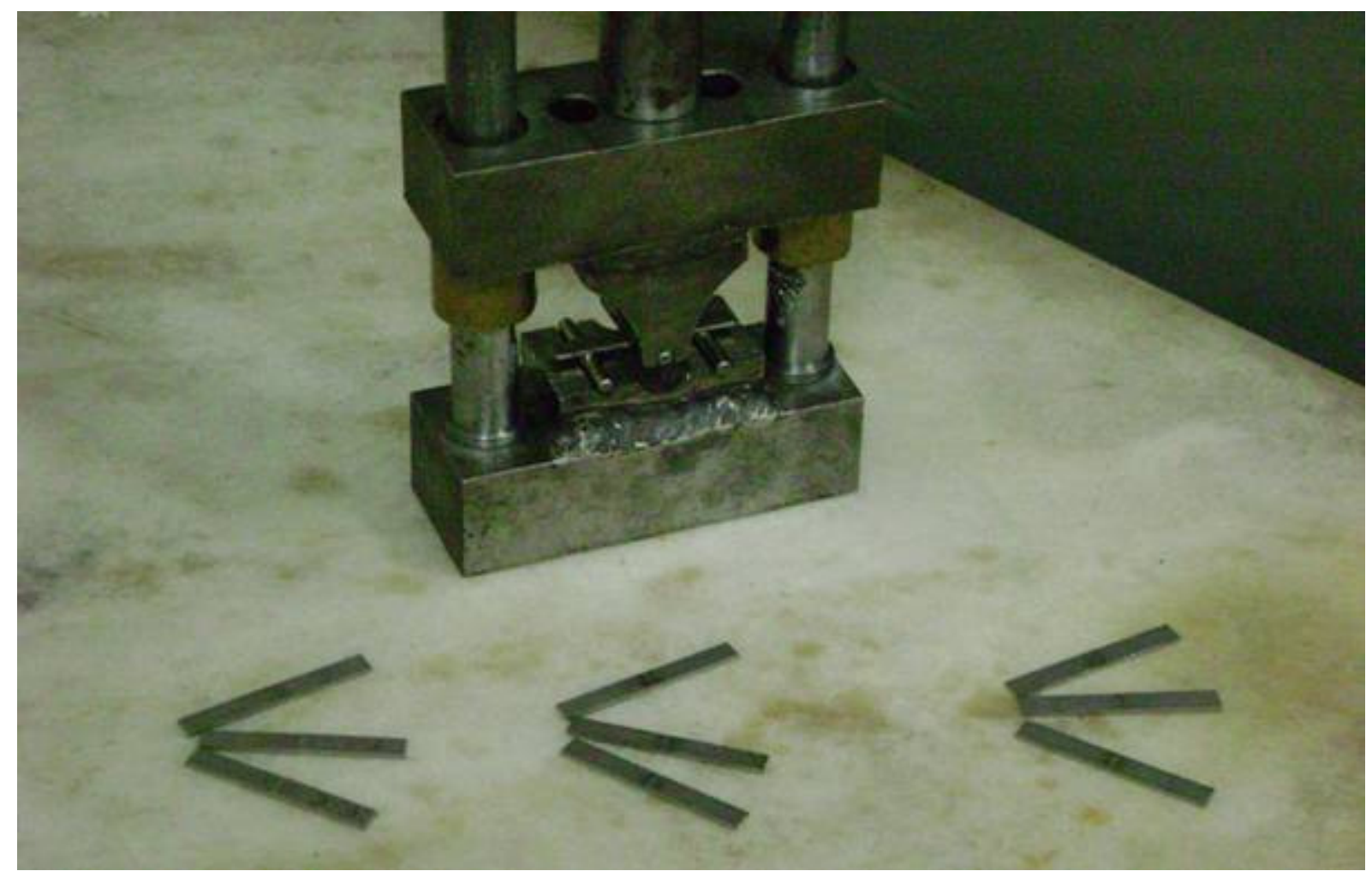

Figura 5-5 - Dispositivo e amostras do ensaio de flexão

As amostras utilizadas no ensaio de tração seguiam a norma ABNT [20] e foram tracionadas na velocidade de $1 \mathrm{~mm} / \mathrm{min}$. A figura abaixo mostra as dimensões e forma do corpo de prova utilizado.

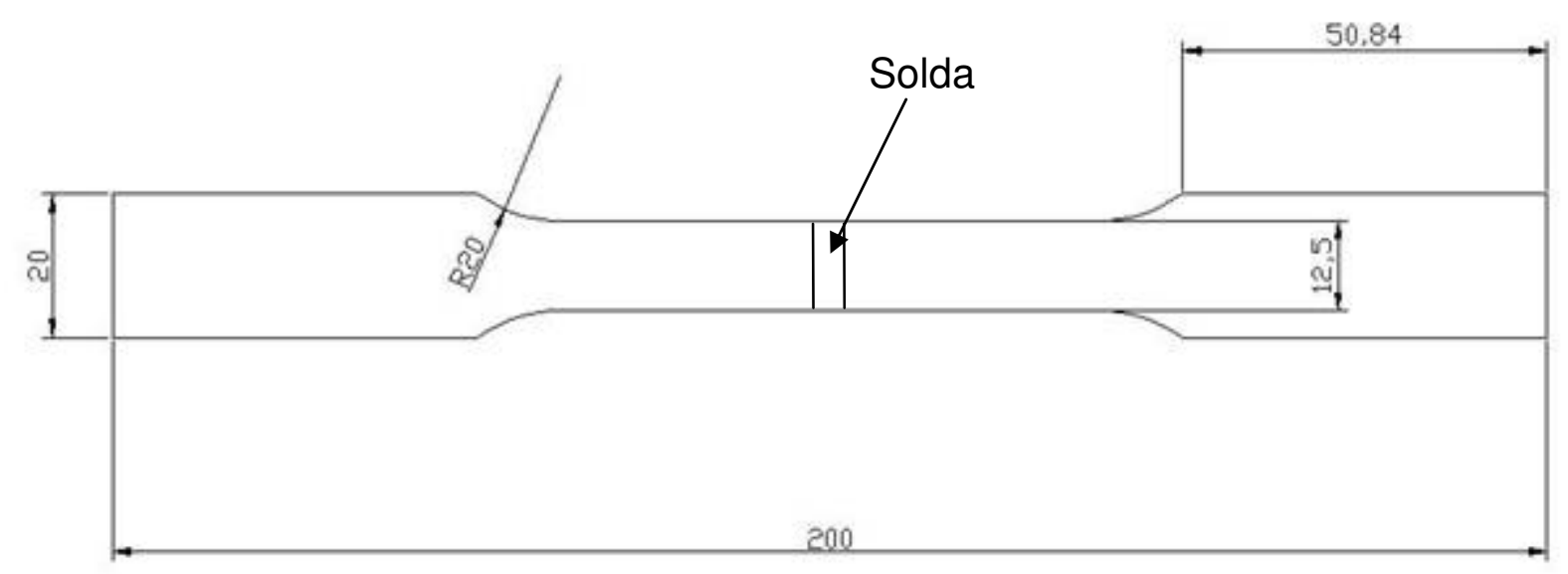

Figura 5-6 - Corpo de prova utilizado no ensaio de tração 
Os corpos de prova eram retirados a partir de chapas de $30 \times 220 \mathrm{~mm}$, onde se tirava um corpo de prova, ou a partir de chapas de 55×220, de onde se retirava 2 corpos de prova. Os corpos de prova eram cortados a partir destas chapas na Central de Processamento de Materiais a Laser.

\subsection{Microscopia eletrônica de varredura e espectroscopia por energia dispersiva}

O microscópio eletrônico de varredura e o espectrômetro por energia dispersiva utilizados são ambos pertencentes ao Centro de Ciência e Tecnologia dos Matérias (CCTM). O microscópio é da marca Philips, modelo XL30 e o espectrômetro é da marca EDAX.

\subsection{Dispositivo de entrega de gás}

\subsubsection{Dispositivo de proteção de raiz}

Neste trabalho os dispositivos de entrega de gás compreenderam o bocal, que é coaxial ao feixe laser e faz o papel de proteção primária e uma câmara colocada na parte inferior do dispositivo de posicionamento da peça que faz o papel de proteção de raiz (backshielding), mostrado na Figura 5-7. 


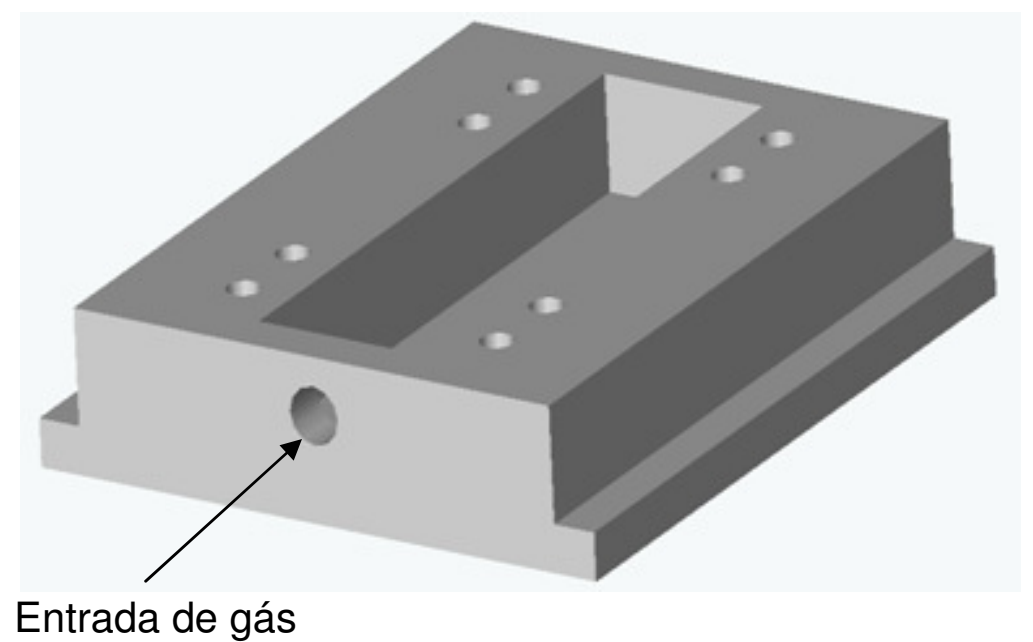

Figura 5-7 -Dispositivo de proteção com câmara inferior.

Este dispositivo foi projetado para soldar peças de até $60 \mathrm{~mm}$ de comprimento. É importante observar que dependendo do comprimento é necessário utilizar uma "máscara" acima deste dispositivo que faça com que o gás saia o mais próximo possível da peça, pois se o vão entre a peça e o dispositivo for muito grande haverá um grande desperdício de gás que não será utilizado para proteção. No trabalho foram utilizados vãos de no máximo $2 \mathrm{~mm}$.

\subsubsection{Projeto do bocal de proteção}

Como já visto, o gás que sai do bocal deve estar em um regime laminar para que a proteção seja realizada sem riscos de contaminação. Assim, utilizando a Equação 17 e as propriedades na Tabela 3-1, é possível determinar em qual regime o gás se encontra para um determinado fluxo e diâmetro de bocal. Os gráficos a seguir mostram o fluxo máximo no qual há um regime laminar para diferentes diâmetros de bocais: 
Fluxo limite - Argônio

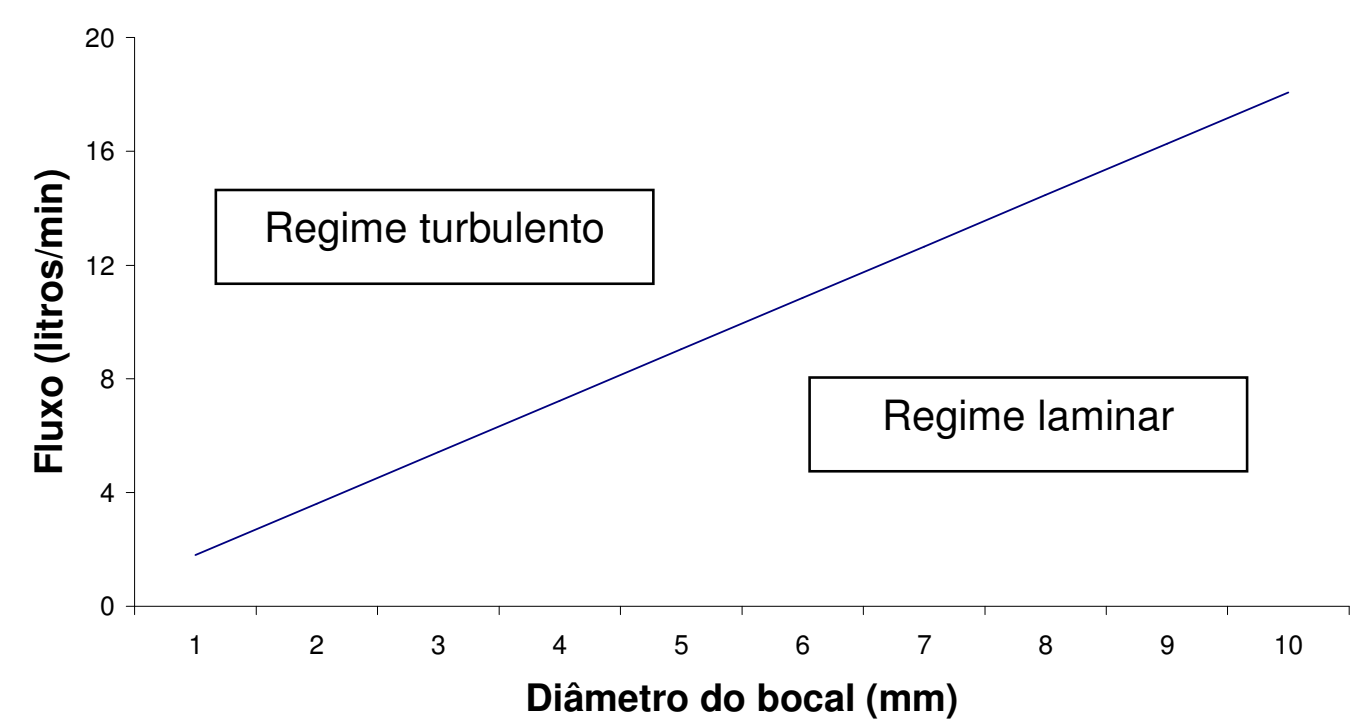

Figura 5-8 - Fluxo limite para o argônio

Fluxo limite - Hélio

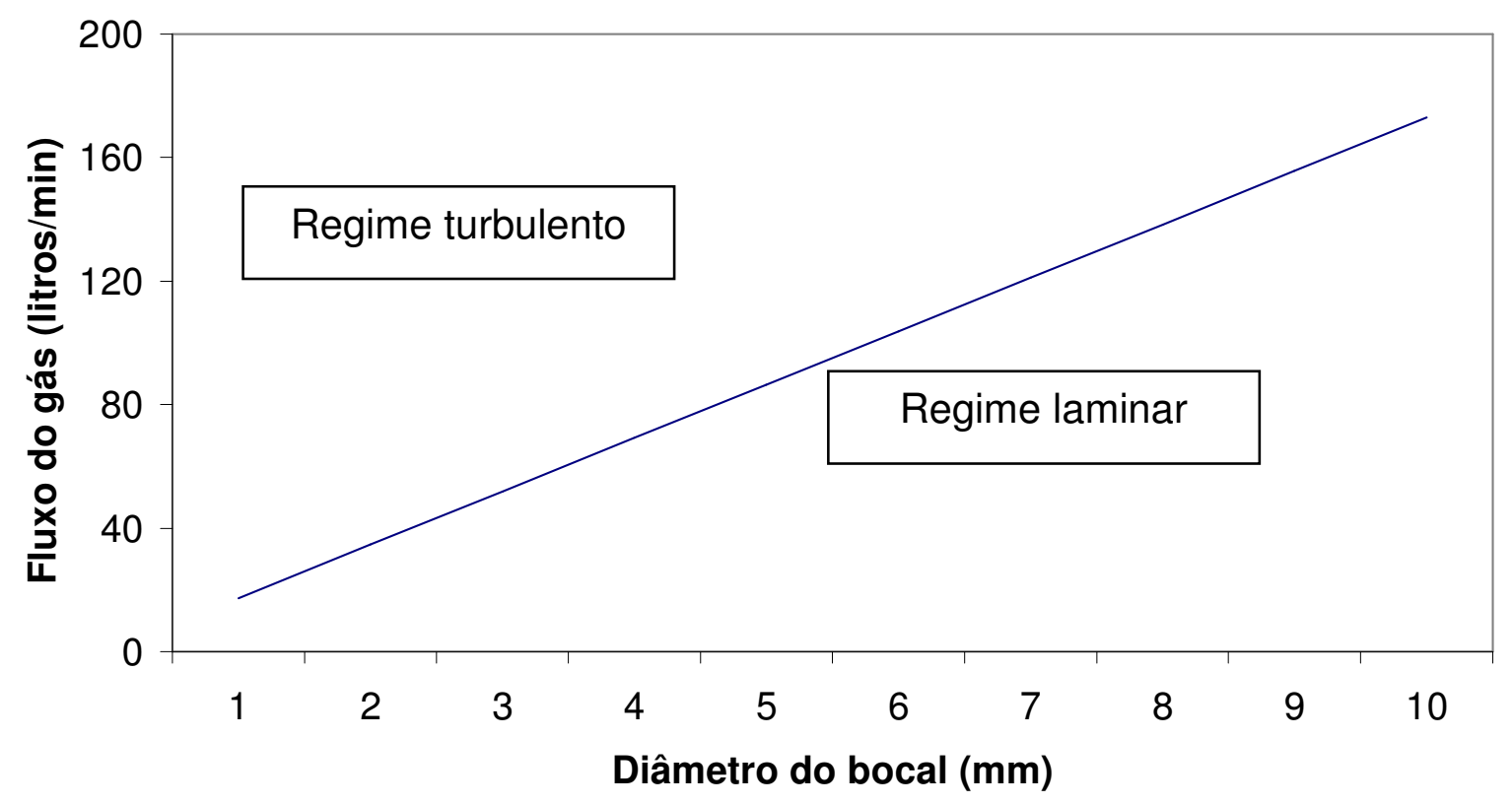

Figura 5-9 - Fluxo limite para o hélio 
A partir dos gráficos, percebe-se claramente que o único gás que poderá apresentar turbulência é o argônio, já que para o hélio atingir o regime turbulento, o gás deve estar em altas velocidades.

Como o bocal deve abranger uma área razoavelmente grande, e também deve ser menor que o limite físico estabelecido pela central de processamento, adotou-se o diâmetro interno de $8 \mathrm{~mm}$, por estar dentro destes limites e poder operar até um valor de fluxo razoável sem entrar em regime turbulento $(14,5$ litros/minuto).

Este fluxo laminar deve manter-se também na saída do gás, então é necessário o estudo para verificar se haverá um aumento do número de Reynolds ou não.

Para facilitar os cálculos, foi feita uma aproximação, transformando a área cilíndrica de onde termina a região bico-peça como sendo formada por vários cilindros, como mostrado abaixo: 


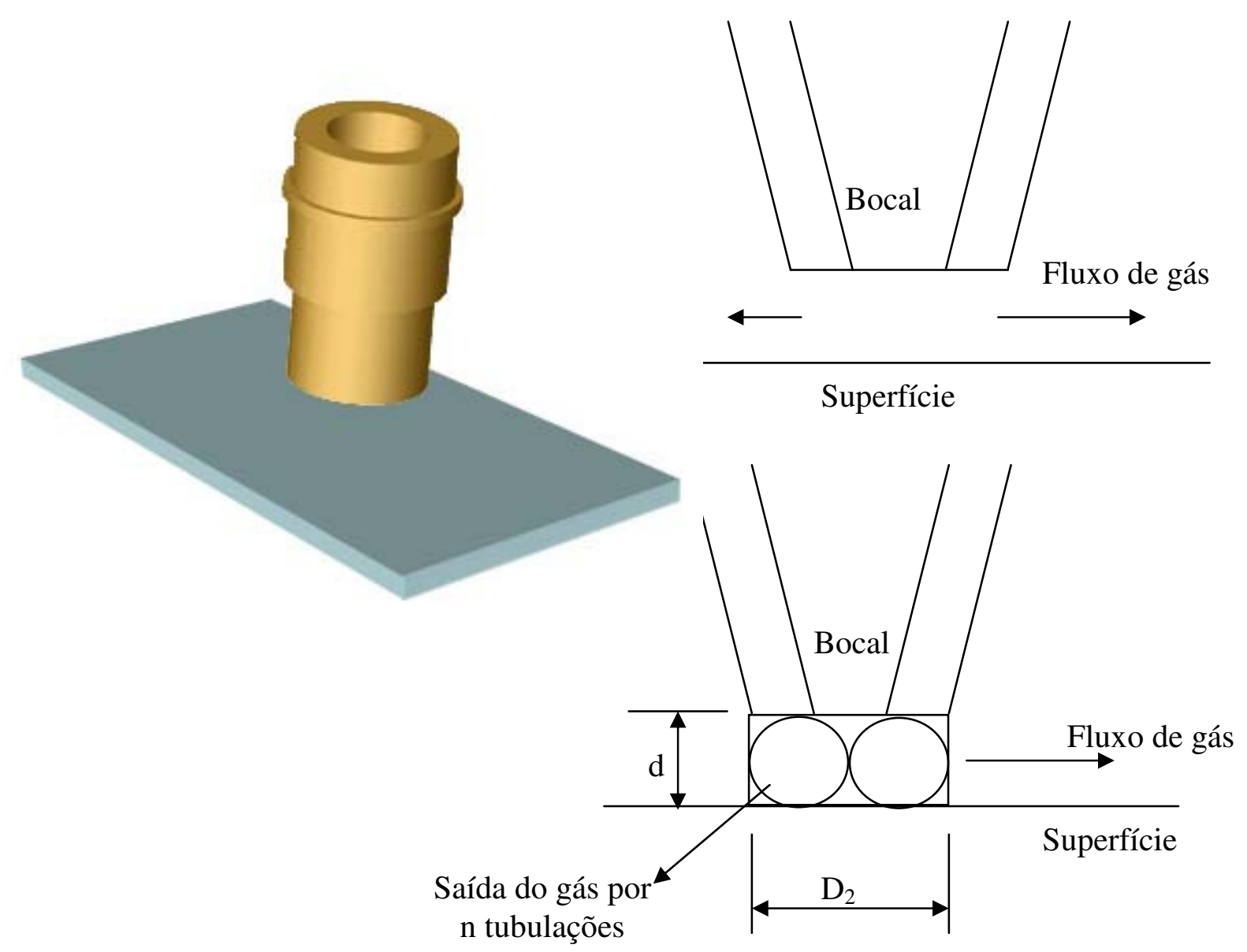

Figura 5-10 - Aproximação para cálculo do número de Reynolds na saída bicopeça.

O número de círculos (n) será dado pela razão do perímetro do cilindro pela distância bico-peça (d):

$$
\mathrm{n}=\frac{\pi \cdot \mathrm{D}_{2}}{\mathrm{~d}}
$$

Onde $\mathrm{D}_{2}$ é o diâmetro externo do bocal e d é a distância bico-peça.

Assim o fluxo que passa por cada um dos tubos de diâmetro d é dado por:

$$
\phi^{\prime}=\frac{\phi}{\mathrm{n}}=\frac{\phi \cdot \mathrm{d}}{\pi \cdot \mathrm{D}_{2}}
$$

O número de Reynolds é calculado apenas para um dos tubos, pois será igual para todos os outros, assim temos: 


$$
\begin{aligned}
& \mathrm{R}=\frac{4 \cdot \phi}{\pi \cdot \mathrm{D} \cdot v} \\
& \mathrm{R}=\frac{4 \cdot \phi^{\prime}}{\pi \cdot \mathrm{d} \cdot v} \\
& \mathrm{R}=\frac{4 \cdot \phi \cdot \mathrm{d}}{\pi \cdot \mathrm{d} \cdot v \cdot \pi \cdot \mathrm{D}_{2}} \\
& \mathrm{R}=\frac{4 \cdot \phi}{\pi^{2} \cdot v \cdot \mathrm{D}_{2}}
\end{aligned}
$$

Comparando esta equação com a equação (17), onde podemos calcular o número de Reynolds a partir do diâmetro interno, $D_{1}$, percebe-se que a única diferença é a presença de mais um fator $\pi$ no denominador. $E$ como $D_{2}$ será sempre maior que $D_{1}$, o valor do número de Reynolds na saída bico-peça será sempre menor do que aquele calculado na saída do bocal.

Segundo Grevey [28], quando o gás proveniente do bocal atinge a superfície, ele produz um aumento de pressão sobre ela. Porém na saída da divisão bico-peça, há uma diminuição deste valor de pressão, provocado pela diferença de velocidades entre as moléculas do gás de proteção e do ar. As análises aqui realizadas não levam em conta o movimento do bocal. A figura abaixo mostra esta diferença de pressão: 


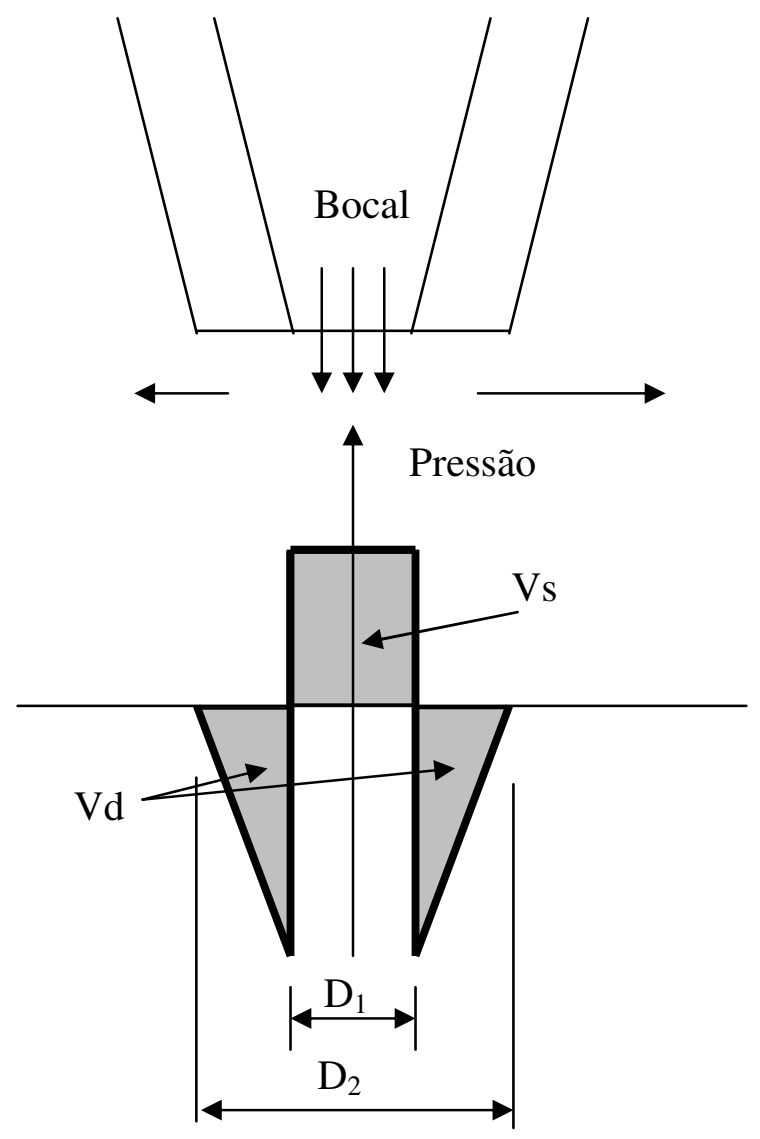

Figura 5-11 - Modificações na pressão provocadas pelo gás de proteção.

A oxidação irá ocorrer caso a zona perturbada pelo gás esteja com uma pressão negativa, ou seja [28]:

$$
\int \mathrm{P}(\mathrm{x}, \mathrm{y}) \mathrm{d} \mathrm{S} \leq 0
$$

Portanto, para que não ocorra oxidação, o volume Vs tem que ser maior do que Vd. Uma das maneiras de controlar esta diminuição de pressão é diminuindo o valor da velocidade $v_{2}$ : uma menor velocidade do gás de proteção implica em uma menor diferença da velocidade das moléculas deste comparado com as moléculas do ar, provocando uma menor queda de pressão [28].

Partindo do princípio da conservação de fluxo, é possível chegar na seguinte relação: 


$$
\begin{aligned}
& \mathrm{V}_{1} \cdot \mathrm{A}_{1}=\mathrm{V}_{2} \cdot \mathrm{A}_{2} \\
& \mathrm{~V} 1 \cdot \frac{\pi}{4} \cdot \mathrm{D}_{1}{ }^{2}=\mathrm{V}_{2} \cdot \pi \cdot \mathrm{D}_{2} \cdot \mathrm{d} \\
& \frac{\mathrm{V}_{1}}{\mathrm{~V}_{2}}=\frac{4 \mathrm{D}_{2}}{\mathrm{D}_{1}{ }^{2}} \cdot \mathrm{d}
\end{aligned}
$$

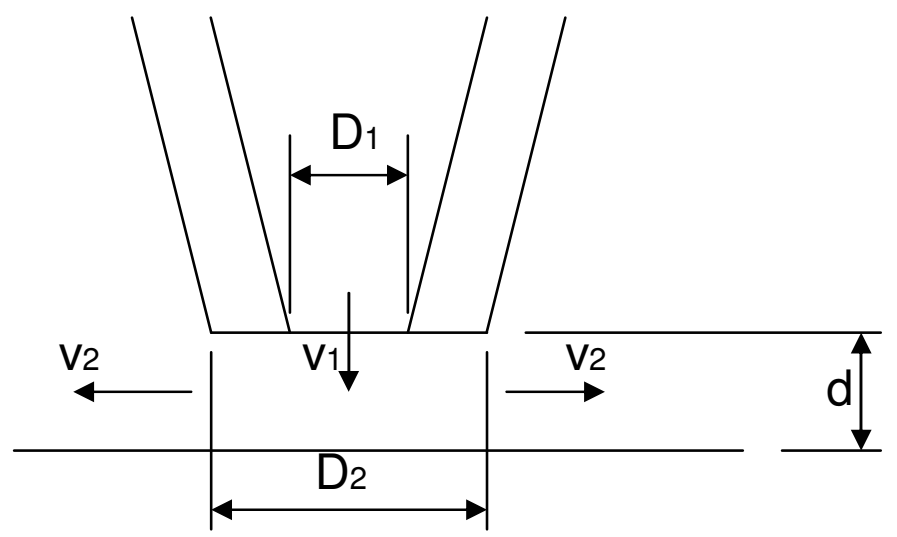

Figura 5-12 - Variáveis do projeto do bocal.

Onde $D_{1}$ e $D_{2}$ são respectivamente os diâmetros externo e interno do bico de solda, $v_{1}$ e $v_{2}$ são as velocidades de saída do bico e do bocal e d é a distância bico-peça.

A idéia é dimensionar o bico de solda de tal maneira que v1/v2 >1, ou seja, de tal maneira que a velocidade diminua. Assim, diminui-se a queda de pressão e aumenta-se o tempo de permanência do gás sobre o material. Seguindo isto, temos:

$$
\text { 4. } D_{2} \cdot d \geq D_{1}^{2}
$$

Com o valor de $D_{1}=8 \mathrm{~mm}$, e utilizando o valor de $\mathrm{d}=2 \mathrm{~mm}$, que é um valor freqüentemente adotado, tem-se que $D_{2} \geq 8$.

Assim $D_{2}$ foi adotado como $11 \mathrm{~mm}$. A figura abaixo mostra o projeto final do bocal de proteção utilizado na soldagem com laser pulsado. 

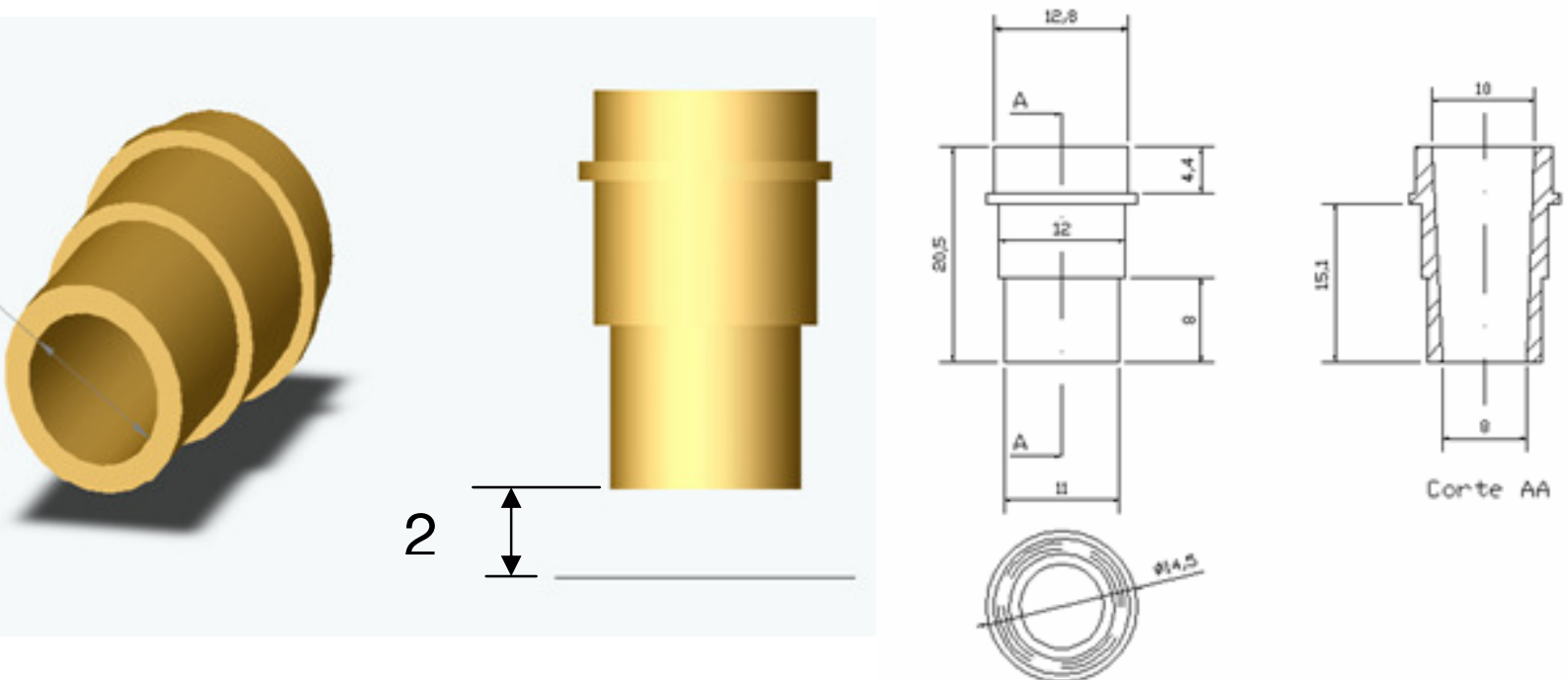

Figura 5-13 - Projeto do bocal utilizado nas soldas. 


\section{RESULTADOS E discusSÃo}

\subsection{Laser pulsado}

6.1.1 Análise dos parâmetros iniciais na soldagem com o laser pulsado

Os primeiros cordões de solda realizados tiveram como objetivo uma análise geral dos principais parâmetros de soldagem, observando sua influência quanto ao formato do cordão de solda e à contaminação por oxigênio. Estes cordões foram realizados no próprio material (alma cheia), para evitar a influência da junta.

As condições utilizadas são mostradas a seguir, onde tp é largura temporal do pulso e fé a freqüência:

Tabela 6-1 - Primeiras condições de soldagem utilizadas no laser de Nd:YAG

\begin{tabular}{|c|c|c|c|c|c|}
\hline Condição & Fluxo (l/min) & Atmosfera & Velocidade (mm/min) & $\mathrm{tp}(\mathrm{ms})$ & $\mathrm{f}(\mathrm{Hz})$ \\
\hline 1 & 3 & Argônio & 100 & 7 & 11 \\
\hline 2 & 3 & Argônio & 100 & 4 & 11 \\
\hline 3 & 0 & ar & 100 & 7 & 11 \\
\hline 4 & 0 & ar & 100 & 4 & 11 \\
\hline 5 & 3 & Argônio & 50 & 4 & 11 \\
\hline 6 & 3 & Argônio & 50 & 7 & 11 \\
\hline
\end{tabular}

\section{Energia por pulso: $5 \mathrm{~J}$}


As condições 3 e 4, que não tinham atmosfera de proteção, serviram de referência para estabelecer um parâmetro de melhora no nível de contaminação das soldas e de suas propriedades mecânicas.

A seguir observam-se duas fotos das superfícies da chapa onde foram obtidos os cordões de solda a laser:

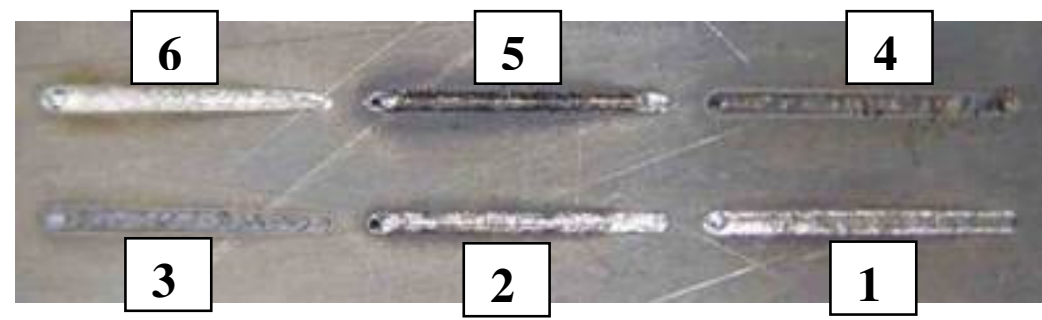

$1 \mathrm{~cm}$

Figura 6-1 - Aspecto da parte superior da chapa de Ti6Al4V após os testes.
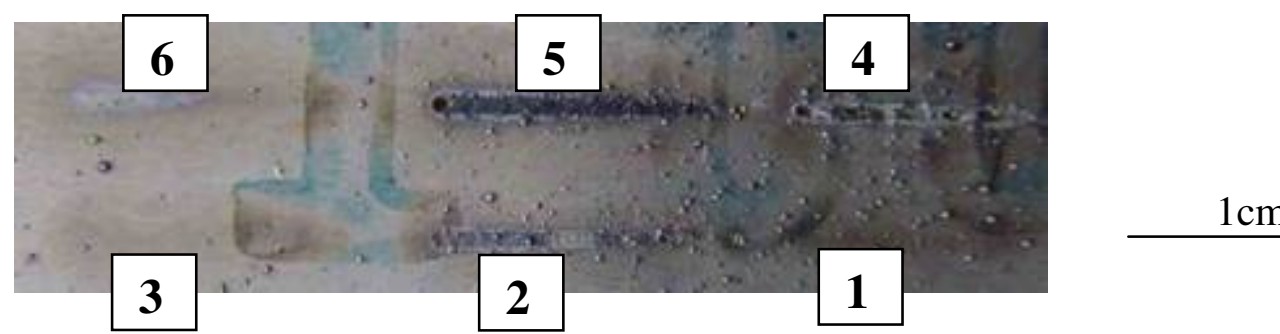

Figura 6-2 - Aspecto do verso da chapa de Ti6Al4V após os testes.

As fotos mostram que as soldas com melhor aspecto foram a 1, 2 e 6, enquanto que as demais apresentaram contaminações em excesso, devido à falta de atmosfera de proteção, excesso de material expelido devido à alta taxa de sobreposição ou ainda a maior intensidade causada pela menor largura temporal. Na parte da raiz da solda, verifica-se também a contaminação por oxigênio em todas as soldas que apresentaram penetração total, mostrando a necessidade de proteção da raiz. Percebe-se também que o uso de um fluxo de $3 \mathrm{l} / \mathrm{min}$ apesar de baixo é suficiente para proteger o material.

A seguir têm-se os valores das extensões da zona fundida (ZF), da zona afetada pelo calor (ZAC) e da cavidade formada pela solda (daquelas que tiveram 
penetração total) ou a profundidade da poça fundida (PPF) (daquelas que tiveram apenas penetração parcial). Os valores estão em micrometros e foram medidos com o auxílio de um programa de edição de imagens a partir da Figura 6-3.

Tabela 6-2- Valores da extensão da zona afetada pelo calor, cavidade formada pela solda e profundidade da poça fundida em micrometros.

\begin{tabular}{|c|c|c|c|c|c|c|}
\hline & \multicolumn{6}{|c|}{ Condição } \\
\hline & 1 & 2 & 3 & 4 & 5 & 6 \\
\hline ZF & 770 & 880 & 720 & 790 & 880 & 850 \\
\hline ZAC & 78 & 74 & 130 & 138 & 93 & 102 \\
\hline PPF & 781 & - & 681 & - & - & 798 \\
\hline Cavidade & - & 96 & - & 88 & 155 & - \\
\hline
\end{tabular}

Verifica-se que as amostras com velocidades de soldagem de $100 \mathrm{~mm} / \mathrm{min}$ e proteção de argônio apresentaram um valor de zona afetada pelo calor de $78 \mu \mathrm{m}$ e $74 \mu \mathrm{m}$ respectivamente (tabela 1 ). Com a diminuição da velocidade, teve-se um aumento da zona afetada pelo calor para $93 \mu \mathrm{m}$ e $102 \mu \mathrm{m}$.

Nas amostras 2 e 5, onde obteve-se soldas com penetração total, as cavidades formadas nas partes superior e inferior da solda tiveram valores médios de $96 \mu \mathrm{m}$ e $155 \mu \mathrm{m}$ respectivamente. Isto mostra que a diminuição de velocidade de soldagem acarreta em uma maior perda de material, e, portanto, uma solda menos resistente. Entretanto, esta perda não é significativa nas amostras que não apresentaram penetração total.

Isto pode ser explicado pelo seguinte raciocínio: as amostras que foram submetidas a uma maior intensidade (menor largura temporal) tiveram material 
fundido por toda a extensão da chapa, fazendo com que haja maior instabilidade e que o material possa ser ejetado pela parte inferior do cordão. Com uma menor taxa de sobreposição (e por conseqüência um menor aporte térmico), esta zona fundida era menos alterada e uma menor quantidade de material era ejetado. Com a diminuição da velocidade e aumento da sobreposição, uma maior área do material era perturbado e por conseqüência mais material era ejetado.

Com uma menor intensidade do laser, a profundidade da poça fundida era inferior à espessura da chapa, portanto as perturbações causadas por uma maior taxa de sobreposição não necessariamente causavam ejeção de material.

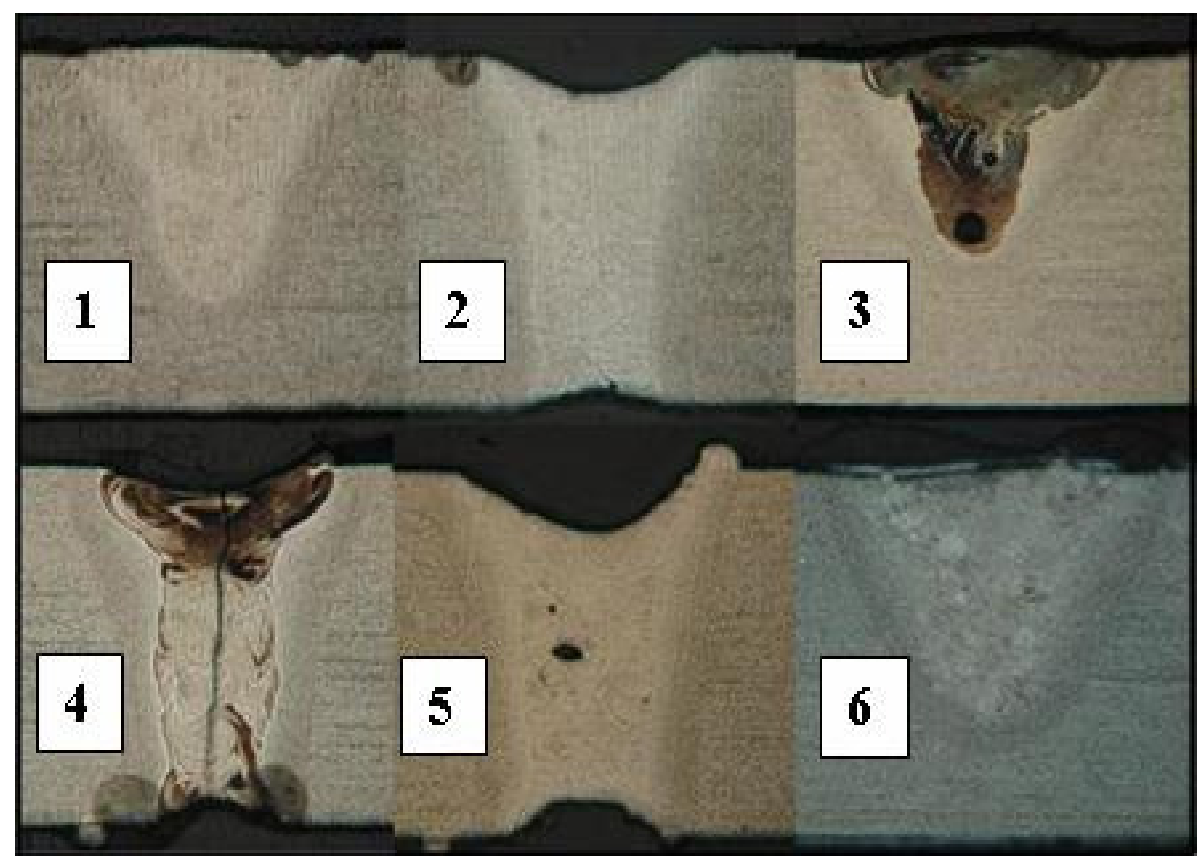

Espessura da chapa $=1 \mathrm{~mm}$

Figura 6-3 - Microscopia óptica da secção transversal das soldas realizadas.

Um ensaio de microdureza foi realizado nas amostras 2 e 4, pelo fato delas apresentarem penetração total e também porque os parâmetros se diferenciam apenas pela atmosfera de proteção (ver Tabela 6-1). Os resultados obtidos são mostrados nos gráficos a seguir, onde o ponto "0" localiza-se 600 micrometros à 
esquerda do centro da amostra e as medidas foram feitas para 3 profundidades (medidas a partir da superfície): $200 \mu \mathrm{m}, 500 \mu \mathrm{m}$ e $900 \mu \mathrm{m}$.
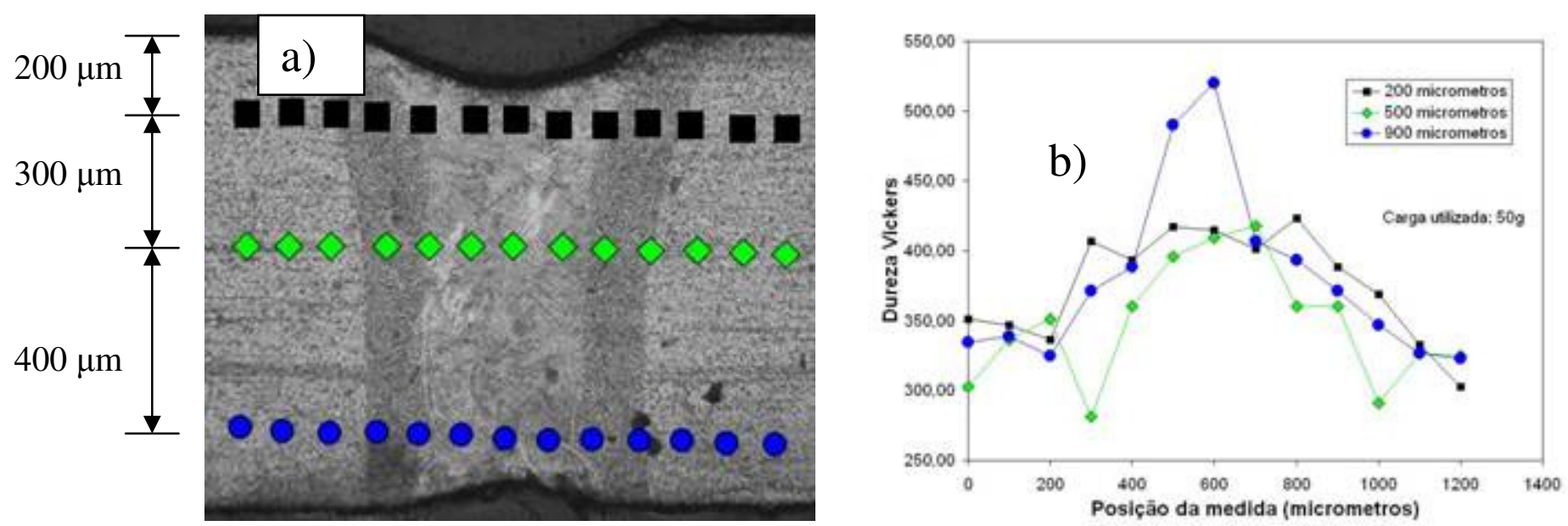

Figura 6-4 - Resultados do ensaio de microdureza da amostra 2: a) pontos analisados; b) Gráfico com os valores medidos.
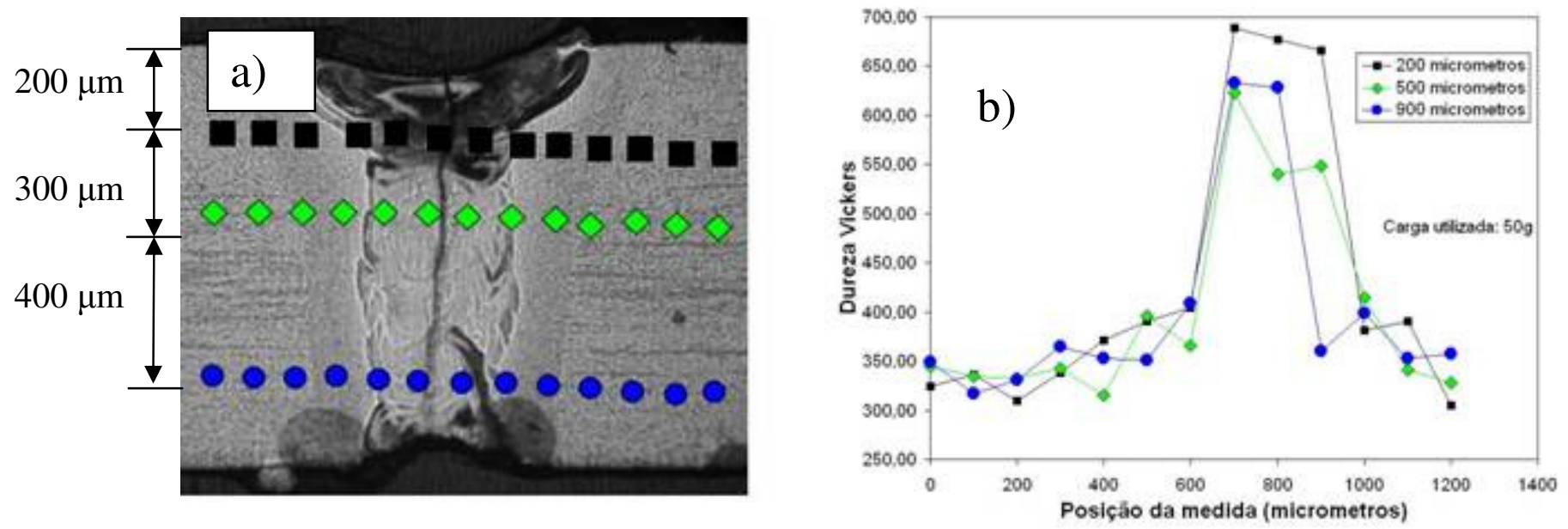

Figura 6-5- Resultados do ensaio de microdureza da amostra 4: a) pontos analisados; b) Gráfico com os valores medidos.

O aumento na dureza da solda pode ser dado por dois fatores: o primeiro é o rápido resfriamento do material, que faz com que a estrutura não tenha tempo de se estabilizar, ficando desordenada. Esta estrutura desordenada possui uma 
alta dureza devido às tensões internas que ficam no material; o segundo pode ser devido à contaminação por oxigênio na solda, que aumenta a dureza do material.

Analisando a Figura 6-4, percebe-se que na região protegida há um máximo de dureza de aproximadamente 400 HV (Hardness Vickers). Este aumento de dureza pode ser explicado pela mudança de fase ocorrida na soldagem. Porém na parte inferior, que não foi protegida, há um pico de dureza de aproximadamente $520 \mathrm{HV}$, que é muito superior àquele alcançado pela mudança de fase. Este aumento foi provavelmente ocasionado pela contaminação por elementos do ar.

Quanto à microestrutura, as amostras 1,2, 5 e 6 apresentaram uma estrutura alfa equiaxial em uma matriz de beta retida contendo alfa acicular [60], conforme mostrado nas figuras a seguir.

Na figura da amostra 6 mostrada a seguir, é possível visualizar duas regiões distintas no cordão de solda, uma clara e uma escura, que representam respectivamente uma fase alfa equiaxial e uma fase beta retida do titânio [61].

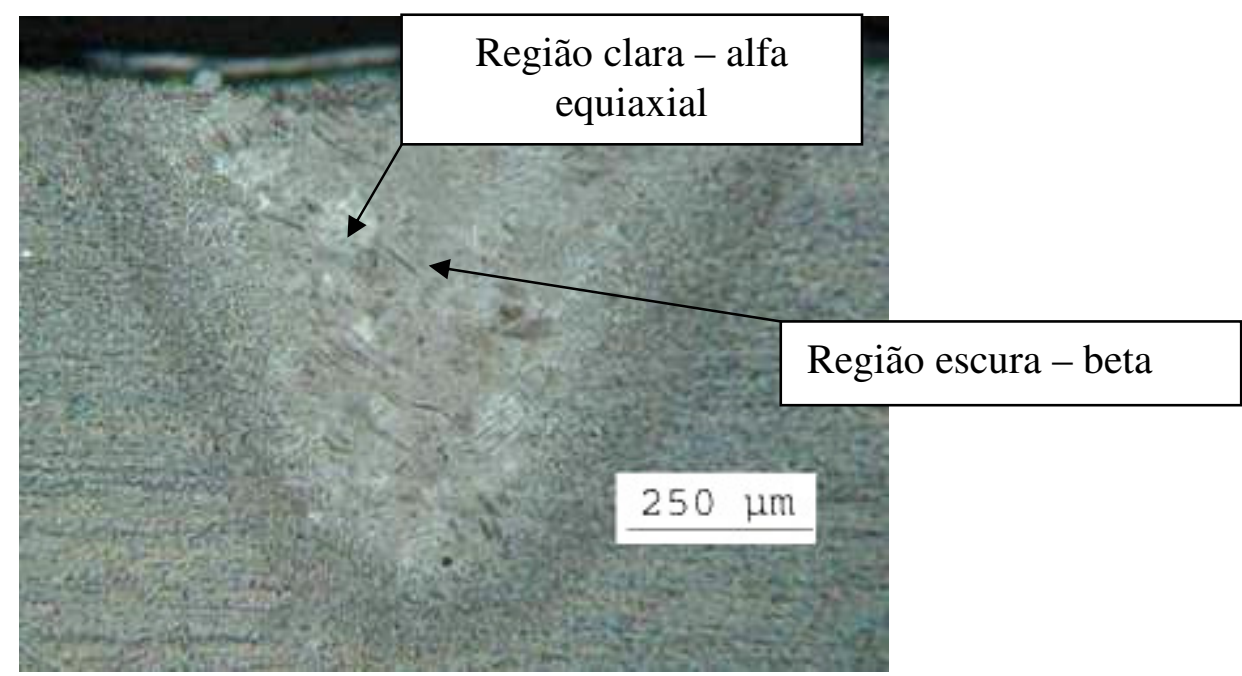

Figura 6-6 - Microscopia óptica da amostra 6 mostrando duas fases distintas na região soldada 
Nas amostras 3 e 4 foram notadas a formação de compostos com crescimento em forma de dendritas e pequenos grãos na zona fundida. A formação de uma estrutura dendrítica já foi associada por outros autores como característica de uma atmosfera de proteção deficiente [57].

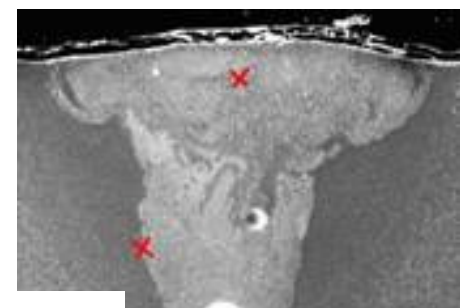

a)
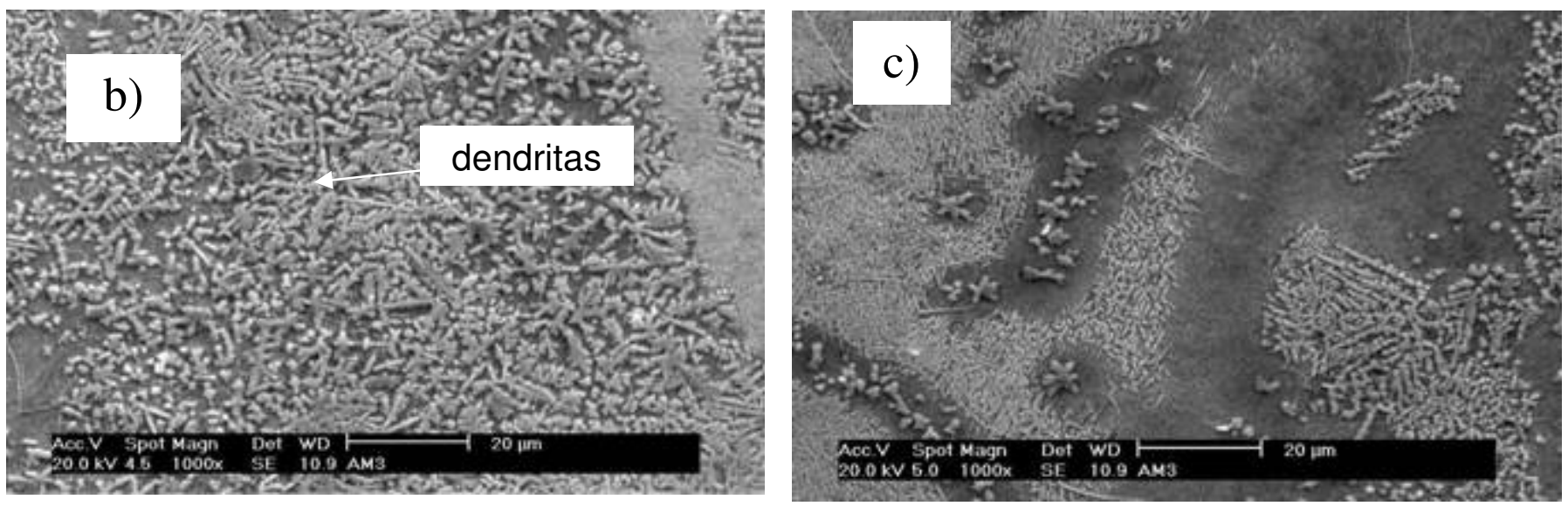

Figura 6-7 - Estruturas formadas nas soldas 3: a) pontos observados na amostra;

b) próximo à superfície; c) próximo à divisória entre a zona afetada pelo calor e zona fundida.

Análises por EDS foram realizadas nas superfícies dos cordões de solda e naqueles que apresentaram algum nível de contaminação, a análise também foi realizada para checar a profundidade desta contaminação. 


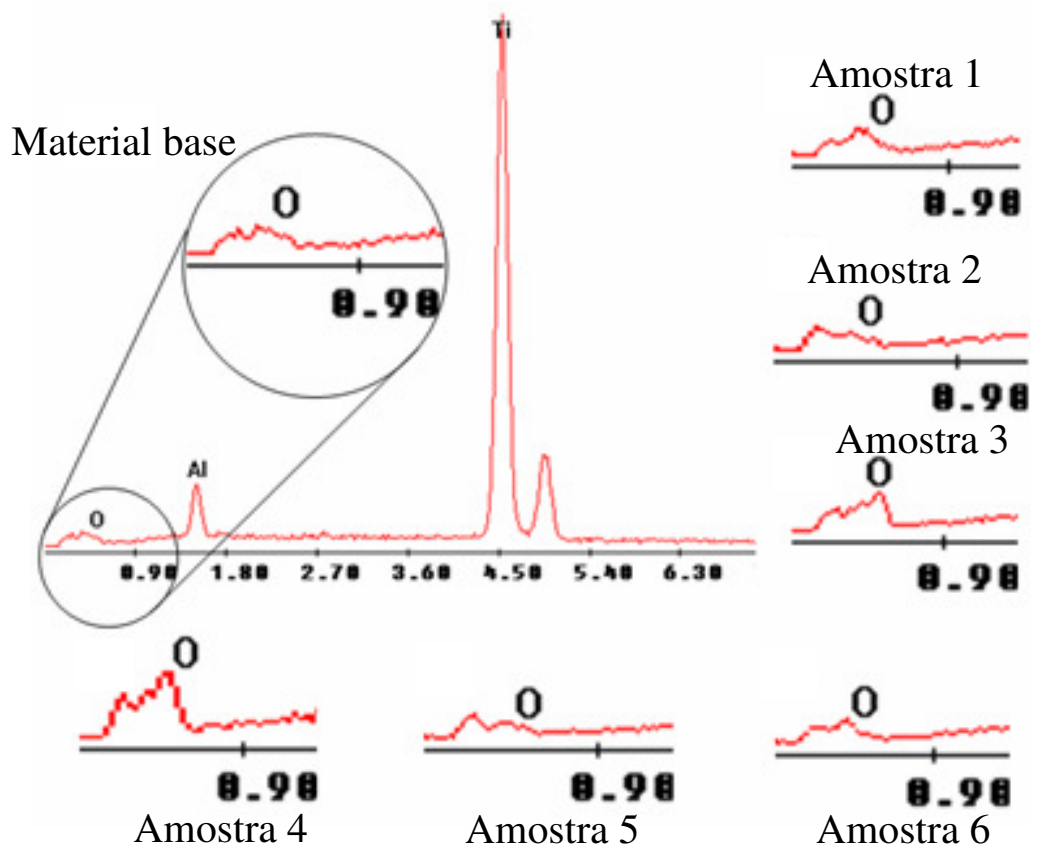

Figura 6-8 - Análises por EDS realizadas no centro dos cordões de solda.

Os resultados mostraram que segundo as análises, nenhuma das amostras que foram protegidas apresentou contaminação significativa, enquanto que as amostras 3 (d) e 4 (e) apresentaram picos nas energias correspondentes ao oxigênio.

Assim, para estas amostras, também foi realizada uma análise para ver a profundidade desta contaminação.

$\mathrm{Na}$ amostra 3, como pode ser visto, o oxigênio foi detectado a uma distância de até $5 \mu \mathrm{m}$, sem sinal de contaminação a $15 \mu \mathrm{m}$. 
a)

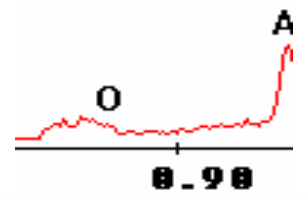

b)

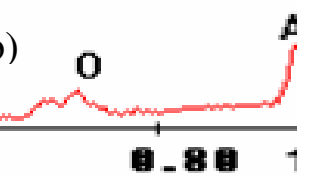

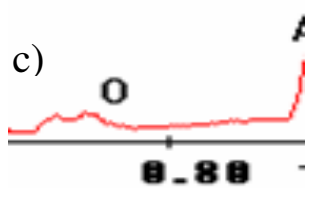

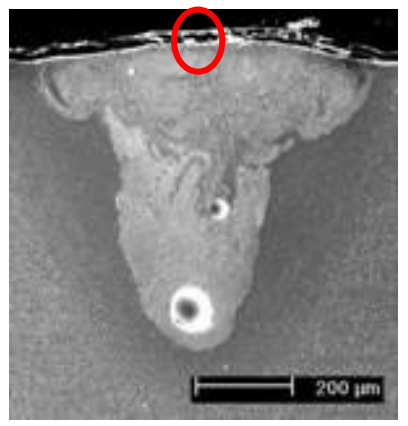

b) $5 \mu \mathrm{m}$ de profundidade; c) $15 \mu \mathrm{m}$ de profundidade.

Esperava-se, devido à microestrutura encontrada, uma maior quantidade do elemento em toda a extensão da poça fundida, o que não ocorreu. Isto sugere que o mecanismo de formação da estrutura dendrítica precisa de uma quantidade muito pequena de oxigênio, que não pôde ser identificada pelo equipamento.

Na raiz de solda da amostra 4 foram obtidos os seguintes resultados:

a)
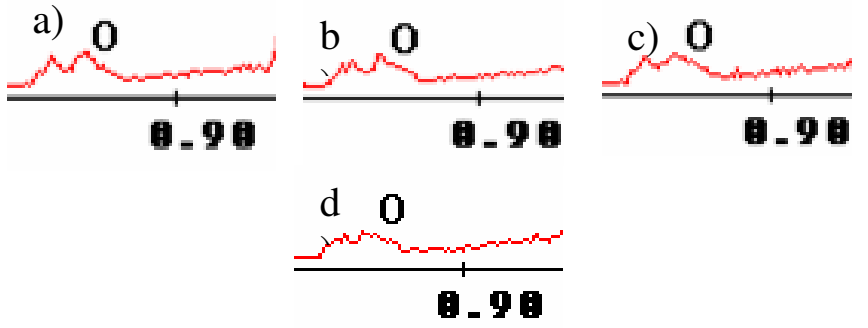
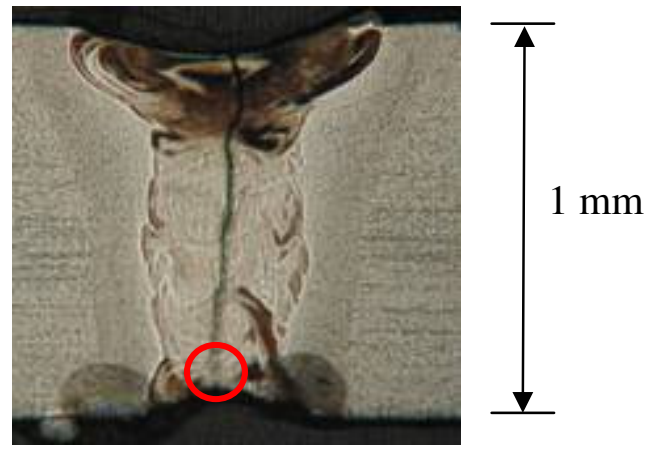

Figura 6-10 - Análises de EDS da raiz de solda da amostra 4; a) $5 \mu \mathrm{m}$ de profundidade; b) $10 \mu \mathrm{m}$ de profundidade; c) $20 \mu \mathrm{m}$ de profundidade; d) material base. 
Outras análises detectaram contaminação até aproximadamente $1 \mathrm{~mm}$ da borda na superfície do cordão de soldagem, porém uma análise visual da coloração da superfície mostra que não foi formada uma camada significativa de óxido que possa prejudicar o material naquela região.

\subsubsection{Influência dos gases de proteção na soldagem com laser pulsado}

Antes de se analisar a influência do gás de proteção, procurou-se uma nova condição de soldagem que minimizasse as perdas de material, mantendo a característica de penetração total. Isto foi feito com a intenção de variar a intensidade do feixe na superfície da peça a ser soldada. Este parâmetro, que representa a densidade de potência é o mais importante num processo de soldagem, pois através dele é possível o controle do balanço energético e conseqüentemente da temperatura na superfície irradiada.

Uma intensidade muito alta leva a um superaquecimento da superfície com grande formação de vapor no centro da poça, o qual (devido à sua expansão) expulsa uma certa quantidade de material. Uma intensidade muito baixa leva a uma perda muito grande de energia devido à condução e diminui muito a profundidade da poça, podendo até não haver a formação do "keyhole".

Baseando-se na energia e largura temporal utilizadas na seção anterior, foi realizada a avaliação do diâmetro do feixe sobre a superfície da peça, pois I = $E /\left(t_{p} \cdot A\right)$. Assim, uma variação da posição focal com relação à superfície foi feita com o intuito de variar esta área.

Supondo que a energia por pulso ficasse próxima do que foi obtido com os outros cordões (na faixa de $5 \mathrm{~J}$ ), esta condição deveria ter uma largura de pulso entre 4 e $7 \mathrm{~ms}$ e velocidade de $100 \mathrm{~mm} / \mathrm{min}$, que se mostrou ser mais apropriada. 
Assim, foram utilizadas 3 condições, mostradas na Tabela 6-3.

Delas, a condição 3 não obteve penetração total, sendo então descartada. A condição 1 apresentou excesso de material perdido e de oxidação de raiz em comparação com as outras condições. Porém a condição 2 se apresentou ideal para a soldagem da liga com $1 \mathrm{~mm}$ de espessura, apresentando penetração total sem perda de material.

Tabela 6-3 - Condições utilizadas para verificação da influência dos gases de proteção

\begin{tabular}{|c|c|c|c|}
\hline Condição & $\begin{array}{c}\text { Largura temporal } \\
\text { do pulso }(\mathrm{ms})\end{array}$ & $\begin{array}{c}\text { Velocidade de } \\
\text { soldagem } \\
(\mathrm{mm} / \mathrm{min})\end{array}$ & $\begin{array}{c}\text { Posição focal em relação } \\
\text { à superfície }(\mathrm{mm})^{*}\end{array}$ \\
\hline 1 & 6 & 100 & +3 \\
\hline 2 & 6 & 100 & +4 \\
\hline 3 & 6 & 100 & +5 \\
\hline
\end{tabular}

${ }^{*} \mathrm{O}$ sinal de positivo significa que o foco encontrava-se acima da superfície. Energia por pulso: 5,2J

Para verificar a influência dos gases de proteção na soldagem com o laser pulsado, foram realizados 2 cordões de solda para cada uma das 5 condições estabelecidas com base nos resultados obtidos com os cordões anteriores. 
Tabela 6-4 - Condições utilizadas para verificar a influência do tipo de gás na soldagem com laser pulsado

\begin{tabular}{|c|c|c|c|c|}
\hline Amostra & $\begin{array}{c}\text { Velocidade } \\
(\mathrm{mm} / \mathrm{min})\end{array}$ & $\begin{array}{c}\text { Largura do } \\
\text { pulso }(\mathrm{ms})\end{array}$ & $\begin{array}{c}\text { Atmosfera } \\
\text { axial }\end{array}$ & $\begin{array}{c}\text { Atmosfera } \\
\text { raiz }\end{array}$ \\
\hline 1 & 100 & 6 & Argônio & Argônio \\
\hline 2 & 100 & 6 & $50 \mathrm{Ar} / 50 \mathrm{He}$ & Argônio \\
\hline 3 & 100 & 6 & $25 \mathrm{Ar} / 75 \mathrm{He}$ & Argônio \\
\hline 4 & 100 & 6 & Hélio & Argônio \\
\hline 5 & 100 & 6 & Argônio & Hélio \\
\hline
\end{tabular}

Energia por pulso: 5,2 J Largura temporal do pulso: $6 \mathrm{~ms}$

Freqüência: $11 \mathrm{~Hz}$

Foco $4 \mathrm{~mm}$ acima da superfície Fluxo de gás: $5 \mathrm{l} / \mathrm{min}$ *

*Os fluxos de gás com hélio e misturas foram medidos a partir de um medidor de fluxo calibrado para o argônio, portanto os valores de fluxo são maiores que 5 I/min.

Após a soldagem, as larguras dos cordões foram medidas na expectativa de verificar uma mudança no valor da absorção do plasma durante o processo; note que a intensidade do processo foi a mesma para todos os casos. Os seguintes resultados foram obtidos: 
Tabela 6-5 - Média dos valores obtidos

\begin{tabular}{|c|c|c|c|c|}
\hline Condição & Atmosfera axial & Atmosfera de raiz & Largura do cordão $(\mathrm{mm})$ & Desvio $(\mathrm{mm})$ \\
\hline 1 & Argônio & Argônio & 1,37 & 0,05 \\
\hline 2 & $50 \mathrm{Ar} / 50 \mathrm{He}$ & Argônio & 1,38 & 0,06 \\
\hline 3 & $25 \mathrm{Ar} / 75 \mathrm{He}$ & Argônio & 1,29 & 0,03 \\
\hline 4 & Hélio & Argônio & 1,29 & 0,03 \\
\hline 5 & Argônio & Hélio & 1,35 & 0,04 \\
\hline
\end{tabular}

Destes resultados, percebe-se que não houve influência significativa do tipo de gás na energia adquirida pelo material. Observa-se uma tendência dos cordões soldados com argônio de serem maiores que os que foram soldados com hélio, como é mostrado na literatura, mas mesmo assim com diferenças mínimas entre eles.

A análise visual dos cordões revela que não houve oxidação com nenhum dos gases utilizados, mostrando que o fluxo utilizado é adequado para qualquer gás.

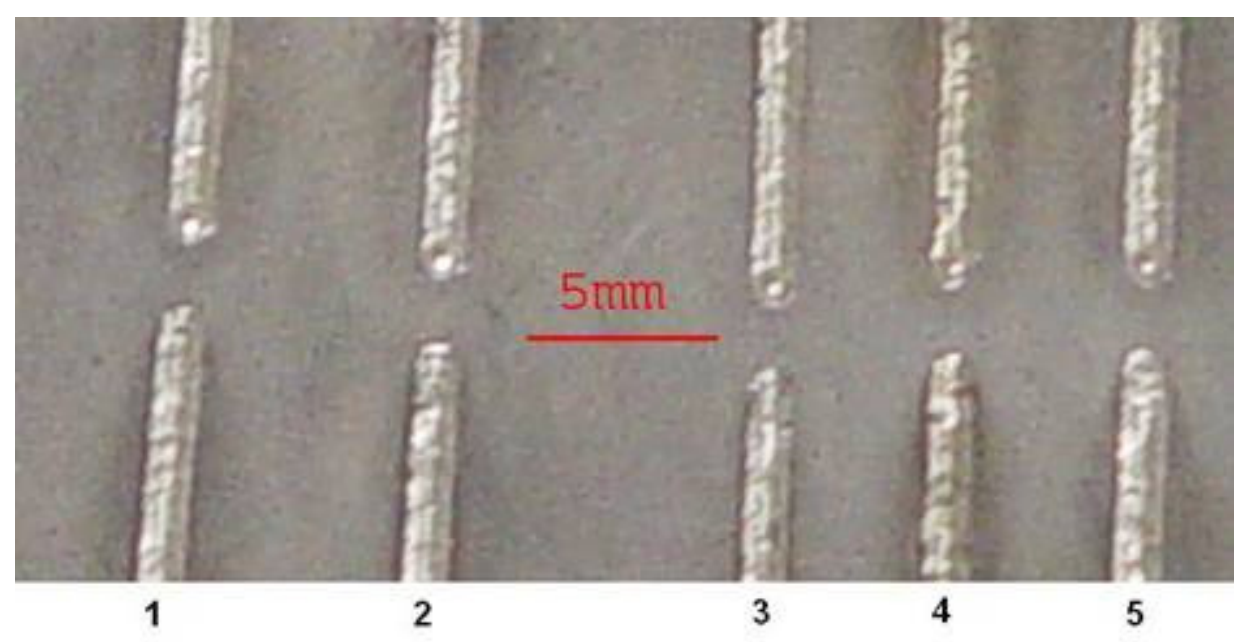

Figura 6-11 - Aspecto da chapa irradiada, mostrando as amostras de 1 a 5, conforme Tabela 6-4. 
Também é possível verificar que não houve influência da natureza do gás de proteção de raiz no resultado final.

Um ensaio de dureza foi realizado para verificar se o nível de contaminação de impurezas das soldas mudava com o gás de proteção utilizado. Para isto, foram feitos um cordão protegido com argônio e outro protegido com hélio. Os resultados são mostrados nas figuras a seguir.

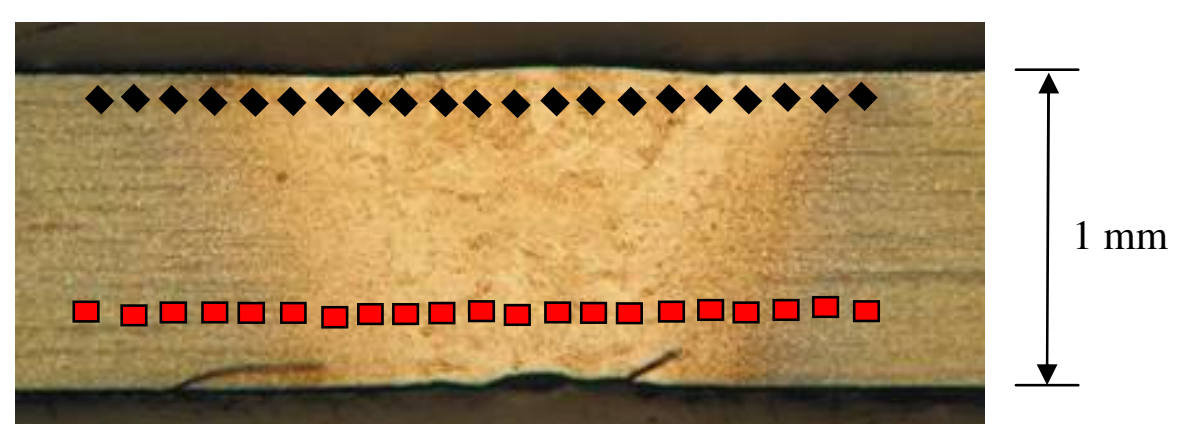

Figura 6-12 - Cordão de solda protegido com hélio axialmente e argônio na raiz.

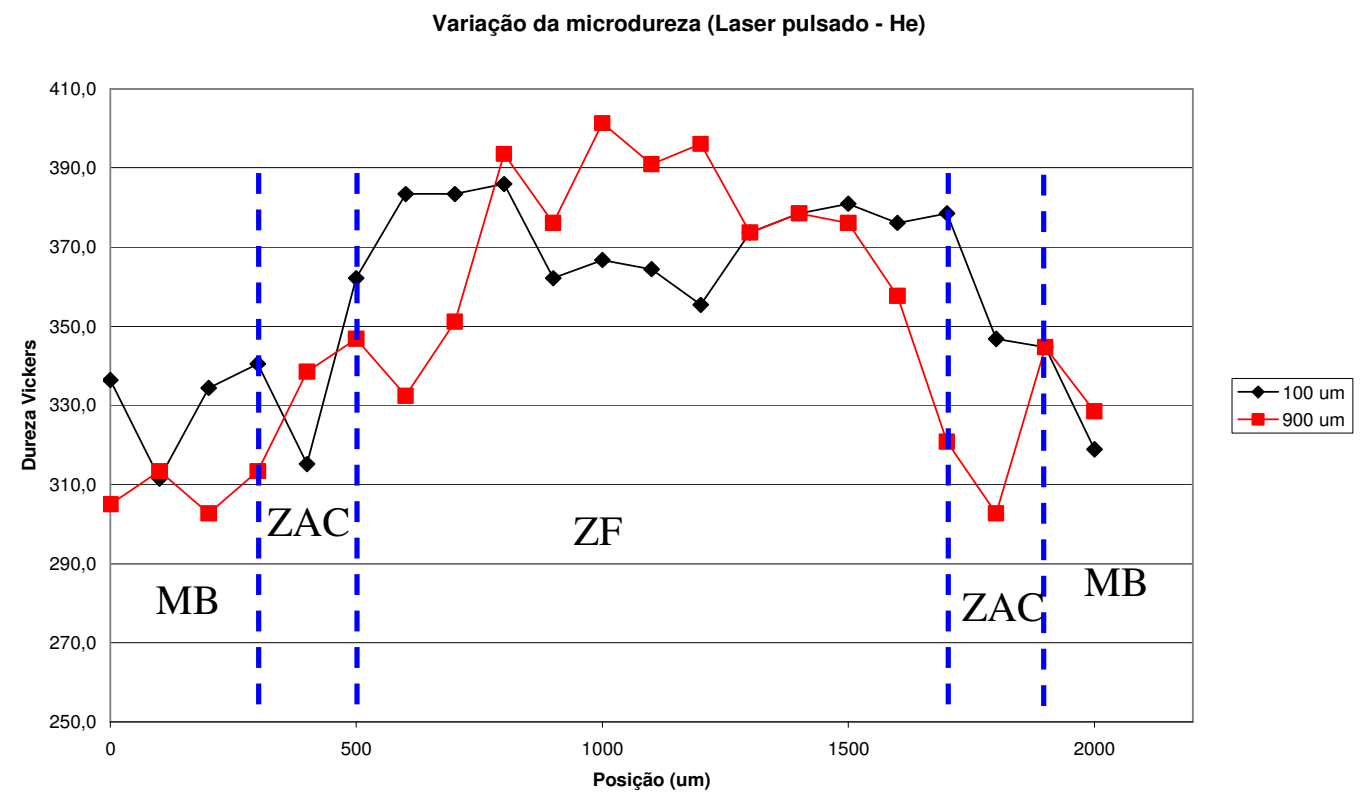

Figura 6-13 - Padrão de microdureza da solda da Figura 6-12. 


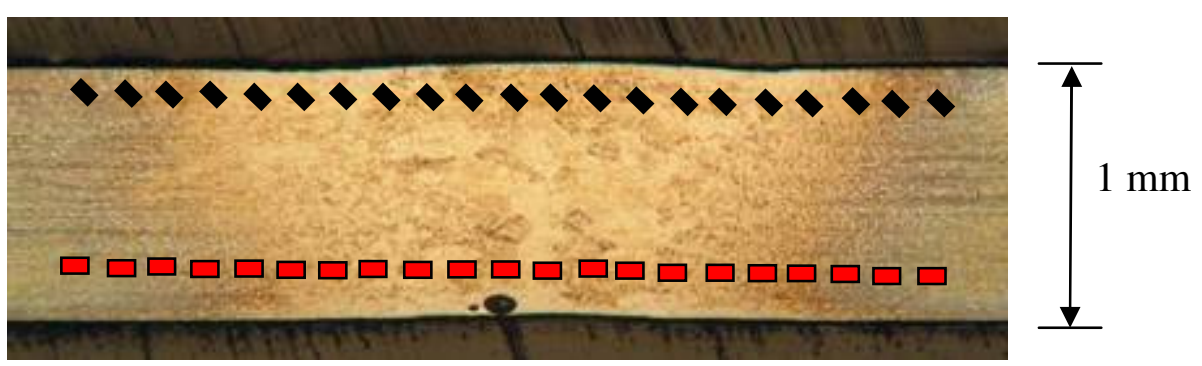

Figura 6-14 - Cordão de solda protegido com argônio axialmente e na raiz.

Valores de microdureza (Laser pulsado - Ar)

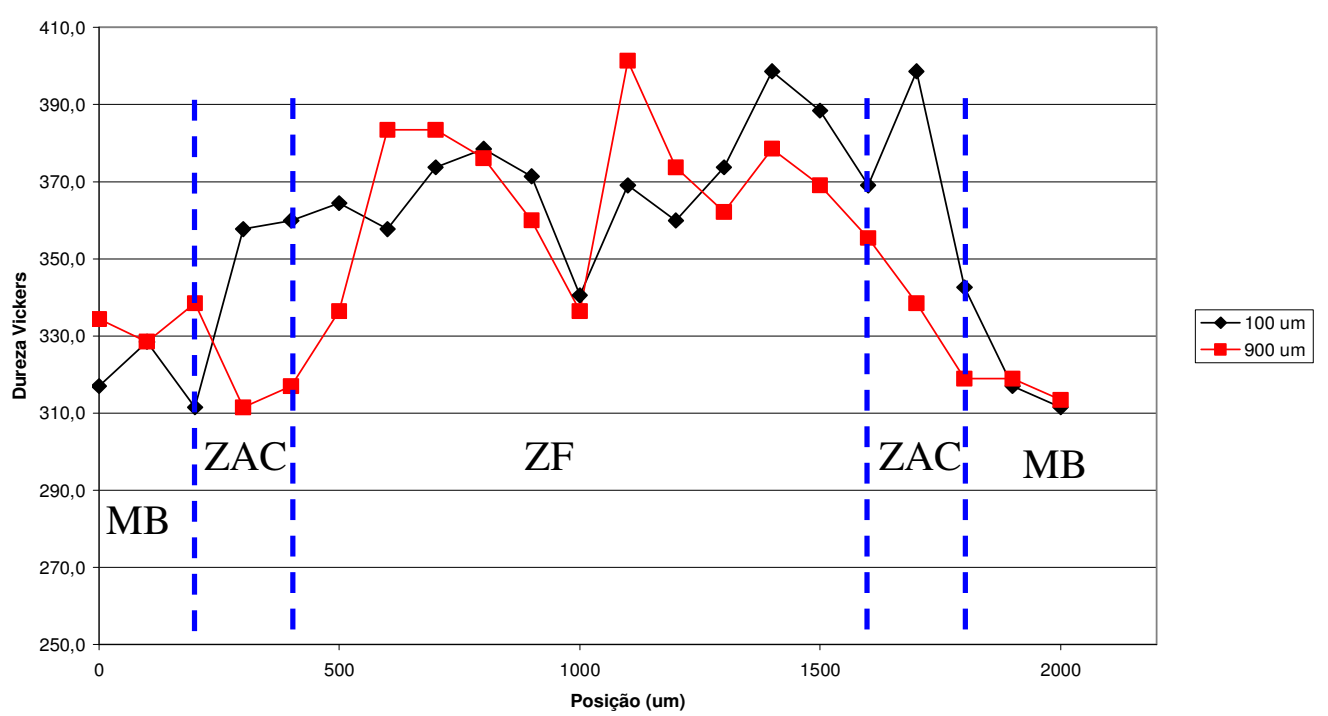

Figura 6-15 - Padrão de microdureza obtido para a solda da Figura 6-14.

Com estes resultados, é possível comparar as diferentes condições de gases de proteção utilizados até agora para o laser pulsado: 
Tabela 6-6 - Valores médios de dureza para diferentes condições de proteção da solda

\begin{tabular}{|c|c|c|}
\hline Gás de soldagem & Região analisada & Dureza Vickers \\
\hline \multirow{3}{*}{ Argônio com proteção de raiz } & Material base & $321,2 \pm 7,7$ \\
\hline & Zona afetada pelo calor & $343,3 \pm 25,3$ \\
\hline & Zona fundida & $369,8 \pm 16,9$ \\
\hline \multirow{3}{*}{ Argônio sem proteção de raiz } & Material base & $339,49 \pm 22,6$ \\
\hline & Zona afetada pelo calor & $395,63 \pm 35,9$ \\
\hline & Zona fundida & $426,60 \pm 33,0$ \\
\hline \multirow{3}{*}{ Hélio com proteção de raiz } & Material base & $318,9 \pm 12,1$ \\
\hline & Zona afetada pelo calor & $337,9 \pm 20,7$ \\
\hline & Zona fundida & $374,4 \pm 15,8$ \\
\hline \multirow{3}{*}{ Sem proteção de gás neutro } & Material base & $343,10 \pm 22,6$ \\
\hline & Zona afetada pelo calor & $419,60 \pm 79,1$ \\
\hline & Zona fundida & $589,75 \pm 82,9$ \\
\hline
\end{tabular}

Os valores de dureza obtidos são similares àqueles obtidos em trabalhos anteriores com o mesmo material, onde os autores também não constataram contaminação do cordão de solda [62,63].

\subsubsection{Influência do fluxo de gás}

Apesar do uso de um baixo fluxo de gás ter se mostrado eficaz para a proteção era necessário verificar se com um fluxo maior de gás haveria modificação da largura do cordão e se era possível utilizar fluxos ainda menores. 
Assim, foram feitos cordões protegidos com argônio com os fluxos de 3, 5, 10, 20 e 30 litros/minuto. A tabela a seguir mostra os resultados obtidos.

Tabela 6-7 - Valores da largura do cordão de solda para diferentes fluxos

\begin{tabular}{|c|c|c|c|c|c|}
\cline { 2 - 6 } \multicolumn{1}{c|}{} & \multicolumn{5}{c|}{ Fluxo utilizado (litros/minuto) } \\
\cline { 2 - 6 } \multicolumn{1}{c|}{} & 3 & 5 & 10 & 20 & 30 \\
\hline Largura do cordão $(\mathrm{mm})$ & 1,33 & 1,32 & 1,35 & 1,35 & 1,37 \\
\hline Desvio (mm) & 0,04 & 0,06 & 0,07 & 0,06 & 0,05 \\
\hline
\end{tabular}

Gás: Argônio

Percebe-se que não houve variação significativa na largura do cordão de solda, independente do fluxo de gás utilizado. Isto ocorreu provavelmente devido ao baixo tempo de interação do pulso do laser com o material, formando uma menor quantidade de plasma e fazendo com que pouco gás seja ionizado, independente do fluxo. Porém, é possível ver que há uma tendência de aumento da largura dos cordões de solda com o aumento do fluxo.

Valores de fluxo abaixo de 3 litros/minuto apresentaram oxidação na zona fundida.

\subsubsection{Verificação da influência da proteção de raiz}

A oxidação ocorrida nas raízes dos cordões de solda quando elas não eram devidamente protegidas foi facilmente constatada por análise visual. Para se verificar o efeito que esta falta de proteção poderia causar, foram realizados ensaios mecânicos de flexão e de tração no Centro de Ciências e Tecnologia dos Materiais (CCTM) do IPEN. 
As condições utilizadas nas soldas para os ensaios são mostradas a seguir:

Tabela 6-8 - Condições utilizadas nas soldas dos ensaios mecânicos

\begin{tabular}{|c|c|c|}
\hline Amostra & Gás axial & Gás na raiz \\
\hline 1 & Argônio & Argônio \\
\hline 2 & Argônio & ar \\
\hline 3 & Hélio & Argônio \\
\hline
\end{tabular}

* Ou seja, não houve injeção de gás neutro.

\section{Ensaio de flexão}

O ensaio foi realizado de duas maneiras distintas. Na primeira colocou-se a face irradiada pelo laser na parte superior e na segunda na parte inferior. A idéia era verificar se a camada de óxido encontrada na raiz teria comportamento diferente quando submetida a uma tensão de tração ou compressão.

A seguir, temos os resultados obtidos:

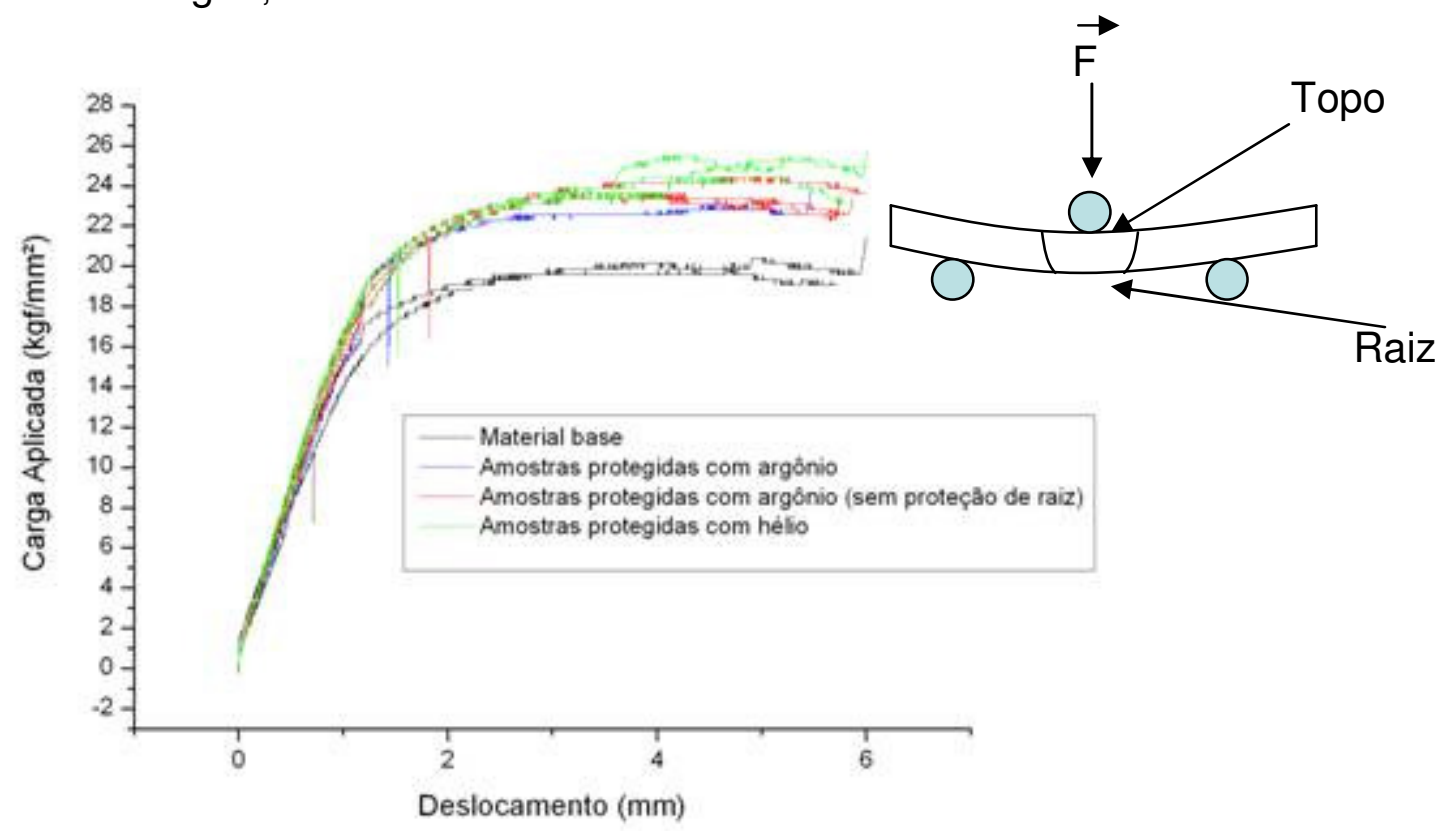

Figura 6-16 - Ensaio de flexão das soldas com laser pulsado com a carga aplicada no topo. 


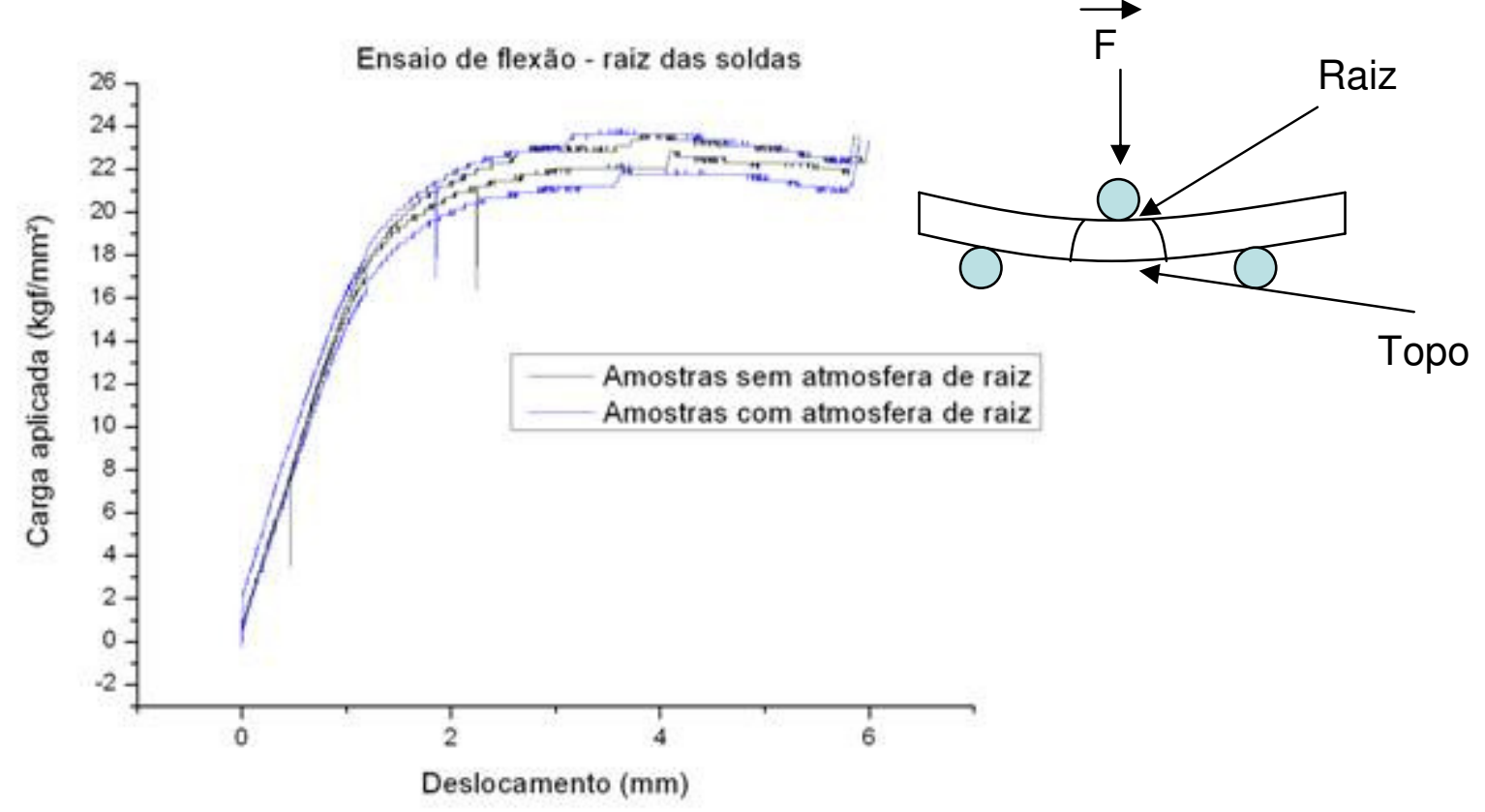

Figura 6-17 - Ensaio de flexão das soldas com laser pulsado com a carga aplicada na raiz.

A tabela a seguir resume os resultados obtidos:

Tabela 6-9 - Valores médios de carga máxima alcançados nos ensaios de flexão

\begin{tabular}{|l|c|}
\hline \multicolumn{2}{|l|}{ Condição 1 - Carga aplicada no topo da solda } \\
\hline & Valor máximo de carga alcançado $\left(\mathrm{kgf} / \mathrm{mm}^{2}\right)$ \\
\hline Material base & 20,00 \\
\hline $\begin{array}{l}\text { Amostras protegidas com } \\
\text { argônio }\end{array}$ & 23,00 \\
\hline $\begin{array}{l}\text { Amostras protegidas com } \\
\text { argônio e sem proteção de raiz }\end{array}$ & 23,90 \\
\hline Amostras protegidas com hélio & 25,50 \\
\hline
\end{tabular}

\begin{tabular}{|l|c|}
\hline Condição 2 - Carga aplicada na raiz da solda \\
\hline & Valor máximo de carga alcançado $\left(\mathrm{kgf} / \mathrm{mm}^{2}\right)$ \\
\hline Amostras com proteção de raiz & 23,00 \\
\hline Amostras sem proteção de raiz & 23,25 \\
\hline
\end{tabular}


Aqui é possível verificar que não houve diferenças significativas entre quaisquer condições utilizadas. Todas as soldas apresentaram um limite de resistência maior que o material base, porém a proteção ou não da raiz da solda não influenciou os resultados. Devido a limitações do dispositivo utilizado, as amostras não chegaram a romper.

Percebe-se aqui também que a proteção da atmosfera na raiz da solda não acarretou em nenhum benefício do ponto de vista de resistência.

\section{Ensaio de tração}

Para confirmar os resultados obtidos com o ensaio de flexão e principalmente para verificar o que acontece com as soldas até sua fratura também foi realizado um ensaio de tração para estas condições. A figura a seguir mostra um exemplo destes ensaios.

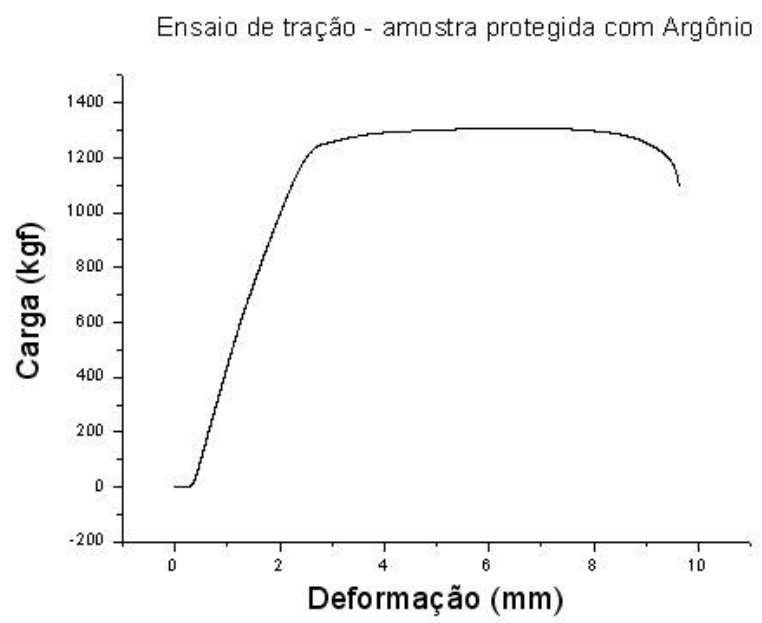

Figura 6-18 - Ensaio de tração de amostra protegida axialmente com argônio

A Tabela 6-10 resume os resultados obtidos nos ensaios de tração. 
Das 18 amostras apresentadas (5 para cada condição e 3 do material base), apenas 3 delas romperam nos cordões de solda: as duas soldas realizadas com hélio e uma das realizadas sem proteção de raiz (amostra 4). Assim, pode-se chegar a conclusão de que as soldas são idênticas do ponto de vista de resistência. A ruptura das duas soldas protegidas com hélio pode ser explicada por um pequeno desalinhamento das peças que foram soldadas, ocasionando assim diminuição da área de contato entre as amostras e ocasionando a ruptura precoce.

Tabela 6-10 - Resultados obtidos no ensaio de tração das soldas com laser pulsado

\begin{tabular}{|c|c|c|}
\hline Condições & Elongação (\%) & Carga máxima (kgf) \\
\hline Argônio & $5,21 \pm 0,28$ & $1312,81 \pm 18,48$ \\
\hline Hélio & $4,57 \pm 0,96$ & $1290,8 \pm 12,23$ \\
\hline Argônio sem proteção de raiz & $4,13 \pm 0,89$ & $1292,24 \pm 22,70$ \\
\hline Material base & $5,75 \pm 0,24$ & $1282,67 \pm 23,16$ \\
\hline
\end{tabular}

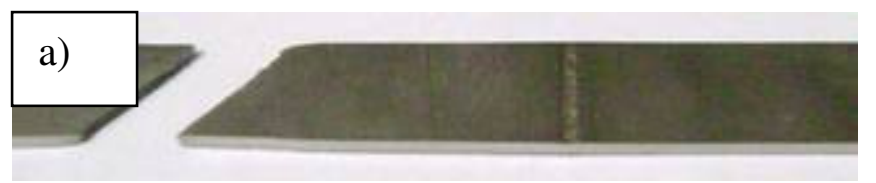

\section{b)}
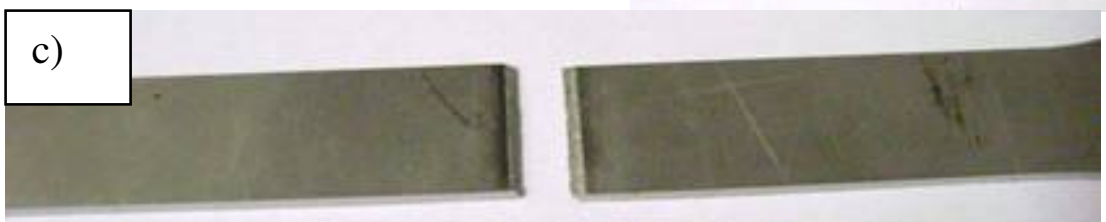

Figura 6-19 - Algumas amostras após o ensaio de tração; a) protegida axialmente com argônio; b) sem proteção de raiz; c) protegida axialmente com hélio 
Embora a elongação das amostras varie razoavelmente de uma condição para outra, percebe-se que o valor do desvio padrão destas medidas é alto, fazendo com que não seja possível chegar a uma conclusão sobre a influência dos gases de proteção sobre estes valores medidos.

A fratura das amostras que romperam na solda foi visualizada através do microscópio eletrônico de varredura, a fim de verificar o tipo de fratura ocorrida e possíveis problemas na solda.

Primeiramente, percebeu-se que não há regiões não fundidas, porém foi detectada uma grande quantidade de poros na região fundida. Apesar da presença de poros ser um fator normal na soldagem a laser, um aumento na quantidade destes pode ter ocorrido devido a um mau posicionamento da peça no dispositivo de soldagem. Realizando alguns cálculos, tem-se que a concentração de área porosa é de aproximadamente $0,011 \mathrm{~mm}^{2} / \mathrm{mm}$ com diâmetro médio de $0,02 \pm 0,01 \mathrm{~mm}$.

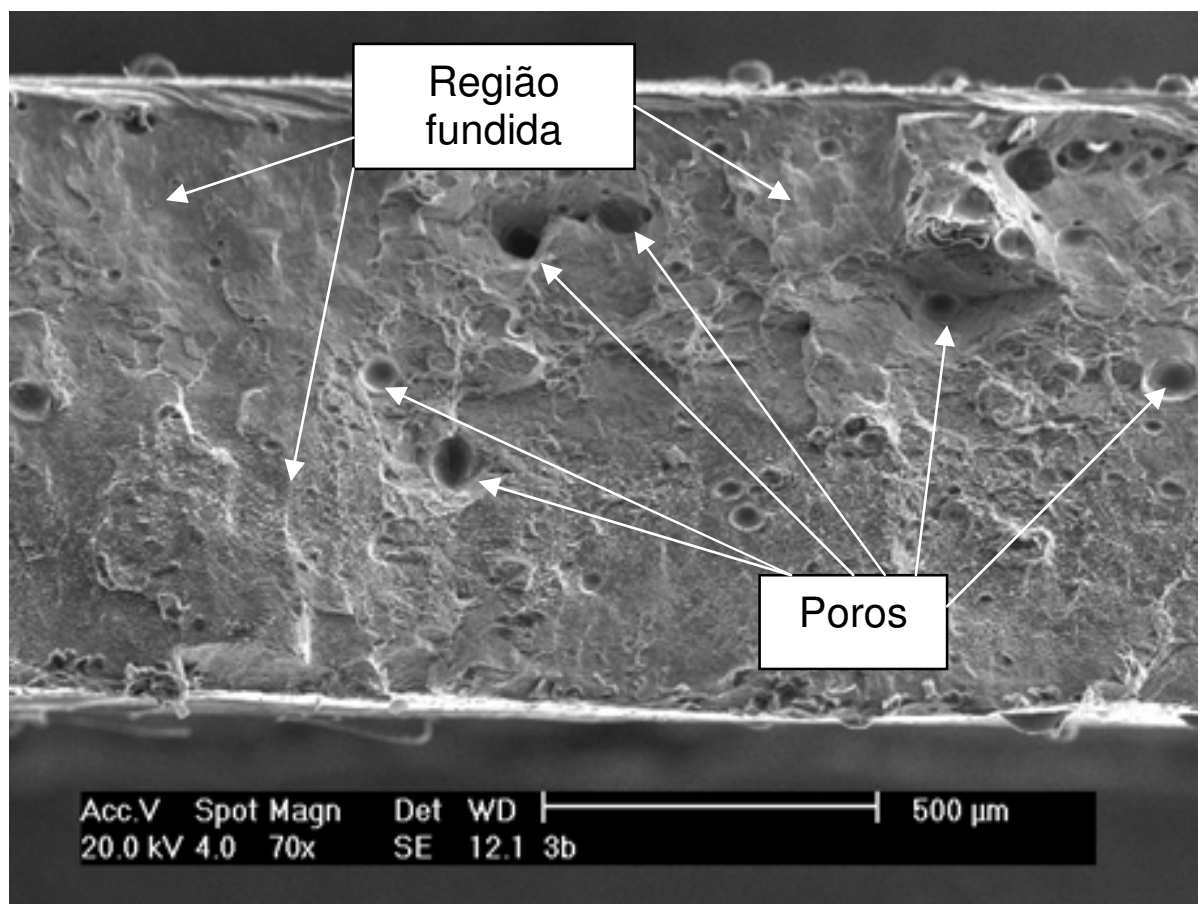

Figura 6-20 - Fratografia de uma das amostras rompidas na zona fundida. 
Também foi possível verificar o tipo de fratura ocorrido. Existem dois tipos de fratura: a dúctil e a frágil. A fratura dúctil ocorre quando há a deformação plástica antes do rompimento do material. Ela é caracterizada pela formação de dimples que são regiões formadas por causa desta deformação. Na fratura frágil não ocorre deformação plástica e tudo que se vê é uma superfície lisa.

$\mathrm{Na}$ visualização foi constatado que ocorreu uma fratura dúctil como mostrado na Figura 6-21.

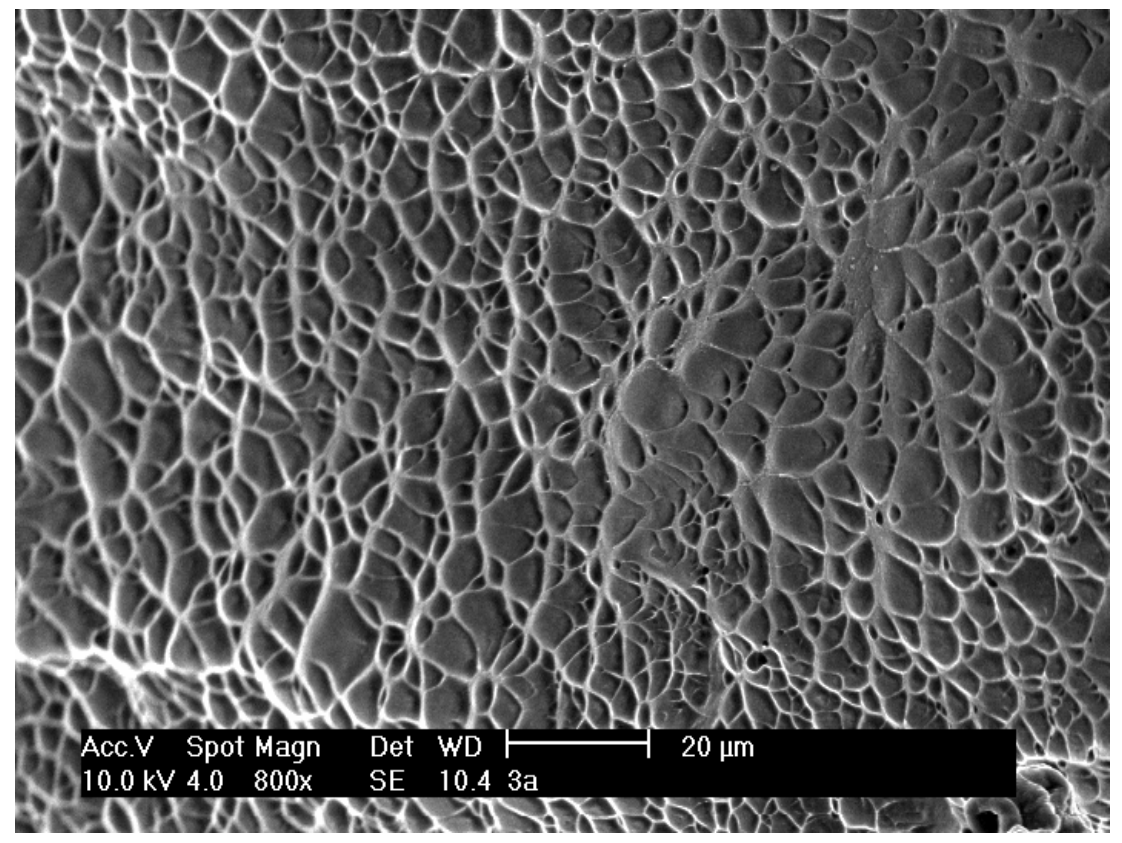

Figura 6-21 - Fratografia revelando a presença de dimples.

\subsubsection{Microestrutura formada}

Quanto à microestrutura, foi formada uma estrutura alfa equixial com uma matriz de beta retida contendo alfa acicular, como mostrado na Figura 6-22. 


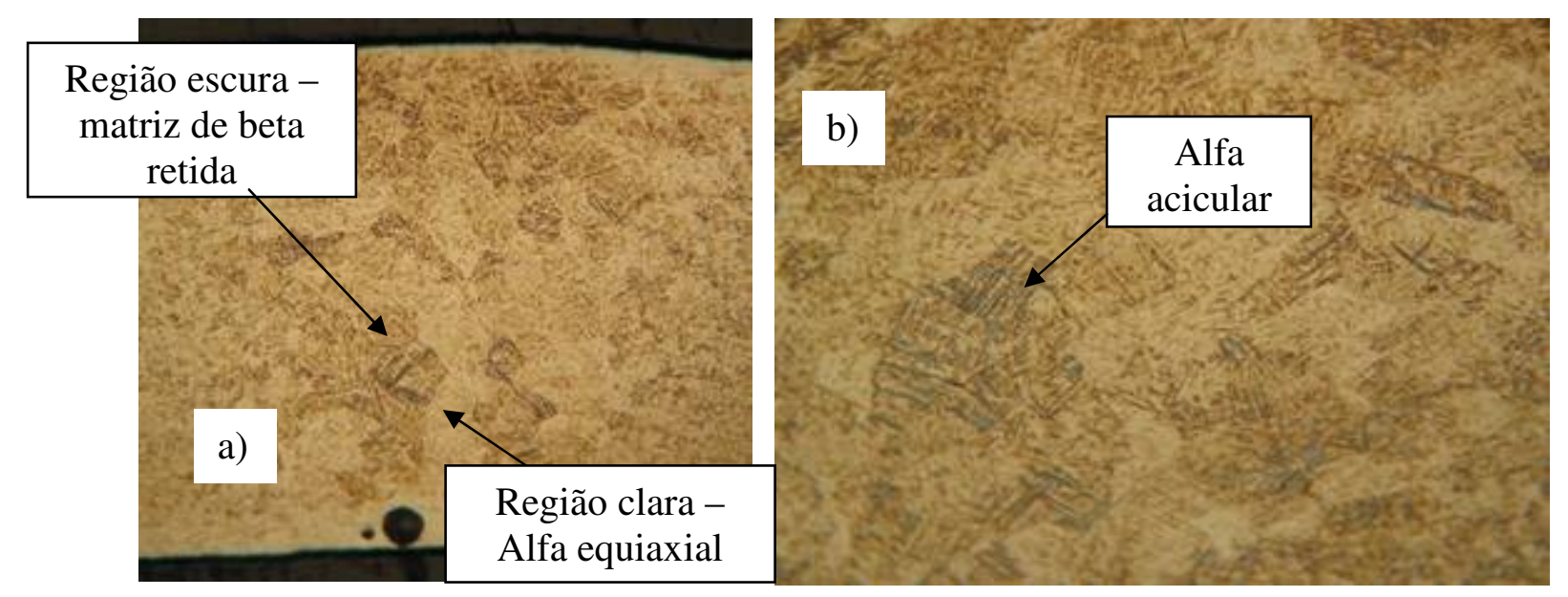

Figura 6-22 - Estruturas formadas na soldagem com laser pulsado; a) amostra $1 \mathrm{e}$ b) amostra 2, conforme Tabela 6-4.

Na mesma figura é possível perceber uma grande quantidade de regiões claras espalhadas na zona fundida, que é a formação de grãos alfa equiaxiais. $O$ pequeno tamanho dos grãos se deve ao rápido resfriamento da região de soldagem: a partir do material fundido, a primeira fase a ficar estável é a fase beta, de forma que todos os primeiros grãos crescidos serão desta fase. Com o material solidificado e com o decréscimo da temperatura, começam a surgir grãos da fase alfa na matriz escura. O tamanho dos grãos da fase alfa dependerão do tempo que a matriz teve até o resfriamento à temperatura ambiente. Se houve um resfriamento rápido, os grãos serão pequenos enquanto que se o resfriamento foi mais lento, os grãos serão maiores. 


\subsection{Laser contínuo}

6.2.1 Análise dos parâmetros iniciais na soldagem com o laser contínuo

A mesma análise de parâmetros iniciais que foi realizada com o laser pulsado foi repetida para o laser contínuo, analisando a velocidade de soldagem, posição focal e a potência de entrada. O gás utilizado foi argônio.

Os parâmetros utilizados são mostrados a seguir:

Tabela 6-11 - Parâmetros utilizados para o laser desfocalizado $(\mathrm{d}=1,9 \mathrm{~mm}$ acima da superfície)

\begin{tabular}{|c|c|c|}
\hline Amostra & Velocidade $(\mathrm{mm} / \mathrm{min})$ & Potência (W) \\
\hline 1 & 240 & 200 \\
\hline 2 & 240 & 300 \\
\hline 3 & 240 & 500 \\
\hline 4 & 240 & 200 \\
\hline 5 & 360 & 300 \\
\hline 6 & 360 & 200 \\
\hline 7 & 480 & 300 \\
\hline 8 & 480 & 500 \\
\hline 9 & 480 & 600 \\
\hline 10 & 480 & 700 \\
\hline 11 & & \\
\hline & & \\
\hline
\end{tabular}

Diâmetro focal do laser na superfície: $1,9 \mathrm{~mm}$

Gás utilizado: Argônio

Fluxo: $10 \mathrm{l} / \mathrm{min}$ 
Tabela 6-12 - Parâmetros utilizados para soldagem com o laser focalizado na superfície

\begin{tabular}{|c|c|c|c|}
\hline Amostra & Velocidade (mm/min) & Potência (W) & Fluxo (l/min) \\
\hline 12 & 480 & 700 & 10 \\
\hline 13 & 480 & 200 & 10 \\
\hline 14 & 480 & 300 & 10 \\
\hline 15 & 360 & 200 & 10 \\
\hline 16 & 240 & 200 & 15 \\
\hline
\end{tabular}

Diâmetro na superfície: $0,3 \mathrm{~mm}$

Após a irradiação, as amostras foram devidamente cortadas, lapidadas, polidas e atacadas quimicamente para revelar a microestrutura e também tiveram seus cordões medidos. Os gráficos a seguir mostram a variação da largura do cordão de solda (Figura 6-23) e da profundidade alcançada (Figura 6-24) com os parâmetros utilizados. 
Largura dos cordões de solda a soldagem com o laser contínuo

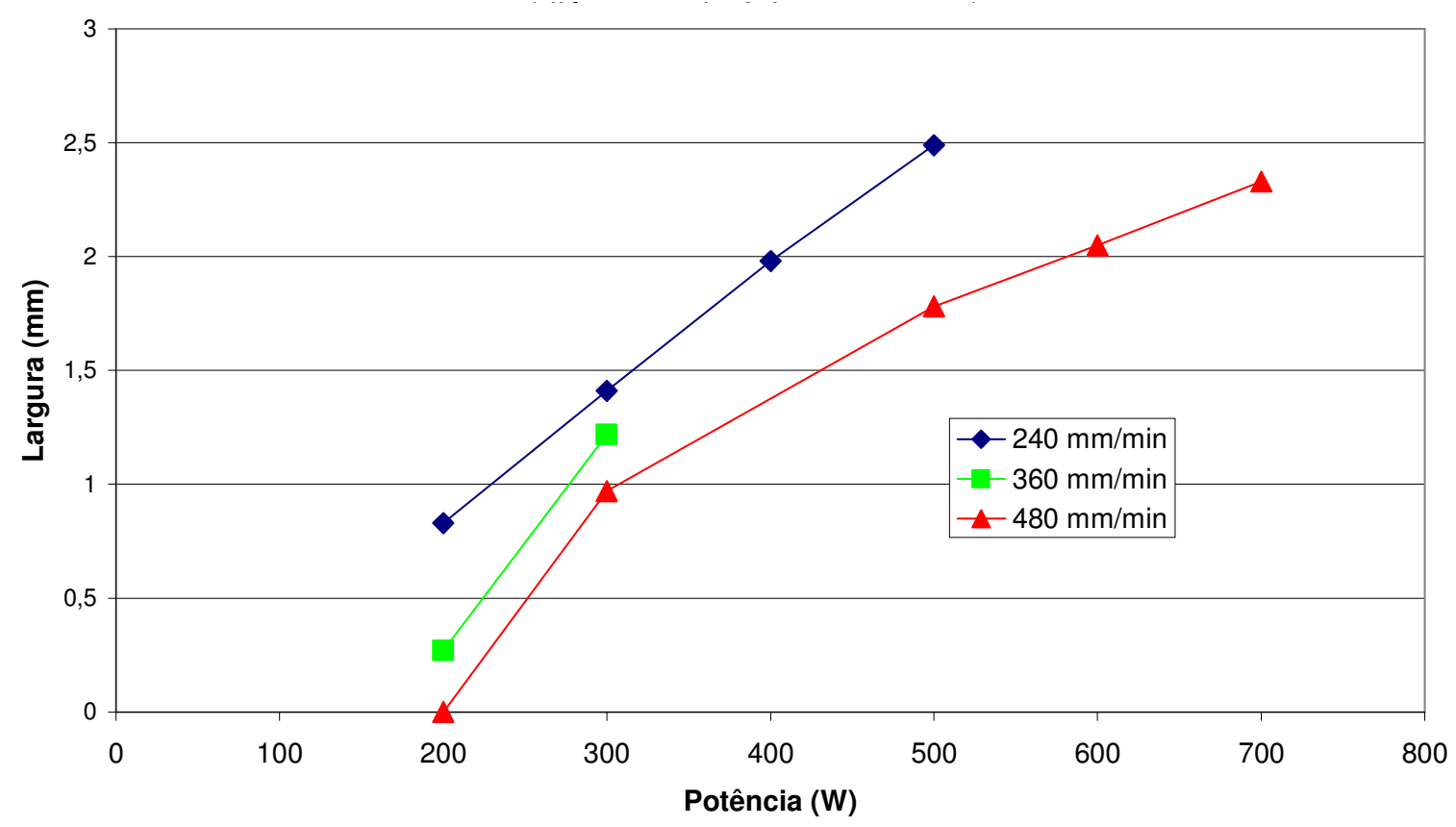

Figura 6-23 - Variação da largura do cordão de solda para o laser contínuo desfocalizado.

Profundidade alcançada na soldagem com o laser contínuo (diâmetro do feixe $=1,9 \mathrm{~mm}$ )

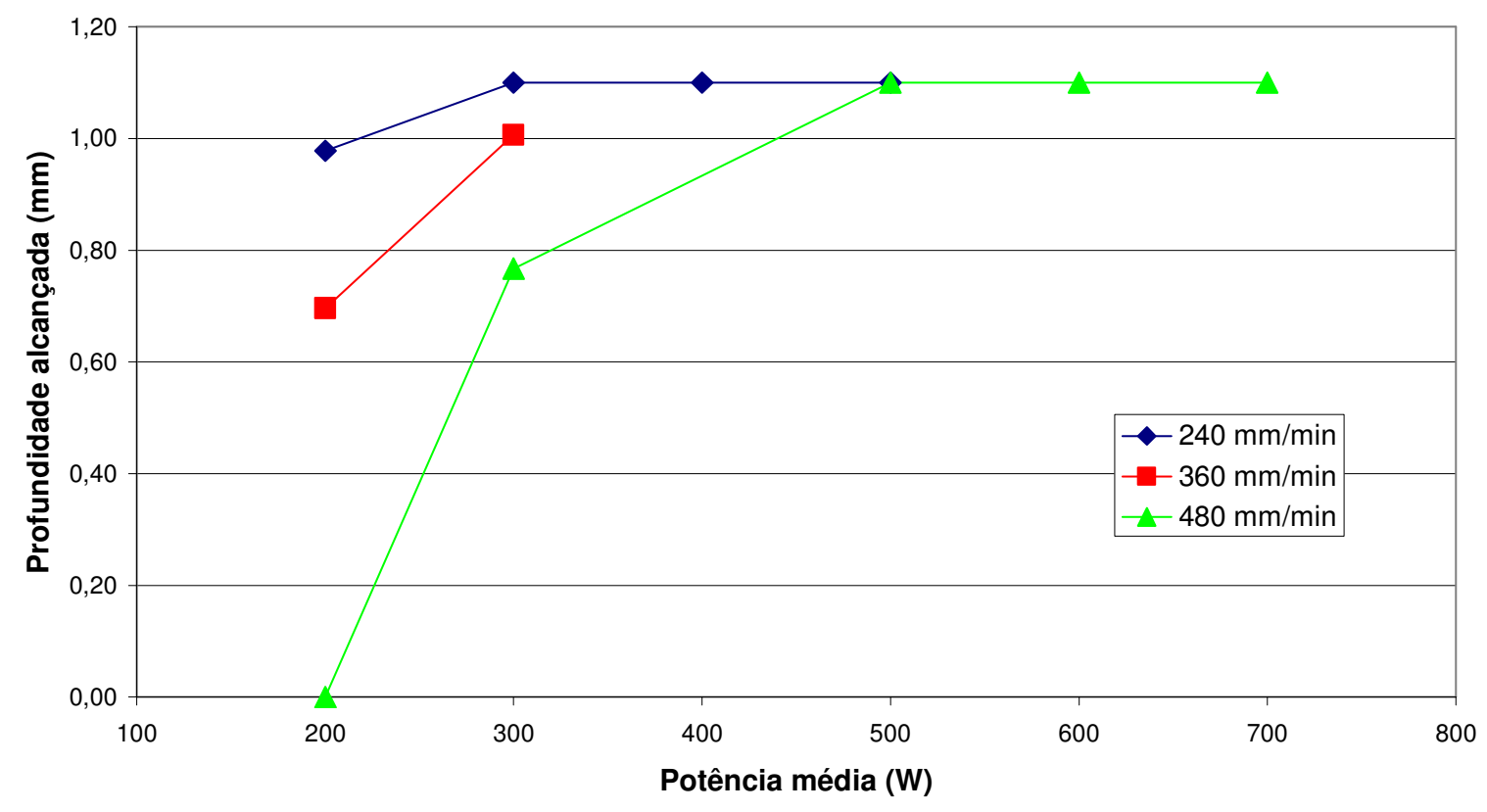

Figura 6-24 - Variação da profundidade da poça de fusão para o laser contínuo desfocalizado. 
Na soldagem com o laser contínuo sem atmosfera de proteção na raiz do cordão, foi notado que mesmo que a radiação não provoque penetração total, um alto nível de oxidação é encontrado, indicando que há uma necessidade ainda maior de proteção para este caso do que para o laser pulsado.
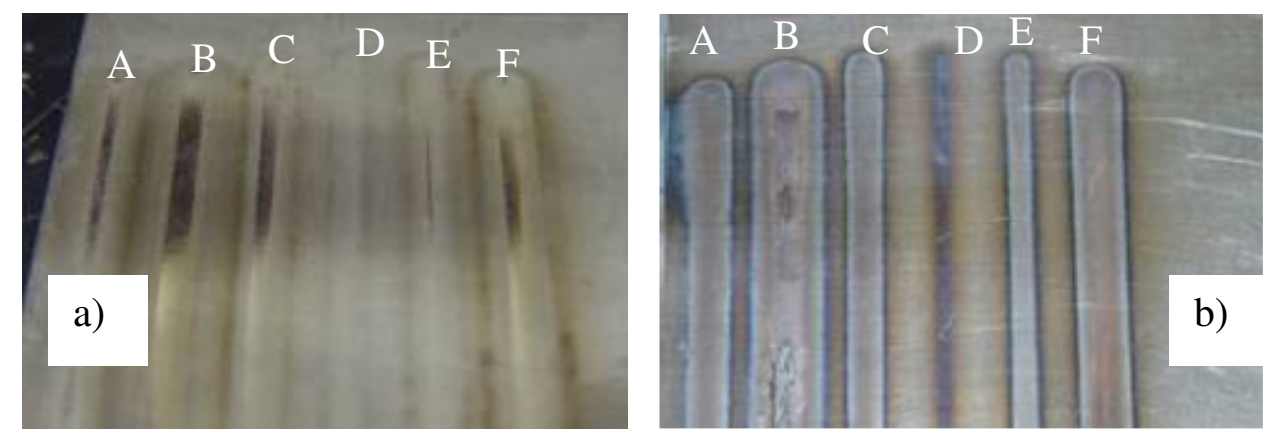

Figura 6-25 - Alguns cordões de solda realizados com o laser contínuo; a) frente; b) raiz sem proteção.

Percebe-se que no cordão $D$ da Figura 6-25 não houve sequer fusão do material, porém já se verifica um alto nível de contaminação na raiz, que estava sem a devida proteção.

Com a utilização do dispositivo de proteção de raiz, foi possível evitar que esta oxidação ocorresse, como mostrado na Figura 6-26.

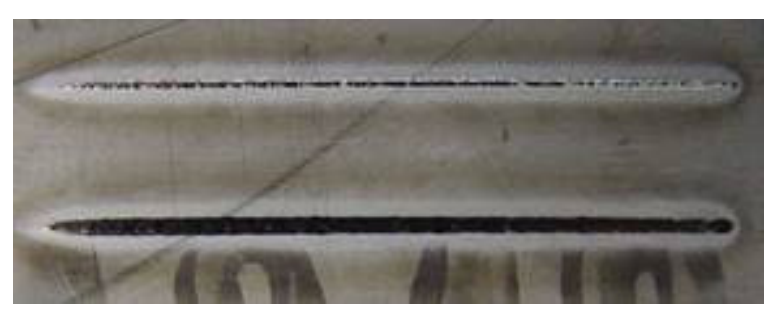

Figura 6-26 - Raízes protegidas com atmosfera neutra 
Das condições analisadas, apenas aquelas com focalização na superfície apresentaram penetração total, e destas, a amostra 15 foi a que apresentou o melhor tamanho de cordão e com mínima oxidação.

Pode-se comparar as condições otimizadas da soldagem com laser pulsado e contínuo a partir do cálculo do aporte térmico (AT). Para o laser contínuo temos:

$$
\mathrm{AT}=\frac{\text { Potência média }}{\text { Velocidade }}
$$

Para o laser pulsado, o número de pulsos que atingirão um ponto $\mathrm{P}$ no final do primeiro pulso pode ser calculado por (ver Figura 3-6):

$$
\mathrm{N}=\mathrm{S} / \mathrm{S}^{\prime}
$$

Assim, a quantidade de energia em um determinado espaço $S$ é calculada por:

$$
E=N \cdot E p
$$

Onde Ep é a energia por pulso.

Assim, o aporte térmico em um determinado comprimento S é dado por:

$$
\mathrm{AT}=\frac{\mathrm{E}}{\mathrm{S}}=\frac{\mathrm{N} \cdot \mathrm{Ep}}{\mathrm{S}}=\frac{\mathrm{S}}{\mathrm{S}^{\prime}} \cdot \frac{\mathrm{Ep}}{\mathrm{S}}=\frac{\mathrm{Ep}}{\mathrm{S}^{\prime}}=\frac{\mathrm{Ep}}{\mathrm{v} \cdot \mathrm{tf}}=\frac{\text { Ep.f }}{\mathrm{v}}=\frac{\text { Potência média }}{\mathrm{v}}
$$

A tabela a seguir mostra os valores de aporte térmico obtidos: 
Tabela 6-13 - Comparação dos melhores parâmetros para o laser contínuo e o laser pulsado

\begin{tabular}{|c|c|c|c|c|}
\hline & $\begin{array}{c}\text { Velocidade } \\
(\mathrm{mm} / \mathrm{min})\end{array}$ & $\begin{array}{c}\text { Potência média } \\
(\mathrm{W})\end{array}$ & $\begin{array}{c}\text { Largura do } \\
\text { cordão }(\mathrm{mm})\end{array}$ & $\begin{array}{c}\text { Aporte térmico } \\
(\mathrm{J} / \mathrm{mm})\end{array}$ \\
\hline $\begin{array}{c}\text { Laser } \\
\text { contínuo }\end{array}$ & 360 & 200 & 1,4 & 33,33 \\
\hline $\begin{array}{c}\text { Laser } \\
\text { pulsado }\end{array}$ & 100 & 57,2 & 1,32 & 33 \\
\hline
\end{tabular}

Percebe-se a partir desta comparação que os valores de aporte térmico para os lasers são idênticos, sugerindo que é possível estimar o valor das variáveis para outros valores de velocidade ou potência média, caso não seja possível atingir aqueles utilizados neste trabalho.

\subsubsection{Simulações Matemáticas}

Esta parte de simulações está dividida em duas: uma comparação entre os modelos de Rosenthal com e sem perdas por convecção e a aplicação do modelo sem perdas de convecção nos resultados experimentais.

A importância da primeira parte é a dificuldade no cálculo de $h$ (coeficiente de película) para aplicá-lo no modelo de Rosenthal com perdas de calor. Assim, uma aproximação é não considerar as perdas por convecção. Porém não se sabe até que ponto ou em que condições estas perdas de calor são significativas, fazendo-se então necessário um estudo da divergência entre os dois modelos para se saber as limitações do modelo mais simples. 


\section{Comparação dos dois modelos de Rosenthal}

Pode-se comparar os dois modelos utilizando os mesmos parâmetros nas duas simulações. Para isto foi escolhido um valor alto e um baixo para a potência, velocidade de soldagem e absorção, como pode ser visto na Tabela 6-14. Três diferentes temperaturas foram escolhidas: $1660^{\circ} \mathrm{C}, 1050^{\circ} \mathrm{C}$ e $540^{\circ} \mathrm{C}$, por possuírem aproximadamente $500^{\circ} \mathrm{C}$ de diferença entre elas e servir de um bom parâmetro para este trabalho. Já para a condutividade de superfície, para uma aproximação alta seu valor seria de $h<100 \mathrm{~W} \cdot \mathrm{m}^{-2} \cdot \mathrm{K}^{-1}[64]$.

Tabela 6-14 - Valores utilizados para comparação dos dois modelos

\begin{tabular}{|c|c|c|c|}
\hline Simulação & Potência & Absorção & Velocidade \\
\hline 1 & 300 & 0,15 & 200 \\
\hline 2 & 300 & 0,45 & 200 \\
\hline 3 & 600 & 0,15 & 200 \\
\hline 4 & 600 & 0,45 & 200 \\
\hline 5 & 300 & 0,15 & 400 \\
\hline 6 & 300 & 0,45 & 400 \\
\hline 7 & 600 & 0,15 & 400 \\
\hline 8 & 600 & 0,45 & 400 \\
\hline
\end{tabular}

Nas figuras abaixo são mostrados os resultados das simulações 1 e 2 , onde os valores de temperatura são colocados a partir de curvas de nível, as linhas pretas representam o modelo de Rosenthal sem perdas de calor por convecção enquanto que as linhas azuis representam o modelo que leva em conta estas perdas por convecção. 


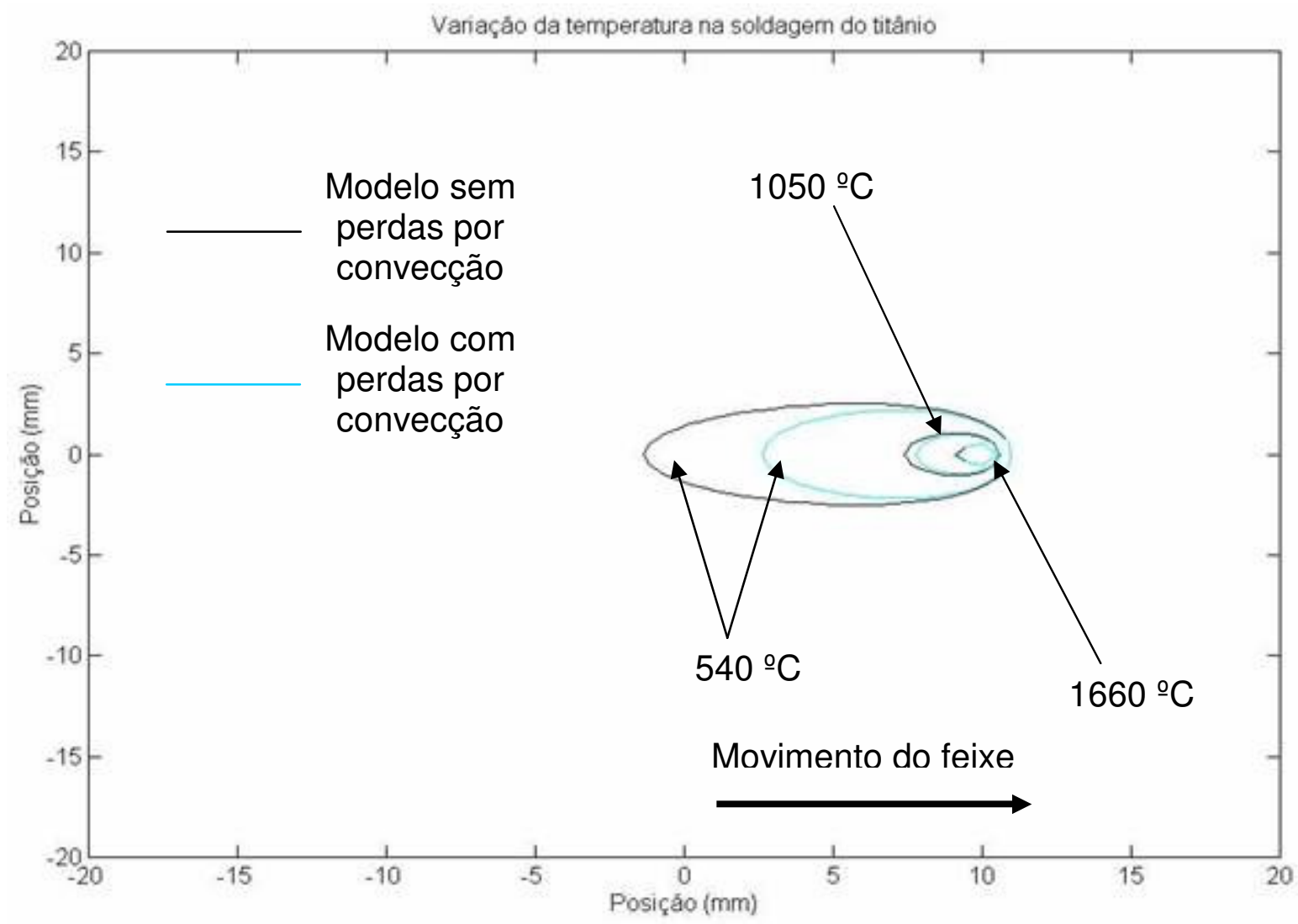

Figura 6-27 - Simulação 1, comparando os modelos de Rosenthal com e sem perdas de calor por convecção 


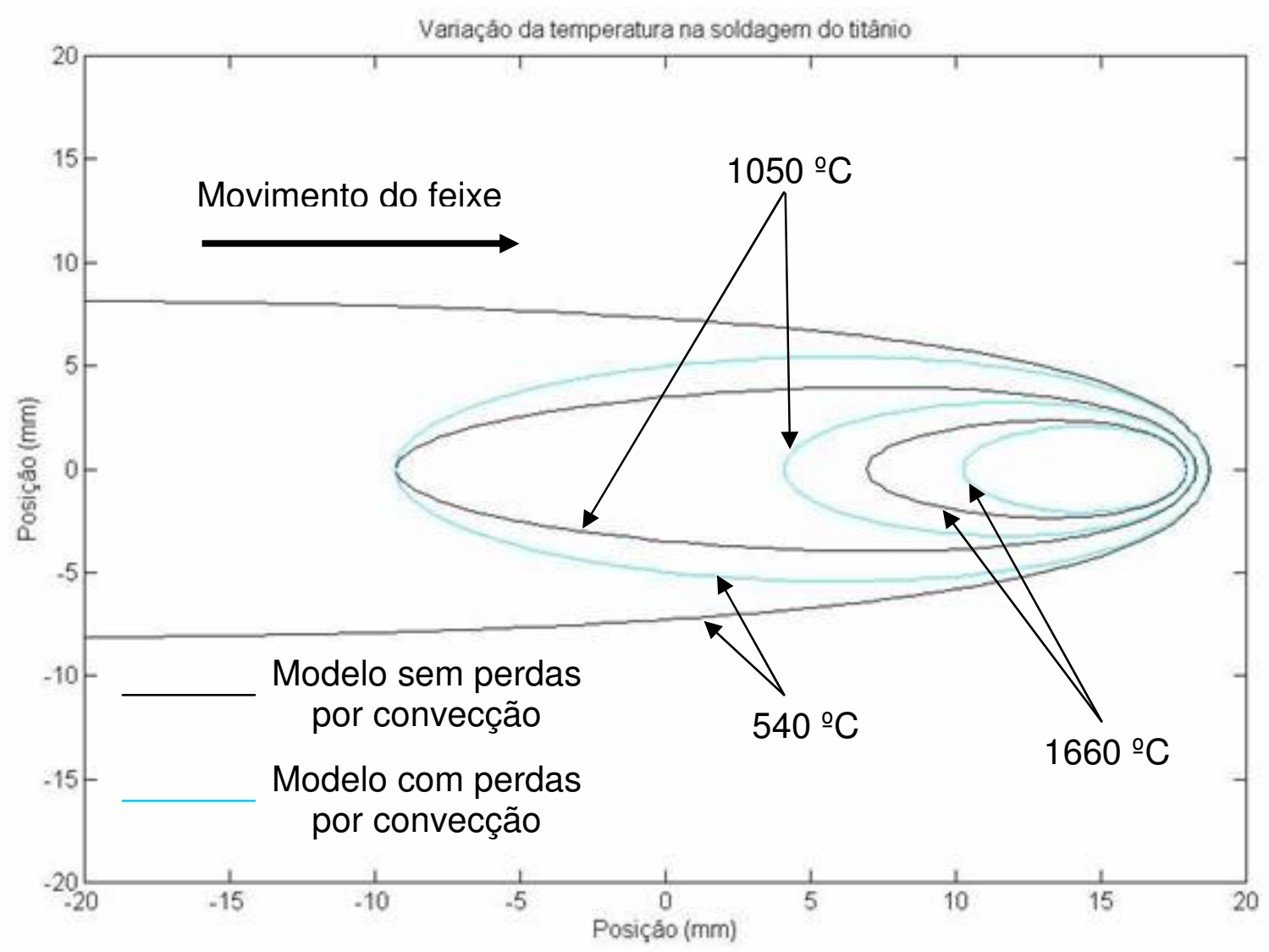

Figura 6-28 - Simulação 2, comparando os modelos de Rosenthal com e sem perdas de calor por convecção

Apenas observando estes modelos percebe-se que as diferenças de temperaturas entre eles depende do valor das variáveis (potência, velocidade e absorção). Além disto, a taxa de variação deste campo é diferente para $\mathrm{x}$ (horizontal) e y (vertical) $\left(\frac{\partial T}{\partial x} \neq \frac{\partial T}{\partial y}\right)$, fazendo com que a isoterma cresça a uma taxa diferente no comprimento e na largura, fazendo com que esta alteração varie dependendo também da temperatura que se analisa.

Para verificar melhor estes fenômenos, temos na Tabela 6-15 o valor da variação entre os raios horizontais e verticais da elipse isoterma. Esta variação 
representa o aumento que se obteve do modelo que considera as perdas de calor para o que não considera estas perdas (ver Figura 6-29).

A importância de se considerar as variações horizontais e verticais se dá na distinta importância de cada uma delas. O campo de temperatura na vertical (perpendicular ao cordão de solda) dará o valor da zona fundida e da temperatura alcançada na zona afetada pelo calor, por exemplo, enquanto que o campo de temperatura horizontal (ao longo do cordão) dará informações como por quanto tempo uma certa região permanece a uma determinada temperatura, o que pode ajudar a ter uma idéia da microestrutura formada na região, por exemplo.

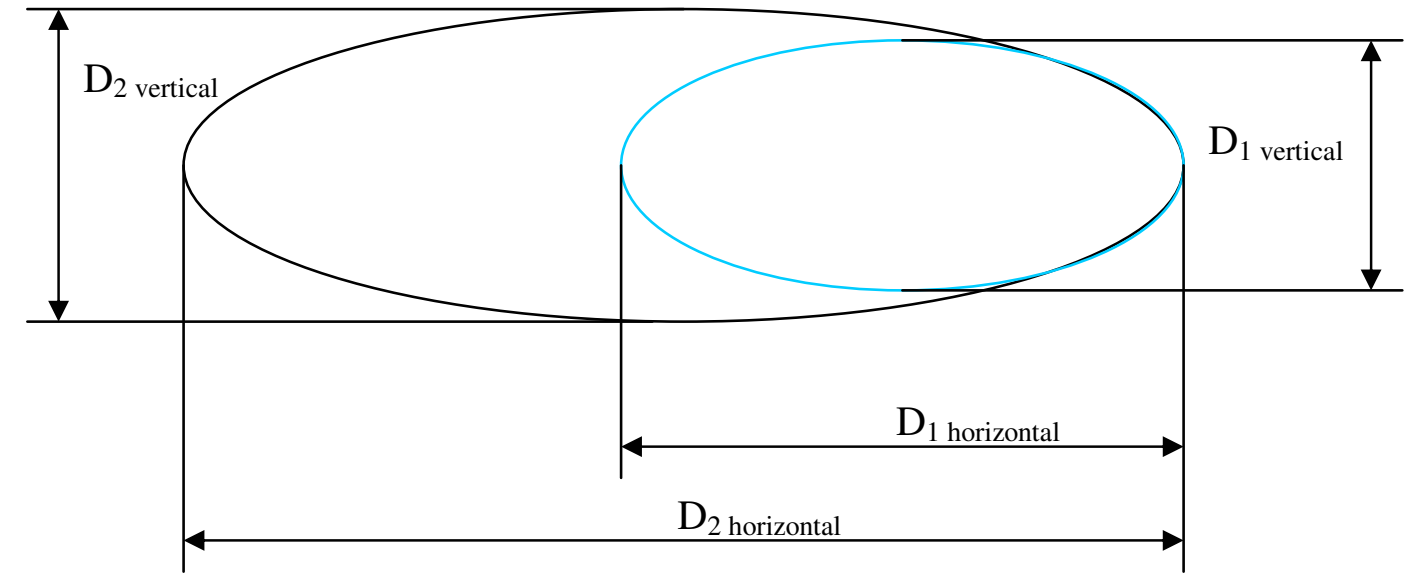

Variação horizontal $(\%)=\frac{\mathrm{D}_{1} \text { horizontal }}{\mathrm{D}_{2} \text { horizontal }} .100 \quad$ Variação vertical $(\%)=\frac{\mathrm{D}_{1} \text { vertical }}{\mathrm{D}_{2} \text { vertical }} .100$

Figura 6-29 - Cálculo da variação dos campos de temperatura nos dois modelos de Rosenthal. 
Tabela 6-15 - Variação vertical e horizontal entre as duas simulações.

\begin{tabular}{|c|c|c|c|c|c|c|}
\hline \multirow{2}{*}{ Amostra } & \multicolumn{5}{|c|}{ Variações (aumento em \%) } \\
\hline & \multicolumn{2}{|c|}{$1660^{\circ} \mathrm{C}$} & \multicolumn{2}{c|}{$1050{ }^{\circ} \mathrm{C}$} & \multicolumn{2}{c|}{$540{ }^{\circ} \mathrm{C}$} \\
\hline 1 & 0,00 & 6,19 & 9,09 & 17,42 & 17,82 & 47,83 \\
\hline 2 & 13,19 & 44,72 & 22,17 & 95,02 & 49,37 & 57,69 \\
\hline 3 & 13,11 & 20,89 & 15,32 & 48,03 & 30,55 & 96,42 \\
\hline 4 & 53,44 & 134,12 & 49,37 & 203,42 & 101,64 & 457,45 \\
\hline 5 & 0,00 & 0,00 & 0,00 & 0,00 & 0,00 & 14,25 \\
\hline 6 & 0,00 & 12,28 & 4,19 & 30,65 & 18,21 & 48,72 \\
\hline 7 & 0,00 & 7,18 & 0,00 & 15,08 & 9,13 & 48,70 \\
\hline 8 & 10,92 & 44,57 & 17,42 & 69,64 & 45,09 & 52,21 \\
\hline
\end{tabular}

A partir desta tabela é possível perceber a dificuldade de interpretar os dados levando-se em conta todas as variáveis envolvidas e as possíveis interações entre elas. Assim, para uma melhor visualização e entendimento do problema, será adotado o método de Taguchi, onde será possível ter uma melhor visão da influência de todas as variáveis.

\section{Método de Taguchi}

O Dr. Genichi Taguchi desenvolveu e promoveu uma filosofia e metodologia para melhoria de qualidade contínua a partir de Projeto Estatístico de Experimentos (Statistical Design of Experiments - SDOE, sigla que será utilizada de agora em diante), mostrando como ele pode ajudar os engenheiros industriais a projetar e produzir produtos de alta qualidade e baixo custo [65]. 
O método se baseia no uso de matrizes ortogonais para analisar os fatores escolhidos no experimento. As matrizes ortogonais mais utilizadas são as L8 (oito tentativas experimentais), L16 e L18. A grande vantagem do método de Taguchi é a facilidade de aplicação e a rapidez em se encontrar os resultados. Além disto, como será visto adiante, o método permite que se chegue em uma conclusão confiável mesmo sem precisar fazer todas as combinações possíveis entre as variáveis.

A explicação do método será realizada em conjunto com a aplicação no problema em questão.

O primeiro passo é a determinação do problema: a partir das duas simulações e dos resultados obtidos, o objetivo é saber quais devem ser os valores das variáveis para que a diferença entre os dois modelos seja a menor possível. Sabendo-se disto, será possível aplicar a equação que não considera as perdas de calor por convecção tendo em mente suas limitações.

O principal problema na aplicação do modelo de convecção é o cálculo de h, que depende de muitas variáveis e seu cálculo está além do proposto neste trabalho.

O segundo passo para se aplicar o método é determinar as variáveis que serão utilizadas. Neste caso haverá 4 variváveis: velocidade de soldagem (v), potência $(P)$, absorção $(A)$ e temperatura $(T)$. Além disto, haverá também um estudo da interação entre a velocidade de soldagem e a potência $(v \times P)$, a velocidade de soldagem e a absorção $(v \times A)$ e entre a potência e a absorção $(P x$ A). Estas interações foram escolhidas porque, embora a temperatura neste problema é considerada como variável, é preciso lembrar que ela é calculada a 
partir dos outros 3 parâmetros. Para cada uma das variáveis, dois níveis foram selecionados. Estes níveis são mostrados na Tabela 6-16.

Tabela 6-16 - Variáveis do problema proposto

\begin{tabular}{|c|c|c|c|}
\hline Variável & Símbolo & Nível 1 & Nível 2 \\
\hline Velocidade de soldagem & $\mathrm{v}$ & $200 \mathrm{~mm} / \mathrm{min}$ & $400 \mathrm{~mm} / \mathrm{min}$ \\
\hline Potência & $\mathrm{P}$ & $300 \mathrm{~W}$ & $600 \mathrm{~W}$ \\
\hline Absorção & A & 0,15 & 0,45 \\
\hline Temperatura & $T$ & $1660 \stackrel{\circ}{\mathrm{C}}$ & $540 \stackrel{\circ}{C}$ \\
\hline
\end{tabular}

Com as variáveis e as interações definidas, é necessário definir o tamanho da matriz ortogonal que se deve trabalhar. Para tanto deve-se calcular os graus de liberdade de cada variável e de suas interações. O grau de liberdade de uma variável é igual ao número de níveis desta variável menos 1. Assim, como todas as variáveis aqui possuem 2 níveis, temos um total de 4 graus de liberdade referente às variáveis. $\mathrm{O}$ grau de liberdade de uma interação é igual ao produto dos graus de liberdade das variáveis envolvidas. Como todas as variáveis tratadas aqui possuem grau de liberdade igual a 1, os graus de liberdade das variáveis também é igual a 1, somando-se 3 graus de liberdade referentes às interações. No total, tem-se $4+3=7$ graus de liberdade para o problema proposto.

O número de tentativas deve ser maior do que o número de graus de liberdade, assim, escolhe-se a matriz ortogonal L8 (caso o número de graus de liberade fosse 9, por exemplo, a matriz escolhida seria a L16).

Assim, a matriz ortogonal fica da maneira encontrada abaixo: 
Tabela 6-17 - Projeto da análise

\begin{tabular}{|c|c|c|c|c|c|c|c|c|c|c|}
\cline { 2 - 8 } \multicolumn{1}{c|}{} & \multicolumn{6}{c|}{ Variáveis e interações } & \multicolumn{2}{c|}{ Variação entre os modelos } \\
\hline Número da combinação & $\mathrm{v}$ & $\mathrm{P}$ & $\mathrm{vP}$ & $\mathrm{A}$ & $\mathrm{vA}$ & $\mathrm{PA}$ & $\mathrm{T}$ & Vertical & Horizontal \\
\hline 1 & 1 & 1 & 1 & 1 & 1 & 1 & 1 & 0 & 6,19 \\
\hline 2 & 1 & 1 & 1 & 2 & 2 & 2 & 2 & 49,37 & 57,69 \\
\hline 3 & 1 & 2 & 2 & 1 & 1 & 2 & 2 & 30,55 & 96,42 \\
\hline 4 & 1 & 2 & 2 & 2 & 2 & 1 & 1 & 53,44 & 134,12 \\
\hline 5 & 2 & 1 & 2 & 1 & 2 & 1 & 2 & 0 & 14,25 \\
\hline 6 & 2 & 1 & 2 & 2 & 1 & 2 & 1 & 0 & 12,28 \\
\hline 7 & 2 & 2 & 1 & 1 & 2 & 2 & 1 & 0 & 7,18 \\
\hline 8 & 2 & 2 & 1 & 2 & 1 & 1 & 2 & 45,09 & 52,21 \\
\hline
\end{tabular}

O nível das interações é 1 quando os valores das duas variáveis em questão for igual, e é 2 quando estes valores forem diferentes.

Os resultados encontrados na tabela acima foram retirados da Tabela 6-15, sendo que quando a variável $T$ fosse 1 , retirava-se a variação da isoterma de $1660{ }^{\circ} \mathrm{C}$, enquanto que se fosse 2 , retirava-se da isoterma de $540{ }^{\circ} \mathrm{C}$.

Em experimentos em que se deseja achar a condição otimizada entre as variáveis, é interessante calcular o valor de saída mais de uma vez e se obter uma média. Porém, neste caso, onde o objetivo é apenas entender as interações envolvidas e onde os resultados são totalmente teóricos, a repetição do experimento não é justificada.

Para a análise destes resultados é necessário calcular o valor da razão entre o sinal e o ruído (Signal-to-Noise Ratio - SNR, como será abreviado de agora em diante), onde é necessário maximizar o efeito do sinal, e minimizar o 
ruído. Em outras palavras, o resultado das variáveis será aquele que apresentar a maior SNR.

O cálculo desta razão dependerá daquilo que se deseja. Neste caso tem-se a necessidade de que a variação vertical e horizontal entre os dois modelos seja a menor possível, portanto será utilizado a SNR ligado ao "menor melhor" (smallerthe-better), dado pela equação a seguir [66]:

$$
S R=-10 \cdot \log \left(\frac{1}{n} \cdot \sum y_{i}{ }^{2}\right)
$$

Onde $n$ é o número de repetições realizadas para cada tentativa e $y_{i}$ é o resultado obtido na repetição. A seguir tem-se um exemplo de cálculo do SR para a primeira combinação de variáveis no caso da variação horizontal.

Os resultados são colocados na tabela a seguir para cada combinação.

Tabela 6-18 - SNR para cada combinação utilizada

\begin{tabular}{|c|c|c|}
\hline & \multicolumn{2}{|c|}{ SNR } \\
\hline Número da combinação & Vertical & Horizontal \\
\hline 1 & 0,00 & $-15,83$ \\
\hline 2 & $-33,87$ & $-35,22$ \\
\hline 3 & $-29,70$ & $-39,68$ \\
\hline 4 & $-34,56$ & $-42,55$ \\
\hline 5 & 0,00 & $-23,08$ \\
\hline 6 & 0,00 & $-21,78$ \\
\hline 7 & 0,00 & $-17,12$ \\
\hline 8 & $-33,08$ & $-34,36$ \\
\hline
\end{tabular}


Agora é necessário calcular o valor da SNR para cada nível de cada variável. Para tanto, deve ser feito a seguinte conta: por exemplo para o nível 1 da variável v, a SNR será a média das SNR das linhas onde v tem nível 1. De acordo com a Tabela 6-17, v assume valor igual a 1 nas linhas 1, 2, 3 e 4, então a SNR para este nível desta variável será:

SNR v1 (vertical $)=\frac{0-33,87-29,7-34,56}{4}=-24,53$

O mesmo cálculo foi realizado para o nível 2 da vertical e para os níveis 1 e 2 da horizontal, chegando aos seguintes resultados:

Tabela 6-19 - Valor da SNR para os níveis 1 e 2 dos parâmetros utilizados

\begin{tabular}{|c|c|c|c|c|}
\hline & \multicolumn{2}{|c|}{ Vertical } & \multicolumn{2}{c|}{ Horizontal } \\
\hline Parâmetro & SNR 1 & SNR 2 & SNR 1 & SNR 2 \\
\hline v & $-24,53$ & $-8,27$ & $-33,32$ & $-24,08$ \\
\hline P & $-8,47$ & $-24,33$ & $-23,98$ & $-33,43$ \\
\hline vP & $-16,74$ & $-16,06$ & $-25,63$ & $-31,77$ \\
\hline A & $-7,43$ & $-25,38$ & $-23,93$ & $-33,48$ \\
\hline vA & $-15,70$ & $-17,11$ & $-27,91$ & $-29,49$ \\
\hline PA & $-16,91$ & $-15,89$ & $-28,95$ & $-28,45$ \\
\hline T & $-8,64$ & $-24,16$ & $-24,32$ & $-33,08$ \\
\hline
\end{tabular}

Para mostrar os resultados obtidos, eles serão colocados em um gráfico de efeitos principais (main effects plot), onde o valor de SNR de cada nível de cada variável é mostrado. Quanto maior for a diferença entre os níveis, mais relevante o parâmetro é para o resultado, que neste caso é a divergência entre os dois modelos. 


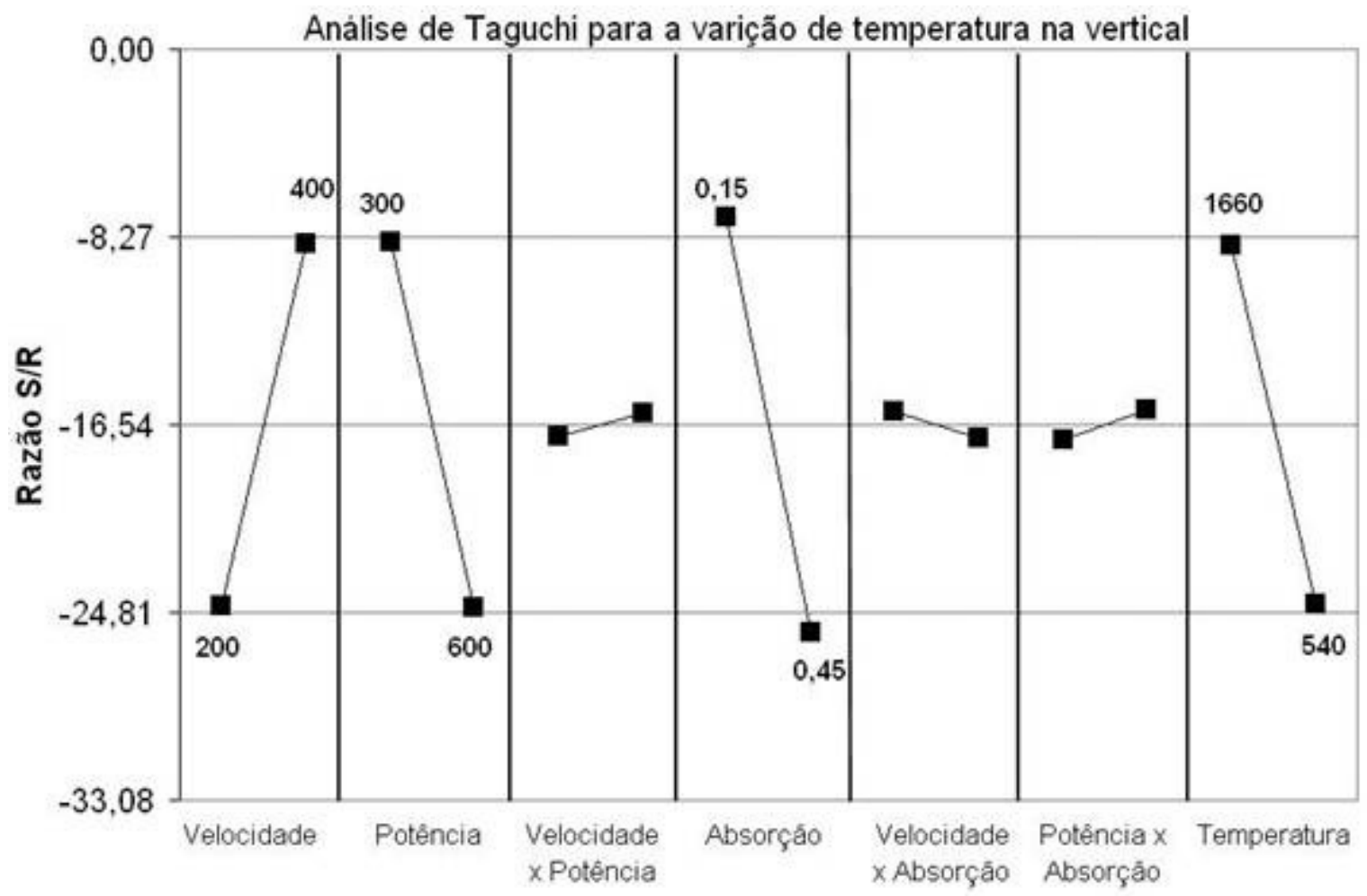

Figura 6-30 - Análise de Taguchi para a divergência de temperatura na vertical

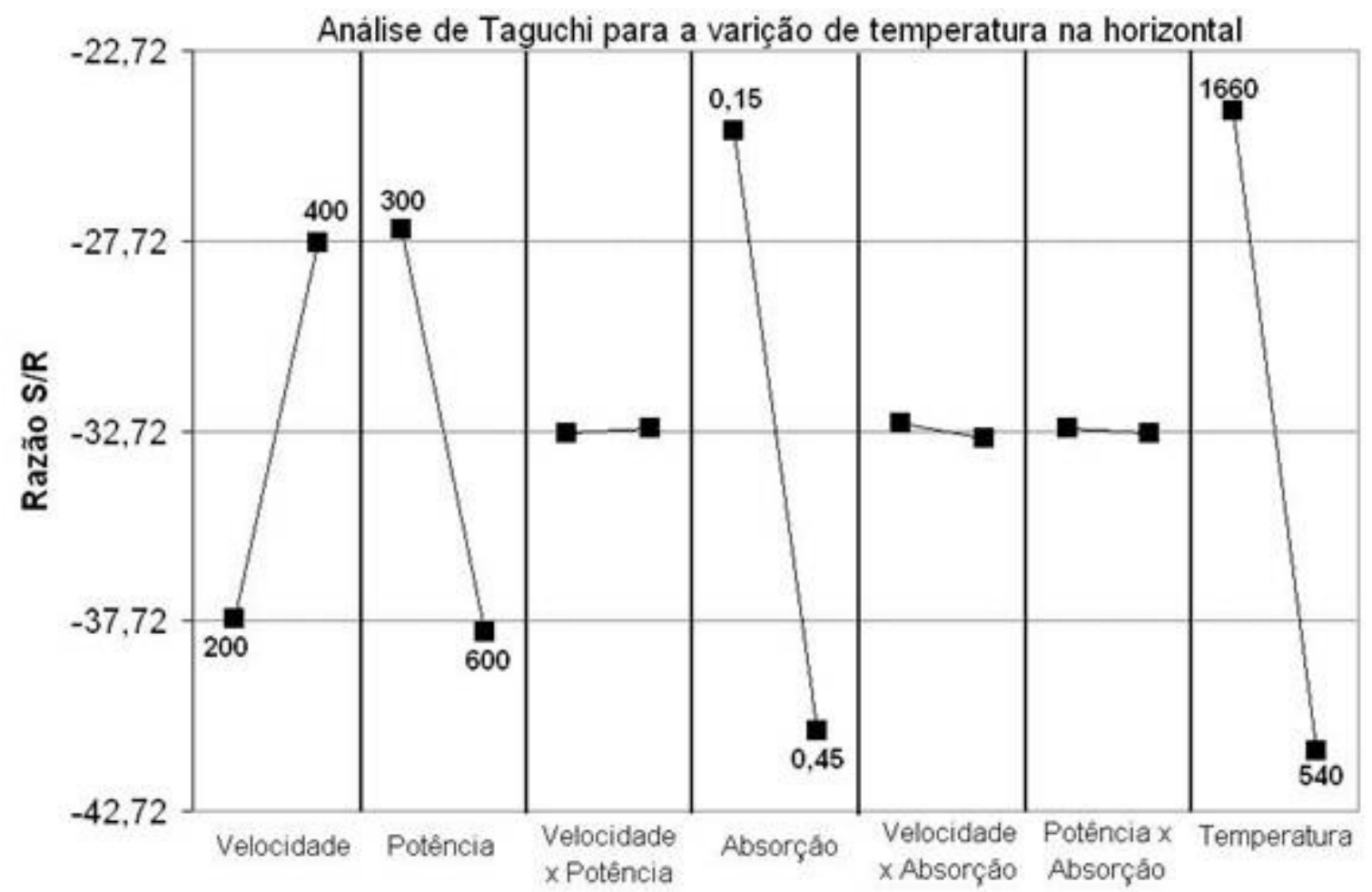

Figura 6-31 - Análise de Taguchi para a divergência de temperatura na horizontal 
Observando-se os resultados, é possível concluir que a divergência é tanto menor quanto maior for a velocidade e a temperatura a qual se analisa, e menor a absorção e potência do laser.

Estes resultados apontam para que quanto mais próximo a fonte de calor estiver da isoterma de estudo (ou seja, quanto maior for o seu valor de temperatura) menor será a divergência entre os dois modelos. Isto pode ser explicado pelo fato de que próximo da fonte os efeitos de perda são menos significativos, já que a própria fonte fornece mais energia para compensar aquela perdida. Agora, quanto mais longe da fonte, uma menor quantidade de energia será fornecida e as perdas por convecção superam a quantidade cedida pela fonte.

Do mesmo modo é possível explicar a absorção do material e a potência, cujo aumento faz com que mais energia seja cedida, fazendo com que as temperaturas mais baixas fiquem mais longe da fonte. Portanto, um menor valor deles provoca uma menor divergência entre os modelos.

Um maior valor de velocidade tem um efeito parecido, pois quanto menor a velocidade, mais tempo a fonte permanecerá sobre o material, aquecendo-o mais, fazendo com que as isotermas de temperaturas menores se afastem da fonte, aumentando a divergência.

Estes resultados mostram que para um alto valor de coeficiente de película $\left(\mathrm{h}=100 \mathrm{~W} \cdot \mathrm{m}^{-2} \cdot \mathrm{K}^{-1}\right)$ e altos valores de potência e absorção e baixos valores de velocidade há sim uma diferença significativa entre os dois modelos. Este limite de se considerar ou não as perdas por convecção deve ser estudado mais profundamente, obtendo-se $\mathrm{o}$ valor $\mathrm{h}$ para $\mathrm{o}$ caso de soldagem a laser, escolhendo de maneira melhor o intervalo utilizado na análise de Taguchi e 
mudando o material, o que vai além do que é proposto neste trabalho. Portanto, para o restante do trabalho será utilizado o modelo que não leva em conta as perdas de calor por convecção.

Como está sendo utilizado um baixo valor de fluxo, e conseqüentemente de h, a divergência aqui deve ser pequena, mas pode ser maior em outras condições.

\section{Simulações realizadas}

Utilizando o modelo de Rosenthal sem perdas de calor (Equação 4), é possível visualizar as isotermas que ocorreram durante a soldagem das chapas. $\bigcirc$ modelo foi utilizado em conjunto com a verificação visual das amostras de zona fundida, zona oxidada e zona afetada pelo calor, na tentativa de determinar em qual temperatura ocorriam tais zonas.

O único termo desconhecido da equação é a absorção do material $(A)$. Para encontrar este valor, utilizava-se a equação variando a absorção até que a largura do cordão de solda coincidisse com a isoterma da temperatura de fusão da liga $\left(1660^{\circ} \mathrm{C}\right)$. O resultado desta simulação para a amostra 2 (Tabela 6-11) é mostrado na Figura 6-32. 


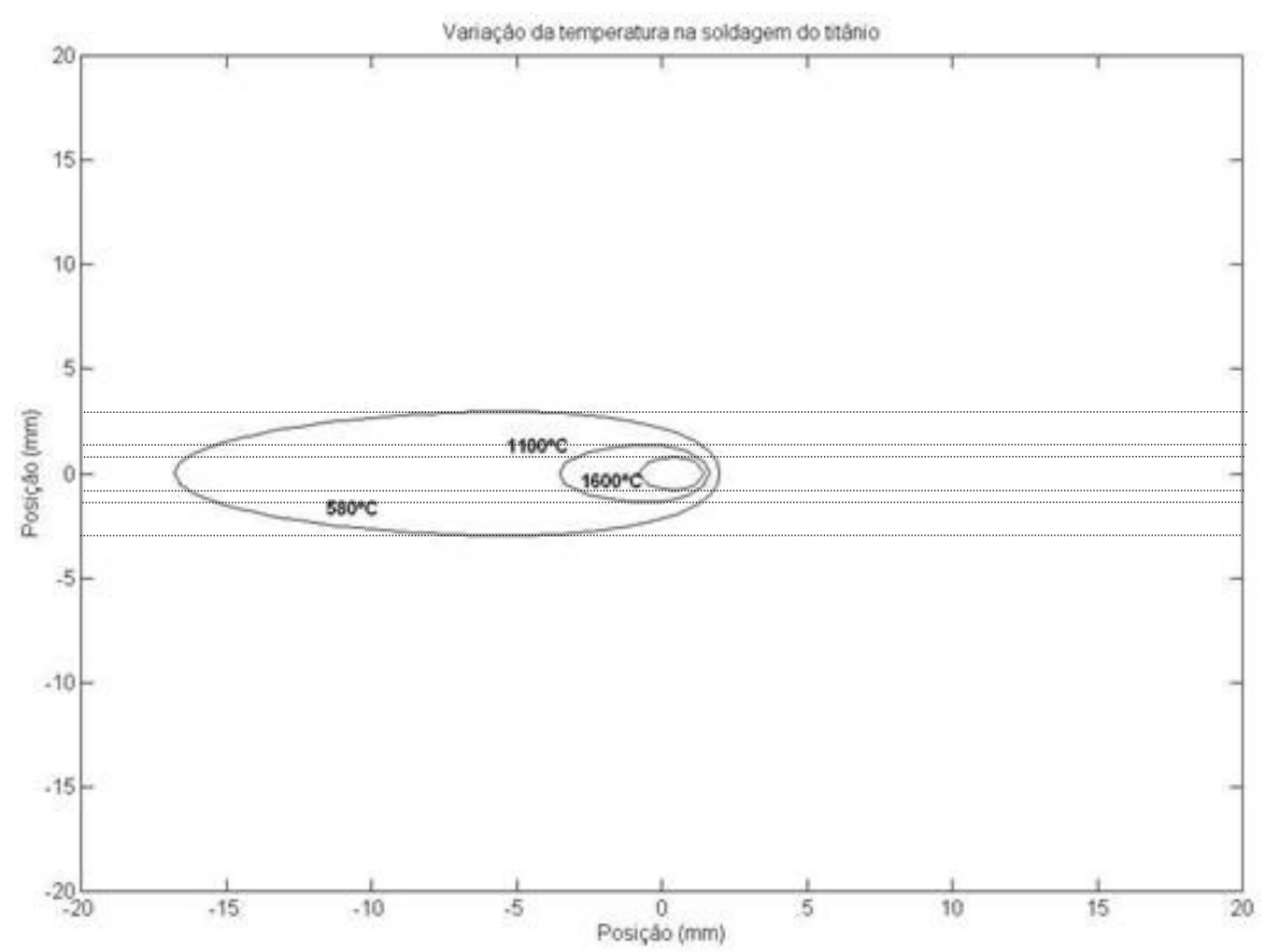

Figura 6-32 - Simulação das isotermas da amostra 2

Sabendo os valores das zonas fundidas e das zonas de oxidação, foi possível determinar as isotermas correspondentes a estes valores.

Na superfície da amostra 2 (Tabela 6-11) é possível observar 3 zonas distintas, conforme visto na Figura 6-33. A primeira delas é a zona fundida (ZF) a segunda é uma zona clara ao redor da zona fundida, que é a zona afetada pelo calor (ZAC) e a terceira é zona oxidada (ZO). 


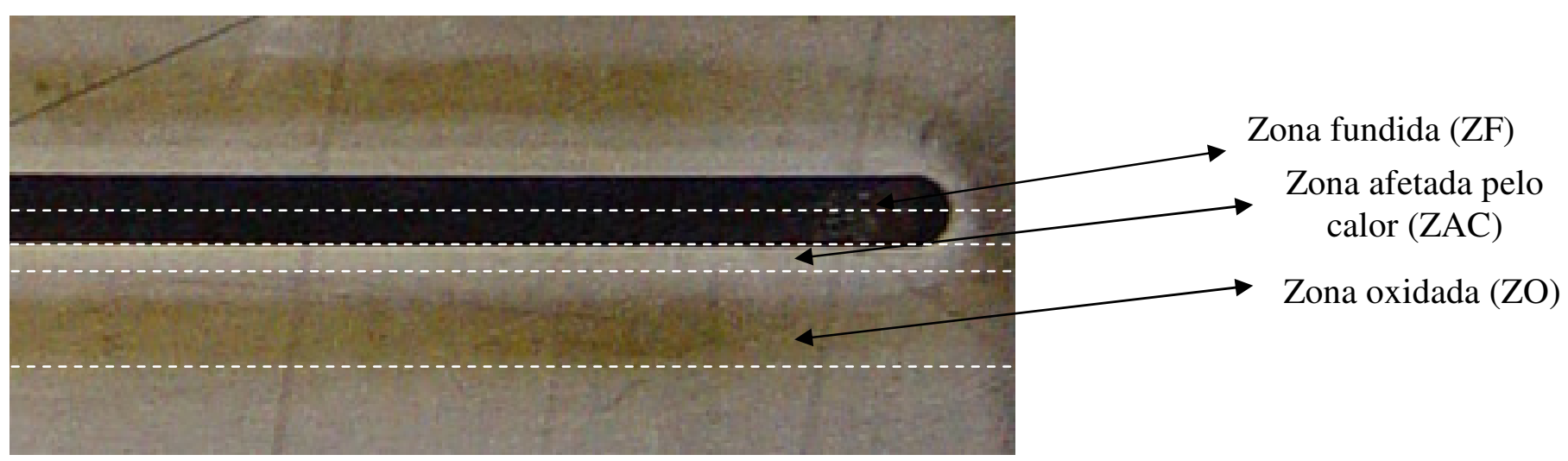

Figura 6-33 - Zonas pressentes na superfície dos cordões de solda

Foram medidos os valores das 3 zonas para cada amostra e o seu resultado foi comparado com aquele obtido nas simulações. Os resultados estão resumidos na tabela a seguir:

Tabela 6-20 - Resultados obtidos a partir de simulações matemáticas

\begin{tabular}{|c|c|c|c|c|c|c|c|}
\hline & \multirow[b]{2}{*}{ Amostra } & \multicolumn{3}{|c|}{$\begin{array}{l}\text { Medidas em } \\
\qquad(\mathrm{mm})\end{array}$} & \multicolumn{2}{|c|}{$\begin{array}{l}\text { Temperatura obtida } \\
\text { em simulação }\left({ }^{\circ} \mathrm{C}\right)\end{array}$} & \multirow[b]{2}{*}{ Absorção } \\
\hline & & ZF & ZAC & $\mathrm{ZO}$ & ZAC & $\mathrm{ZO}$ & \\
\hline \multirow{11}{*}{ 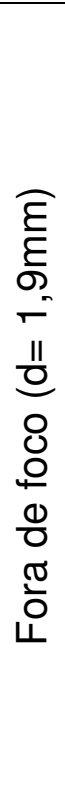 } & 1 & 0,8 & 1,9 & - & 1100 & - & 0,25 \\
\hline & 2 & 1,4 & 2,8 & 6,1 & 1050 & 540 & 0,21 \\
\hline & 3 & 2,0 & 3,2 & 7,7 & 1150 & 550 & 0,20 \\
\hline & 4 & 2,5 & 3,9 & 8,6 & 1150 & 590 & 0,19 \\
\hline & 5 & 0,3 & 1,9 & - & 600 & - & 0,18 \\
\hline & 6 & 1,2 & 2,6 & 5,0 & 1000 & 580 & 0,27 \\
\hline & 7 & - & 1,6 & - & * & * & * \\
\hline & 8 & 1,0 & 2,2 & - & 1000 & - & 0,28 \\
\hline & 9 & 1,8 & 2,6 & 5,0 & 1200 & 660 & 0,25 \\
\hline & 10 & 2,1 & 3,2 & 6,2 & 1200 & 600 & 0,24 \\
\hline & 11 & 2,3 & 3,6 & 6,6 & 1100 & 630 & 0,22 \\
\hline
\end{tabular}




\begin{tabular}{|c|c|c|c|c|c|c|c|}
\hline \multirow{5}{*}{$\begin{array}{l}\stackrel{8}{0} \\
\frac{0}{E}\end{array}$} & Amostra & ZF & ZAC & $\mathrm{ZO}$ & ZAC & $\mathrm{ZO}$ & Absorção \\
\hline & 12 & 1,2 & 2,1 & 4,6 & 1100 & 580 & 0,48 \\
\hline & 13 & 1,7 & 3,0 & 6,7 & 1100 & 500 & 0,42 \\
\hline & 14 & 1,5 & 2,4 & 5,8 & 1200 & 580 & 0,46 \\
\hline & 15 & 2,0 & 3,0 & 7.3 & 1250 & 600 & 0,42 \\
\hline
\end{tabular}

* Não foi possível determinar

** Houve evaporação na amostra, sendo impossível determinar qualquer parâmetro

A figura abaixo mostra a comparação do resultado obtido em simulação com o real:

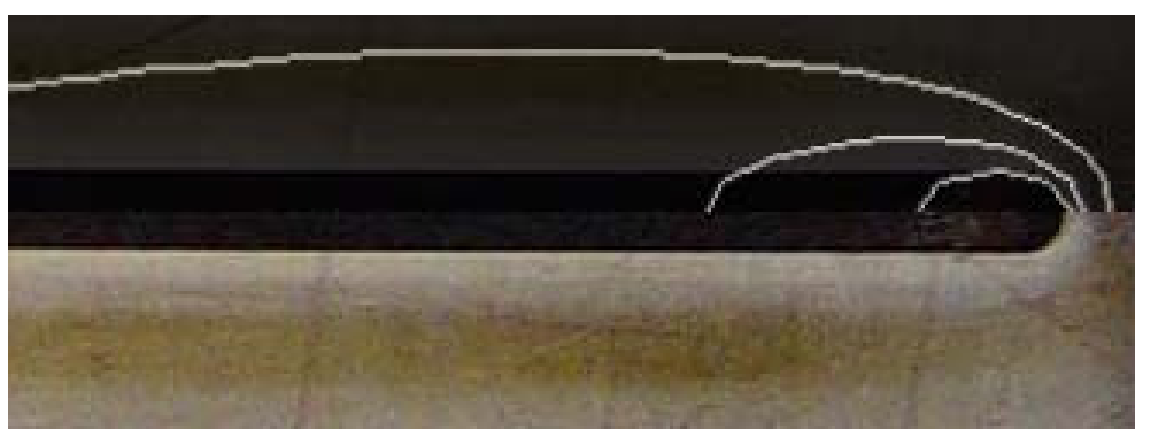

Figura 6-34 - Comparação dos resultados obtidos em simulação com o real.

A partir destes resultados obtidos, é possível perceber que no modelo apresentado a temperatura da ZAC é de aproximadamente $1100^{\circ} \mathrm{C}$ e que a temperatura da zona oxidada é de aproximadamente $600^{\circ} \mathrm{C}$, lembrando que a liga Ti6Al4V sofre transformação alotrópica a 980ํ․

A exceção destes valores é a amostra 5, que apresentou segundo o modelo uma temperatura de $600^{\circ} \mathrm{C}$ na zona afetada pelo calor, o que pode ser uma limitação do modelo de Rosenthal, levando-se em conta que o valor da zona de fusão para esta amostra foi o menor obtido.

A absorção alcançada com o laser no foco foi de $45 \%$, coincidindo com aquela encontrada em outros trabalhos com o mesmo material [67]. 
A diferença do valor da absorção da amostra para as amostras focalizadas e não focalizadas se dá provavelmente pela intensidade fornecida não ser suficiente para uma formação completa do keyhole.

Cabe ainda lembrar que esta absorção está longe de ser a absorção verdadeira, pois no próprio desenvolvimento da equação de Rosenthal (ver apêndice A) é possível observar que a variação de temperatura em z (profundidade) não é levada em conta, enquanto que boa parte da energia cedida pela fonte é utilizada para aquecer regiões abaixo da superfície. Além disto, a absorção no modelo também acaba funcionando como um fator de adaptação: no caso acima, por exemplo, o modelo não distingue o uso de um feixe focalizado ou desfocalizado, portanto os erros decorrentes desta adaptação serão transferidos para o termo da equação sujeito à simulação: a absorção do material.

A divergência entre os valores de temperatura pode ser grande para um estudo mais fiel do que ocorre durante a soldagem, porém são excelentes para simulações rápidas, onde se deseja apenas ter idéia do que será obtido. A única desvantagem deste método é a necessidade de "calibração" do modelo. É realizar pelo menos uma solda com o material naquela condição de foco para obter o valor da absorção.

Também é possível estipular a partir do modelo a eficiência de proteção do bico de solda utilizado no caso do laser de fibra. As amostras 1 e 8 não apresentaram zona oxidada, ou seja, os parâmetros utilizados de fluxo, diâmetro do bico e distância bico-peça foram de maneira que protegeram a região com temperatura a partir de $600^{\circ} \mathrm{C}$.

Simulando esta isoterma nas condições 1 e 8 podemos medir a largura desta isoterma. A Tabela 6-21 mostra os valores obtidos. 
Tabela 6-21 - Valor da largura da isoterma de $600^{\circ} \mathrm{C}$ para as amostras 1 e 8

\begin{tabular}{|c|c|}
\hline Amostra & Largura da isoterma de $600^{\circ} \mathrm{C}(\mathrm{mm})$ \\
\hline 1 & 4,2 \\
\hline 8 & 3,8 \\
\hline
\end{tabular}

Observando a Tabela 6-20, temos que o menor valor de zona oxidada é de 4,6mm. Portanto, para um bico de solda com diâmetro de $4,7 \mathrm{~mm}$, com um fluxo de gás de 10 l/min e a $3 \mathrm{~mm}$ de distância da peça, a eficiência de proteção está entre 4,2 e $4,6 \mathrm{~mm}$.

\subsubsection{Microestrutura formada}

A microestrutura encontrada é igual àquela encontrada no laser pulsado, composta de grãos de alfa equiaxial com matriz de beta retida contendo alfa acicular. 

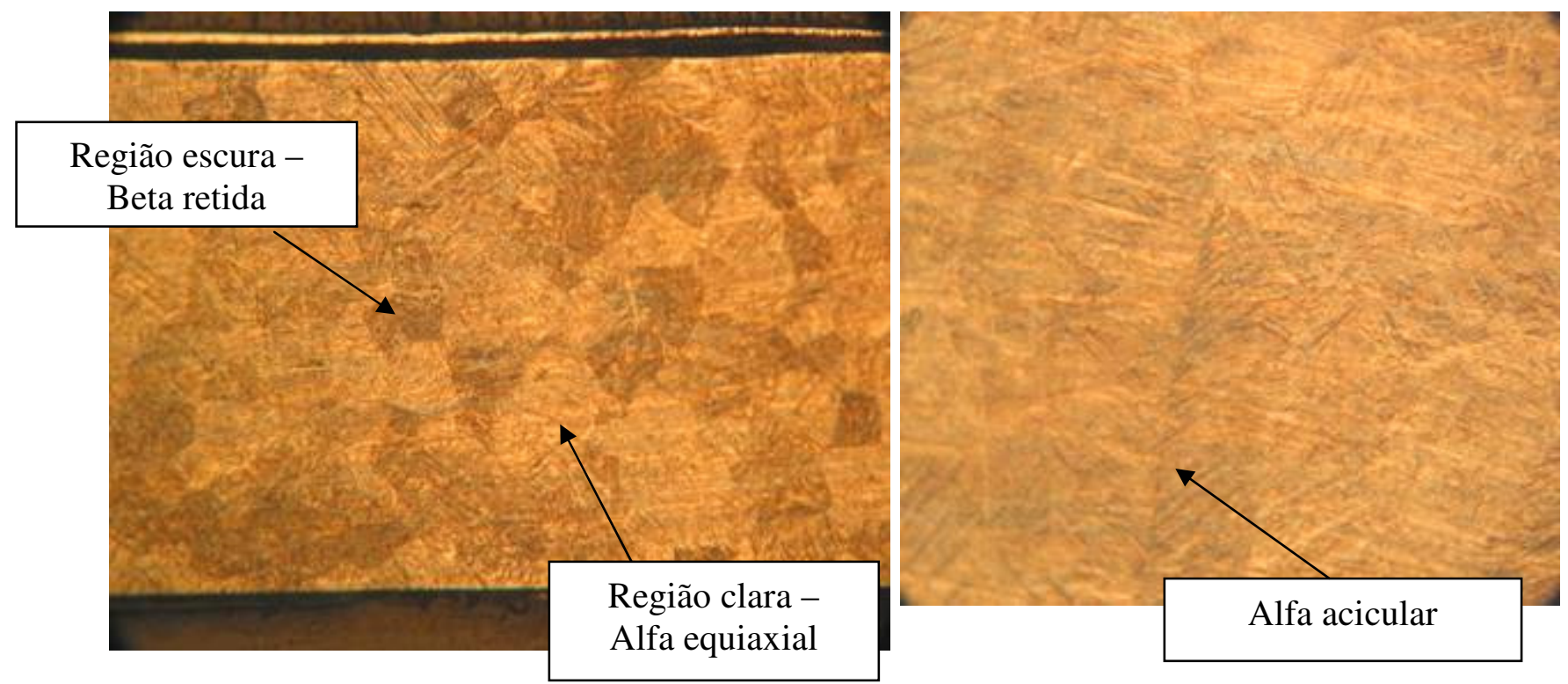

Figura 6-35 - Microestrutura formada nas soldas com penetração total

Comparando os tamanhos dos grãos formados nas duas soldas, percebese claramente que os grãos formados com o laser contínuo são maiores do que aqueles formados pelo laser pulsado.

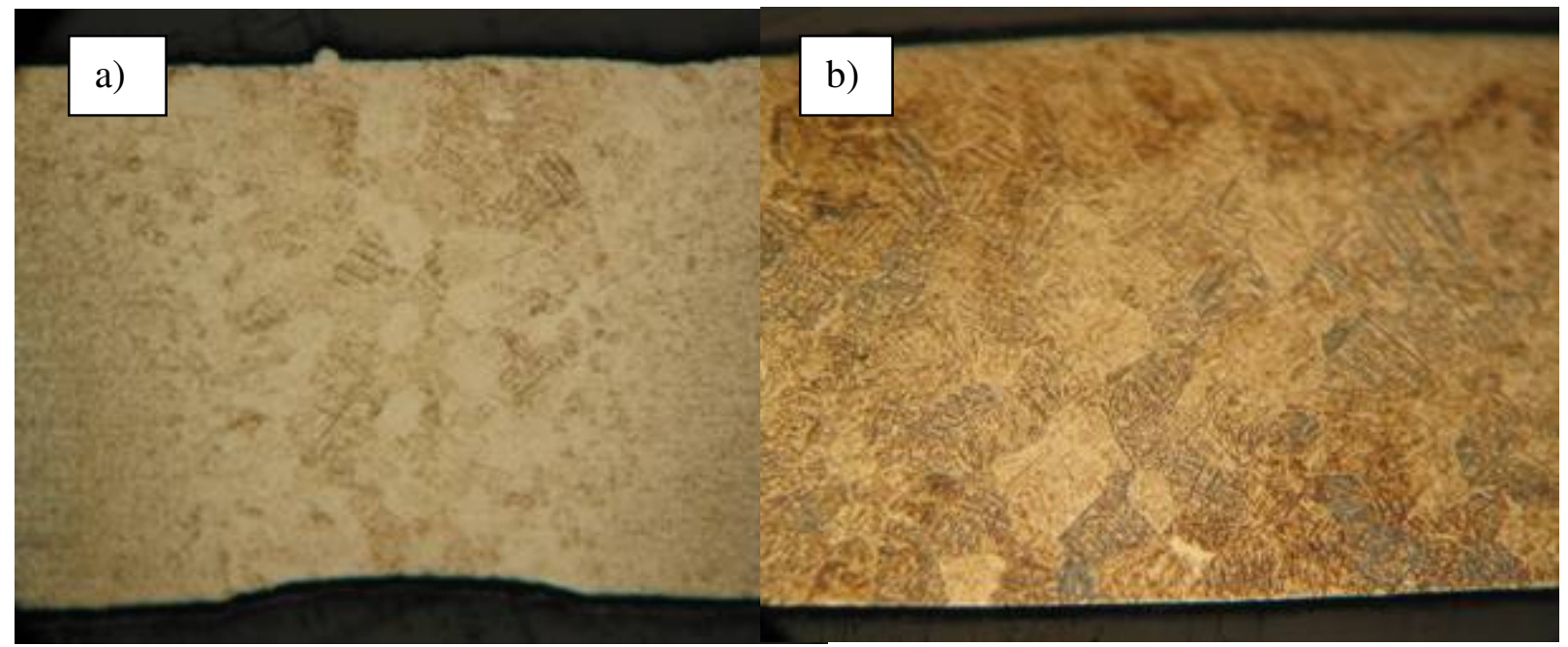

Figura 6-36 - Comparação do tamanho do grão de alfa equixial formado entre a soldagem com laser pulsado (a) e com o laser contínuo (b) 
Isto é devido ao resfriamento mais rápido sofrido no caso do laser pulsado, que faz com que os grãos não tenham tempo de crescer devidamente. Este resfriamento rápido está ligado com o tempo rápido de interação que ocorre no laser pulsado.

Esta diferença no tamanho do grão pode acarretar em uma menor resistência do cordão de laser contínuo, pois este é um dos fatores que contribuem para a alteração do valor máximo de resistência a tração, como mostrado pela equação a seguir [67]:

$$
\sigma=\sigma_{0}+\frac{\mathrm{Kw}}{\sqrt{\mathrm{d}_{\mathrm{k}}}}
$$

Onde Kw é uma constante do material, $\sigma$ é a resistência do material, $\sigma_{0}$ é a resitência do material base e $d_{k}$ é o diâmetro médio dos grãos. 


\section{CONCLUSÕES}

\section{Laser pulsado}

As análises iniciais mostraram que a diminuição da velocidade de soldagem e conseqüentemente, o aumento do aporte térmico, aumenta significativamente a quantidade de material perdido para cordões que obtiveram penetração total, porém pouco influenciam na profundidade alcançada pela poça fundida em materiais que não tiveram penetração total.

Ensaios de dureza realizados em amostras com e sem proteção por atmosfera neutra possibilitaram a visualização do aumento da dureza entre as duas condições, decorrente da maior quantidade de imperfeições causada pela falta de proteção. Mostraram também que a falta de proteção de raiz acarreta em um aumento significativo no valor de dureza nesta região da solda.

As amostras não protegidas apresentaram uma microestrutura dendrítica em toda a zona fundida, porém não foi possível detectar nem oxigênio ou nitrogênio no meio da zona fundida através da análise por EDS.

A otimização das condições de soldagem baseada nos primeiros resultados obtidos foi satisfatória, obtendo-se soldas sem perda de material e com mínima zona afetada pelo calor.

A utilização de um fluxo de 3 litros/min, com o bico de solda de $8 \mathrm{~mm}$ de diâmetro e a $2 \mathrm{~mm}$ da superfície do material é o suficiente para proteger o cordão de solda contra oxidação. 
Os cordões de solda apresentaram mudanças mínimas com a mudança do tipo de gás utilizado, o que significa que, para estas condições do laser e espessura de material, a natureza do gás não é uma variável que modificará as características físicas (largura do cordão, profundidade) ou mecânicas (resistência à tração, flexão, dureza) de maneira significativa. Isto pode ser atribuído à rápida interação do laser com o material, fazendo com que no curto espaço de tempo em que se tem o plasma, este não tenha tempo de interagir com o gás de proteção. A tendência encontrada nas amostras foi um aumento na largura do cordão para o uso do argônio (com concentrações a partir de 50\%) e para um maior fluxo de gás.

Apesar do aumento na dureza devido à aparente oxidação quando não se utilizou uma proteção de raiz, o uso ou não de um dispositivo de proteção adequado não influenciou os resultados dos ensaios de tração ou flexão, mostrando assim que o uso deste dispositivo é dispensável para estas condições de soldagem.

Comparando os resultados alcançados neste trabalho com trabalhos anteriores, houve uma diminuição significativa no uso de gás de proteção. Enquanto que havia propostas do uso de argônio na proteção axial e hélio na proteção de raiz, ambos com 10 litros/min, neste trabalho foram alcançados bons resultados de soldagem utilizando-se apenas uma proteção axial de argônio de 5 litros $/ \mathrm{min}$.

A microestrutura obtida nas amostras não oxidadas foi de alfa equiaxial com uma matriz de beta retida, sendo possível perceber a formação de alfa acicular. 


\section{Laser contínuo}

Devido à dinâmica térmica na soldagem com este laser, a proteção de raiz pareceu mais crítica, pois mesmo amostras que não apresentaram penetração total tiveram alto grau de oxidação.

Os ensaios de dureza mostraram que não houve aumento de dureza nas amostras analisadas e, portanto, não houve aumento na concentração impurezas, e seus valores estão de acordo com o já mostrado em trabalhos anteriores.

A comparação dos dois modelos de Rosenthal, com e sem perdas por convecção, foi realizada utilizando um valor alto de coeficiente de película $(h)$, mostrando que estas perdas passam a ser mais significativas para altos valores de potência e de absorção do material e para baixos valores de velocidade. Além disto, a distorção entre os dois modelos será maior quanto mais longe se estiver da fonte, ou seja, para isotermas de temperaturas mais baixas.

Comparando o modelo de Rosenthal sem perdas de calor com os resultados obtidos, foi mostrado que a zona afetada pelo calor e a zona oxidada ocorrem em média a $1100^{\circ} \mathrm{C}$ e $600^{\circ} \mathrm{C}$ respectivamente. A partir destes dados foi mostrado que o bico de solda utilizado, a $3 \mathrm{~mm}$ da superfície e com um fluxo de argônio de 10litros/min, protege uma área aproximadamente entre 4,2 e 4,6mm de raio.

Também foi percebido que o modelo não consegue bons resultados para zonas fundidas pequenas. O menor valor de zona fundida com que se conseguiu correspondência neste trabalho foi de $0,8 \mathrm{~mm}$.

A microestrutura das amostras soldadas com este laser foi muito semelhante àquela do laser pulsado, porém percebe-se claramente a formação 
de grãos de alfa equiaxial maiores, o que se dá devido ao esfriamento mais lento característico deste processo.

Em nenhuma das condições selecionadas para os dois tipos de laser foi necessário o uso de uma proteção secundária, mostrando que os bocais utilizados protegem de maneira efetiva o material aquecido.

\section{Sugestões para trabalhos futuros}

O uso de diferentes gases de proteção e condições relacionadas a estes (bico de solda, fluxo do gás, dispositivos de proteção) poderia ter uma resposta diferente para o caso de um laser contínuo, o que poderia ser citado como mais uma diferença entre os dois processos.

O cálculo do coeficiente de película, h, para o caso da soldagem a laser permitiria um estudo mais aprofundado da influência das perdas de calor por convecção no processo, impondo limites para processo que não as consideram. 


\section{APÊNDICE - MODELO DE ROSENTHAL COM PERDAS DE CALOR POR CONVECÇÃO}

\subsection{Sistemas de fontes em movimento [13]}

Pela teoria de Rosenthal, uma fonte de calor constante s está no eixo $\xi$ de um sistema de coordenadas retangular que está se movendo com uma velocidade uniforme $v$ com relação a um sistema de coordenadas estacionário e retangular $(x, y, z)-$. Aqui v é paralelo ao eixo $x$.

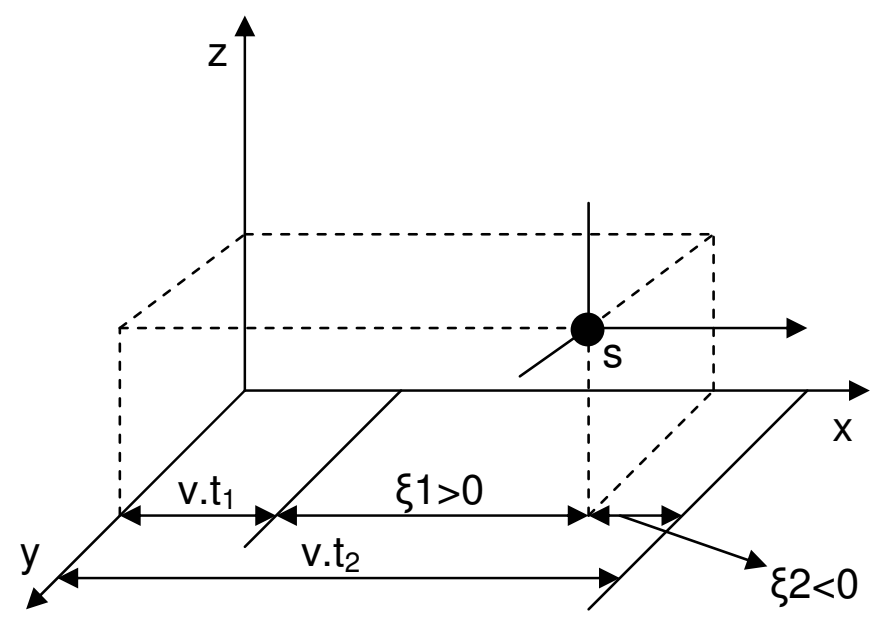

Figura 8-1- Sistema de coordenadas duplo para fontes de calor em movimento ( $\xi$ $=\mathrm{x}-\mathrm{v} \cdot \mathrm{t}$ )

Com este esquema, um observador parado no eixo $\mathrm{x}$ perceberia a mudança de temperatura ao seu redor a medida que a fonte se movesse, enquanto que um observador que estivesse parado em um ponto do eixo em movimento $\xi$ não perceberia tal mudança de temperatura. Esta condição de temperatura aparentemente estacionária foi verificada experimentalmente e se tornou conhecida como um estado quase estacionário. 
Pode-se modificar as coordenadas do sistema estacionário para o sistema de coordenadas em movimento. Por definição deste sistema, temos:

$\mathrm{x}=\xi+\mathrm{v} . \mathrm{t}$

A partir desta definição, chegamos às seguintes conclusões:

$$
\begin{aligned}
& \frac{\partial \xi}{\partial x}=1 \\
& \frac{\partial \xi}{\partial t}=-v
\end{aligned}
$$

E ainda, no estado semi-estacionário, a temperatura não varia com o tempo t' (que é relativo à fonte em movimento), portanto:

$$
\frac{\partial \mathrm{T}}{\partial \mathrm{t}^{\prime}}=0
$$

Onde t' = t. Assim:

$$
\begin{aligned}
& \frac{\partial t^{\prime}}{\partial t}=1 \\
& \frac{\partial t^{\prime}}{\partial x}=0
\end{aligned}
$$

Partindo da equação de Fourrier que considera perdas por convecção, temos:

$$
\frac{\partial^{2} \mathrm{~T}}{\partial \mathrm{x}^{2}}+\frac{\partial^{2} \mathrm{~T}}{\partial \mathrm{y}^{2}}-\left(\frac{\mathrm{h}_{1}+\mathrm{h}_{2}}{\mathrm{k} \delta}\right) \cdot \mathrm{T}=-\frac{1}{\alpha} \frac{\partial \mathrm{T}}{\partial \mathrm{t}}
$$

Como x é uma função de $\xi$ e $t$, a transformação de $x$ para suas duas variáveis será:

$$
\begin{aligned}
& \frac{\partial \mathrm{T}}{\partial \mathrm{x}}=\frac{\partial \mathrm{T}}{\partial \xi}\left(\frac{\partial \xi}{\partial \mathrm{x}}\right)+\frac{\partial \mathrm{T}}{\partial \mathrm{t}^{\prime}}\left(\frac{\partial t^{\prime}}{\partial \mathrm{x}}\right)=\frac{\partial \mathrm{T}}{\partial \xi} \\
& \frac{\partial^{2} \mathrm{~T}}{\partial \mathrm{x}^{2}}=\frac{\partial^{2} \mathrm{~T}}{\partial \xi^{2}}
\end{aligned}
$$




$$
\begin{aligned}
& \frac{\partial \mathrm{T}}{\partial \mathrm{t}}=\frac{\partial \mathrm{T}}{\partial \xi} \frac{\partial \xi}{\partial \mathrm{t}}+\frac{\partial \mathrm{T}}{\partial \mathrm{t}^{\prime}}\left(\frac{\partial t^{\prime}}{\partial \mathrm{t}}\right)=-v \frac{\partial \mathrm{T}}{\partial \xi}+\left(\frac{\partial \mathrm{T}}{\partial \mathrm{t}^{\prime}}\right) \quad \text { (ver equações } 4 \text { e 5) } \\
& \frac{\partial \mathrm{T}}{\partial \mathrm{t}}=-v \frac{\partial \mathrm{T}}{\partial \xi}
\end{aligned}
$$

Assim, substituindo (8) e (9) em (7), temos a equação de Forruier com fonte em movimento, considerando perdas de calor por convecção.

$$
\frac{\partial^{2} \mathrm{~T}}{\partial \xi^{2}}+\frac{\partial^{2} \mathrm{~T}}{\partial \mathrm{y}^{2}}-\left(\frac{\mathrm{h}_{1}+\mathrm{h}_{2}}{\mathrm{k} \delta}\right) \cdot \mathrm{T}=-\frac{\mathrm{v}}{\alpha} \frac{\partial \mathrm{T}}{\partial \xi}
$$

Segundo Schneider [13], a solução desta equação pode ser escrita da forma:

$$
T=e^{-\left(\frac{v}{2 \alpha}\right) \cdot \xi} \cdot f(\xi, y)
$$

Para escrever a equação diferencial (10) em termos de f, é preciso achar o valor das derivadas envolvidas:

$$
\begin{aligned}
& \mathrm{T}=\mathrm{e}^{-\left(\frac{\mathrm{v}}{2 \alpha}\right) \cdot \xi} \cdot \mathrm{f}(\xi, \mathrm{y}) \\
& \mathrm{k}=-\left(\frac{\mathrm{v}}{2 \alpha}\right) \cdot \xi \\
& \frac{\partial \mathrm{T}}{\partial \xi}=\frac{-\mathrm{v}}{2 \alpha} \cdot \mathrm{e}^{\mathrm{k}} \cdot \mathrm{f}+\mathrm{e}^{\mathrm{k}} \cdot \frac{\partial \mathrm{f}}{\partial \xi} \\
& \frac{\partial^{2} \mathrm{~T}}{\partial \xi^{2}}=\left(\frac{\mathrm{v}}{2 \alpha}\right)^{2} \cdot \mathrm{e}^{\mathrm{k}} \cdot \mathrm{f}-\frac{\mathrm{v}}{2 \alpha} \cdot \mathrm{e}^{\mathrm{k}} \cdot \frac{\partial \mathrm{f}}{\partial \xi}-\frac{\mathrm{v}}{2 \alpha} \cdot \mathrm{e}^{\mathrm{k}} \cdot \frac{\partial \mathrm{f}}{\partial \xi}+\mathrm{e}^{\mathrm{k}} \cdot \frac{\partial^{2} \mathrm{f}}{\partial \xi^{2}} \\
& \frac{\partial^{2} \mathrm{~T}}{\partial \xi^{2}}=\left(\frac{\mathrm{v}}{2 \alpha}\right)^{2} \cdot \mathrm{e}^{\mathrm{k}} \cdot \mathrm{f}-\frac{\mathrm{v}}{\alpha} \cdot \mathrm{e}^{\mathrm{k}} \cdot \frac{\partial \mathrm{f}}{\partial \xi}+\mathrm{e}^{\mathrm{k}} \cdot \frac{\partial^{2} \mathrm{f}}{\partial \xi^{2}} \\
& \mathrm{~T}=\mathrm{e}^{-\left(\frac{\mathrm{v}}{2 \alpha}\right) \cdot \xi} \cdot \mathrm{f}(\xi, \mathrm{y}) \\
& \mathrm{k}=-\left(\frac{\mathrm{v}}{2 \alpha}\right) \cdot \xi
\end{aligned}
$$




$$
\begin{aligned}
& \frac{\partial \mathrm{T}}{\partial \mathrm{y}}=\mathrm{e}^{\mathrm{k}} \cdot \frac{\partial \mathrm{f}}{\partial \mathrm{y}} \\
& \frac{\partial^{2} \mathrm{~T}}{\partial \mathrm{y}^{2}}=\mathrm{e}^{\mathrm{k}} \cdot \frac{\partial^{2} \mathrm{f}}{\partial \mathrm{y}^{2}}
\end{aligned}
$$

Substituindo (12) e (13) na equação (10), temos:

$$
\begin{aligned}
& \frac{\partial^{2} \mathrm{~T}}{\partial \xi^{2}}+\frac{\partial^{2} \mathrm{~T}}{\partial \mathrm{y}^{2}}-\left(\frac{\mathrm{h}_{1}+\mathrm{h}_{2}}{\mathrm{k} \delta}\right) \cdot \mathrm{T}=-\frac{\mathrm{v}}{\alpha} \frac{\partial \mathrm{T}}{\partial \xi} \\
& {\left[\left(\frac{\mathrm{v}}{2 \alpha}\right)^{2} \cdot \mathrm{e}^{\mathrm{k}} \cdot \mathrm{f}-\frac{\mathrm{v}}{\alpha} \cdot \mathrm{e}^{\mathrm{k}} \cdot \frac{\partial \mathrm{f}}{\partial \xi}+\mathrm{e}^{\mathrm{k}} \cdot \frac{\partial^{2} \mathrm{f}}{\partial \xi^{2}}\right]+\mathrm{e}^{\mathrm{k}} \cdot \frac{\partial^{2} \mathrm{f}}{\partial \mathrm{y}^{2}}-\left(\frac{\mathrm{h}_{1}+\mathrm{h}_{2}}{\mathrm{k} \delta}\right) \cdot \mathrm{e}^{\mathrm{k}} \mathrm{f}=-\frac{\mathrm{v}}{\alpha}\left(\frac{-\mathrm{v}}{2 \alpha} \cdot \mathrm{e}^{\mathrm{k}} \cdot \mathrm{f}+\mathrm{e}^{\mathrm{k}} \cdot \frac{\partial \mathrm{f}}{\partial \xi}\right)} \\
& {\left[\left(\frac{\mathrm{v}}{2 \alpha}\right)^{2} \cdot \mathrm{e}^{\mathrm{k}} \cdot \mathrm{f}-\frac{\mathrm{v}}{\alpha} \cdot \mathrm{e}^{\mathrm{k}} \cdot \frac{\partial \mathrm{f}}{\partial \xi}+\mathrm{e}^{\mathrm{k}} \cdot \frac{\partial^{2} \mathrm{f}}{\partial \xi^{2}}\right]+\mathrm{e}^{\mathrm{k}} \cdot \frac{\partial^{2} \mathrm{f}}{\partial \mathrm{y}^{2}}-\left(\frac{\mathrm{h}_{1}+\mathrm{h}_{2}}{\mathrm{k} \delta}\right) \cdot \mathrm{e}^{\mathrm{k}} \mathrm{f}+\frac{\mathrm{v}}{\alpha}\left(\frac{-\mathrm{v}}{2 \alpha} \cdot \mathrm{e}^{\mathrm{k}} \cdot \mathrm{f}+\mathrm{e}^{\mathrm{k}} \cdot \frac{\partial \mathrm{f}}{\partial \xi}\right)=} \\
& \left(\frac{\mathrm{v}}{2 \alpha}\right)^{2} \cdot \mathrm{e}^{\mathrm{k}} \cdot \mathrm{f}-\frac{\mathrm{v}}{\alpha} \cdot \mathrm{e}^{\mathrm{k}} \cdot \frac{\partial \mathrm{f}}{\partial \xi}+\mathrm{e}^{\mathrm{k}} \cdot \frac{\partial^{2} \mathrm{f}}{\partial \xi^{2}}+\mathrm{e}^{\mathrm{k}} \cdot \frac{\partial^{2} \mathrm{f}}{\partial \mathrm{y}^{2}}-\left(\frac{\mathrm{h}_{1}+\mathrm{h}_{2}}{\mathrm{k} \delta}\right) \cdot \mathrm{e}^{\mathrm{k}} \mathrm{f}-\frac{\mathrm{v}^{2}}{2 \alpha^{2}} \cdot \mathrm{e}^{\mathrm{k}} \cdot \mathrm{f}+\frac{\mathrm{v}}{\alpha} \mathrm{e}^{\mathrm{k}} \cdot \frac{\partial \mathrm{f}}{\partial \xi}=0 \\
& \frac{\partial^{2} \mathrm{f}}{\partial \xi^{2}}+\frac{\partial^{2} \mathrm{f}}{\partial \mathrm{y}^{2}}+\frac{\mathrm{v}}{\alpha} \cdot \frac{\partial \mathrm{f}}{\partial \xi}-\frac{\mathrm{v}}{\alpha} \cdot \frac{\partial \mathrm{f}}{\partial \xi}+\frac{\mathrm{v}^{2}}{4 \alpha^{2}} \cdot \mathrm{f}-\frac{\mathrm{v}^{2}}{2 \alpha^{2}} \cdot \mathrm{f}-\left(\frac{\mathrm{h}_{1}+\mathrm{h}_{2}}{\mathrm{k} \delta}\right) \cdot \mathrm{f}=0 \\
& \frac{\partial^{2} \mathrm{f}}{\partial \xi^{2}}+\frac{\partial^{2} \mathrm{f}}{\partial \mathrm{y}^{2}}+\frac{\left(\mathrm{v}^{2}-2 \cdot \mathrm{v}^{2}\right)}{4 \alpha^{2}} \cdot \mathrm{f}-\left(\frac{\mathrm{h}_{1}+\mathrm{h}_{2}}{\mathrm{k} \delta}\right) \cdot \mathrm{f}=0 \\
& \frac{\partial^{2} \mathrm{f}}{\partial \xi^{2}}+\frac{\partial^{2} \mathrm{f}}{\partial \mathrm{y}^{2}}-\frac{\mathrm{v}^{2}}{4 \alpha^{2}} \cdot \mathrm{f}-\left(\frac{\mathrm{h}_{1}+\mathrm{h}_{2}}{\mathrm{k} \delta}\right) \cdot \mathrm{f}=0 \\
& \frac{\partial^{2} \mathrm{f}}{2}+\frac{\partial^{2} \mathrm{f}}{\partial \mathrm{y}^{2}}-\left[\left(\frac{\mathrm{v}}{2 \alpha}\right)^{2}-\left(\frac{\mathrm{h}_{1}+\mathrm{h} \mathrm{h}_{2}}{\mathrm{k} \delta}\right) \cdot \mathrm{f}=0\right. \\
& (45)
\end{aligned}
$$$$
\left[\left(\frac{\mathrm{v}}{2 \alpha}\right)^{2} \cdot \mathrm{e}^{\mathrm{k}} \cdot \mathrm{f}-\frac{\mathrm{v}}{\alpha} \cdot \mathrm{e}^{\mathrm{k}} \cdot \frac{\partial \mathrm{f}}{\partial \xi}+\mathrm{e}^{\mathrm{k}} \cdot \frac{\partial^{2} \mathrm{f}}{\partial \xi^{2}}\right]+\mathrm{e}^{\mathrm{k}} \cdot \frac{\partial^{2} \mathrm{f}}{\partial \mathrm{y}^{2}}-\left(\frac{\mathrm{h}_{1}+\mathrm{h}_{2}}{\mathrm{k} \delta}\right) \cdot \mathrm{e}^{\mathrm{k}} \mathrm{f}+\frac{\mathrm{v}}{\alpha}\left(\frac{-\mathrm{v}}{2 \alpha} \cdot \mathrm{e}^{\mathrm{k}} \cdot \mathrm{f}+\mathrm{e}^{\mathrm{k}} \cdot \frac{\partial \mathrm{f}}{\partial \xi}\right)=0
$$

Também será conveniente trabalhar em coordenadas cilíndricas, cuja transformação é dada por [13]:

$$
\frac{\partial^{2} \mathrm{f}}{\partial \mathrm{x}^{2}}+\frac{\partial^{2} \mathrm{f}}{\partial \mathrm{y}^{2}}=\frac{\partial^{2} \mathrm{f}}{\partial \xi^{2}}+\frac{\partial^{2} \mathrm{f}}{\partial \mathrm{y}^{2}}=\frac{\partial^{2} \mathrm{f}}{\partial \mathrm{r}^{2}}+\frac{1}{r} \frac{\partial \mathrm{f}}{\partial \mathrm{r}}+\frac{1}{r^{2}} \frac{\partial^{2} \mathrm{f}}{\partial \varphi^{2}}
$$

Onde

$$
r=\sqrt{(x-v t)^{2}+y^{2}}
$$


$\varphi=\operatorname{arctg}\left(\frac{y}{x-v t}\right)$

Assim, temos:

$\frac{\partial^{2} \mathrm{f}}{\partial \mathrm{r}^{2}}+\frac{1}{r} \frac{\partial \mathrm{f}}{\partial \mathrm{r}}+\frac{1}{r^{2}} \frac{\partial^{2} \mathrm{f}}{\partial \varphi^{2}}-\left[\left(\frac{\mathrm{v}}{2 \alpha}\right)^{2}-\left(\frac{\mathrm{h}_{1}+\mathrm{h}_{2}}{\mathrm{k} \delta}\right)\right] . \mathrm{f}=0$

Como o campo de temperatura é simétrico em torno de $r=0$, a equação diferencial se reduz a:

$\frac{d^{2} \mathrm{f}}{d \mathrm{r}^{2}}+\frac{1}{r} \frac{d \mathrm{f}}{d \mathrm{r}}-\left[\left(\frac{\mathrm{v}}{2 \alpha}\right)^{2}-\left(\frac{\mathrm{h}_{1}+\mathrm{h}_{2}}{\mathrm{k} \delta}\right)\right] \cdot \mathrm{f}=0$

Cuja solução é uma função de Bessel que possui a solução geral [13]:

$$
f=C_{1} J_{0}\left(\sqrt{\left(\frac{\mathrm{v}}{2 \alpha}\right)^{2}-\left(\frac{\mathrm{h}_{1}+\mathrm{h}_{2}}{\mathrm{k} \delta}\right)} i r\right)+C_{2} Y_{0}\left(\sqrt{\left(\frac{\mathrm{v}}{2 \alpha}\right)^{2}-\left(\frac{\mathrm{h}_{1}+\mathrm{h}_{2}}{\mathrm{k} \delta}\right)} i r\right)
$$

Onde $\mathrm{C}_{1}$ e $\mathrm{C}_{2}$ são constantes, $\mathrm{J}_{0}$ é uma função de Bessel de ordem zero e primeiro tipo e $Y_{0}$ é uma função de Bessel de ordem zero e segundo tipo.

Ou ainda podemos representar a Equação (17) em termos de função de Bessel modificadas e re-expressas em função de T [13]:

$$
T=e^{-\left(\frac{v}{2 \alpha}\right) \xi}\left[C_{1} I_{0}\left(\sqrt{\left(\frac{\mathrm{v}}{2 \alpha}\right)^{2}-\left(\frac{\mathrm{h}_{1}+\mathrm{h}_{2}}{\mathrm{k} \delta}\right)}\right)+C_{2} K_{0}\left(\sqrt{\left(\frac{\mathrm{v}}{2 \alpha}\right)^{2}-\left(\frac{\mathrm{h}_{1}+\mathrm{h}_{2}}{\mathrm{k} \delta}\right)}\right)\right]
$$

Onde $\mathrm{I}_{0}$ é uma função de Bessel modificada de ordem zero e primeiro tipo e $\mathrm{K}_{0}$ é uma função de Bessel modificada de ordem zero e segundo tipo.

Esta solução geral precisa satisfazer as condições de fronteira:

$$
\begin{aligned}
& \frac{\mathrm{dT}}{\mathrm{dr}}=0 \quad \text { para } \mathrm{r} \rightarrow \infty \\
& -\mathrm{k}(2 \pi \mathrm{r}) \frac{\mathrm{dT}}{\mathrm{dr}}=\mathrm{q}_{0}^{\prime} \quad \quad \text { para } \mathrm{r} \rightarrow \infty
\end{aligned}
$$


A primeira condição de fronteira significa que não há variação de temperatura em pontos muito distantes da fonte, enquanto que a segunda trata da própria fonte, que será tratada como pontual e no lugar da área será calculado o perímetro.

A figura a seguir mostra o comportamento das funções modificadas de Bessel de primeiro e segundo tipo e de ordens zero e 1 [13]. 


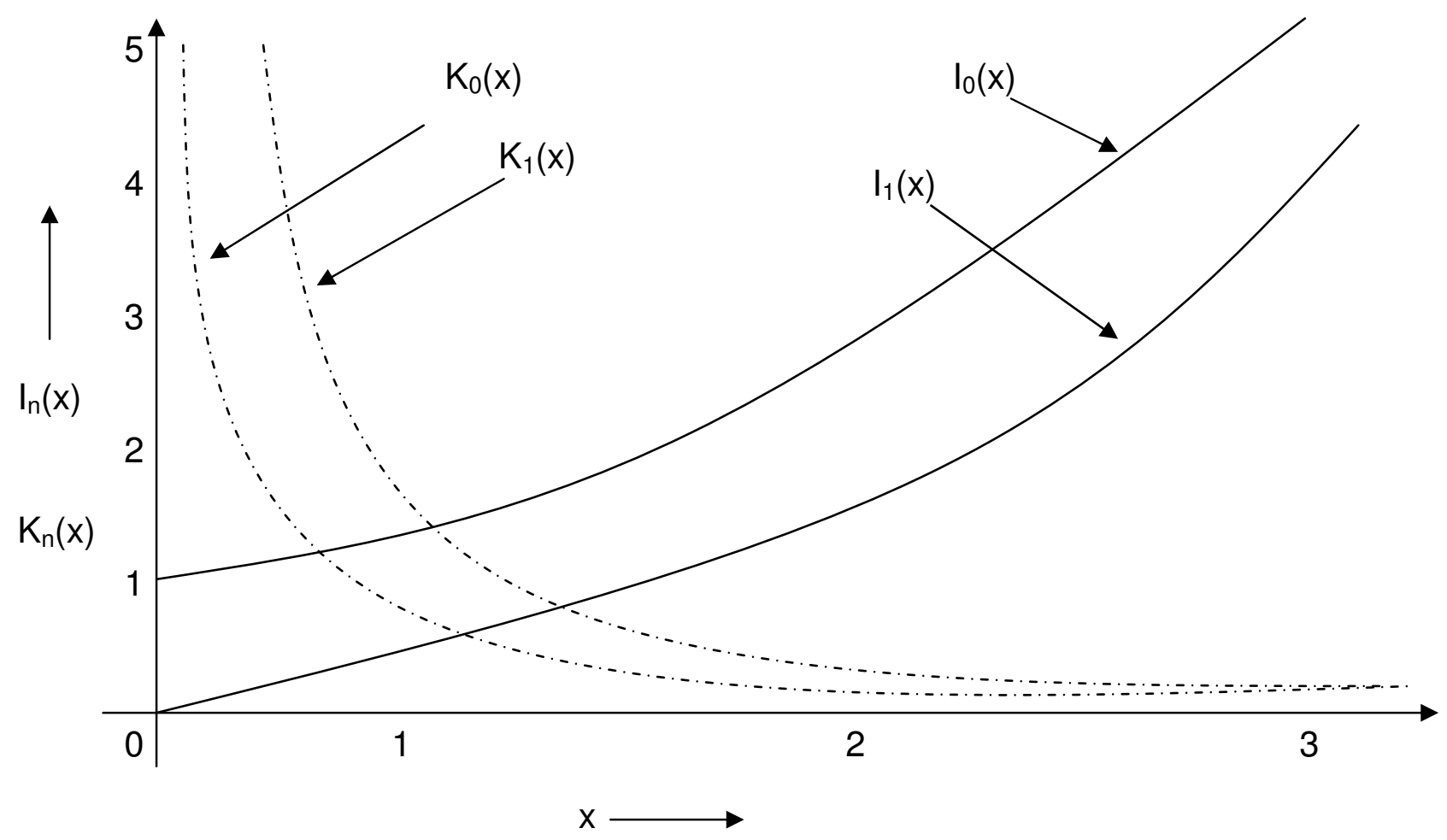

Figura 8-2- Ordens zero e um das funções modificadas de Bessel de primeiro e segundo tipo.

Observando a figura acima, observa-se que das duas funções $K_{0}$ e $I_{0}$, apenas a $\mathrm{K}_{0}$ irá satisfazer a primeira condição e tenderá a 0 para altos valores de r. Assim, $\mathrm{C}_{1}=0$, e temos:

$$
T=C . e^{-\left(\frac{v}{2 \alpha}\right) \xi} \cdot K_{0}\left(\sqrt{\left(\frac{\mathrm{v}}{2 \alpha}\right)^{2}-\left(\frac{\mathrm{h}_{1}+\mathrm{h}_{2}}{\mathrm{k} \delta}\right)}\right)
$$

Aplicando a segunda condição de fronteira:

$$
\left.\left.-\mathrm{k}(2 \pi \mathrm{r}) \frac{\mathrm{dT}}{\mathrm{dr}}\right\}_{\mathrm{r}=0}=-\mathrm{k}(2 \pi \mathrm{r})\left[-\frac{\mathrm{v}}{2 \alpha} \cdot \mathrm{C} \cdot \mathrm{e}^{-\left(\frac{\mathrm{v}}{2 \alpha}\right) \xi} \mathrm{K}_{1}\left(\frac{\mathrm{v}}{2 \alpha} \cdot \mathrm{r}\right)\right]\right\}_{\mathrm{r}=0}=\mathrm{q}_{0}{ }^{\prime}
$$

Pois a derivada de uma função de bessel modificada de ordem zero e segundo tipo é a mesma função, só que com de ordem 1. 
Para valores pequenos, $\mathrm{K}_{1}(\mathrm{x})=\mathrm{x}^{-1}$, e ainda se $\mathrm{r}$ tende a zero, $\xi$ também tende a zero $(r=0, \xi=0)$. Assim temos:

$$
\begin{aligned}
& -\mathrm{k}(2 \pi \mathrm{r})\left[-\frac{\mathrm{v}}{2 \alpha} \cdot \mathrm{C} \cdot \mathrm{e}^{-\left(\frac{\mathrm{v}}{2 \alpha}\right) \cdot 0} \frac{2 \alpha}{\mathrm{v} \cdot \mathrm{r}}\right]=\mathrm{q}_{0}{ }^{\prime} \\
& -\mathrm{k}(2 \pi \mathrm{r})\left[-\frac{\mathrm{v}}{2 \alpha} \cdot \mathrm{C} \cdot 1 \cdot \frac{2 \alpha}{\mathrm{v} \cdot \mathrm{r}}\right]=\mathrm{q}_{0}{ }^{\prime} \\
& \mathrm{k} \cdot 2 \cdot \pi \cdot \mathrm{C}=\mathrm{q}_{0}{ }^{\prime} \\
& \mathrm{C}=\frac{\mathrm{q}_{0}{ }^{\prime}}{2 \cdot \pi \cdot \mathrm{k}}
\end{aligned}
$$

Assim, a equação de Rosenthal que considera as perdas por convecção pode ser escrita como:

$$
T=\frac{\mathrm{q}_{0}{ }^{\prime}}{2 . \pi . \mathrm{k}} \cdot e^{-\left(\frac{v}{2 \alpha}\right) \xi} \cdot K_{0}\left(\sqrt{\left(\frac{\mathrm{v}}{2 \alpha}\right)^{2}-\left(\frac{\mathrm{h}_{1}+\mathrm{h}_{2}}{\mathrm{k} \delta}\right)}\right)
$$

Com $r=\sqrt{(x-v t)^{2}+y^{2}}$ e $\xi=x-v t$ 


\section{BIBLIOGRAFIA}

1 KOECHNER, Solid State Laser Engineering, 5 ed., Berlin - SpringerVerlag, 1999.

2 DUTTA MAJUMDAR, J., MANNA, I., Laser processing of materials, Sadhana, v. 28, p. 495-562, 2003.

3 QUINTINO, L., et. Al., Welding with high power fiber lasers - A preliminary study, Materials and Design, 28, p. 1231 - 1237, 2007.

4 HILL, P., Fiber laser hits $2 \mathrm{~kW}$ record mark. Opto Laser Eur 2002(July/August):9.

5 THOMY, C., SEEFELD, T., VOLLERSTEN, F., Application of high power fiber lasers in laser and MIG welding of steel and aluminium. In: Junek L, editor. Proceedings of the IIW conference on benefits of new methods and tends in welding to economy, productivity and quality, 10-15 July, Prague, Czech Republic; 2005. p. 88-98.

6 A new Generation of lasers for industrial applications: fiber lasers. Disponível em: <http://www.zugo.com.sg>. Acesso em: junho/2007.

7 ION, J. C., Laser Processing of Engineering Materials - Principles, procedure and industrial application, Ed. Elsevier, Londres, 2005.

8 DANIELSON, P., WILSON, R., ALMAN, D., Microstructure of titanium welds, Struers e-Journal of Materialography, v. 3, p. 1-7, 2004.

9 CAIAZZO, F., CURCIO, F., DAURELIO, G., ,MINUTOLO, F. M. C., Ti6Al4V sheets lap and butt joints carried out by CO2 laser: mechanical and morphological characterization, Journal of Materials Processing Technology, v. 149, p.546-55, xx/dez. 2003.

10 DRUDE, P., Theory of Optics, New York: Longmans and Green, 1922.

11 PROKHOROV, A. M., KONOV, V. I., URSU, I., MIHAILESCU, I. N., Laser Heating of Metals, Adam Hilger, Bristol, Filadelfia e Nova lorque, 1990.

12 DULEY, W. W., UV lasers: effects and applications in materials science, Nova lorque, 1996. 
13 SCHNEIDER, P. J., Conduction heat transfer, Addison-Wesley publishing company, Cambridge, 1955.

14 ROSENTHAL, D., The theory of moving sources of heat and its applications to metal treatments. Trans. ASME, 43(11), p. 849-866, 1946.

15 OLIVEIRA, A. C., Microssoldagem de chapas finas utilizando um laser de $\mathrm{Cu}$ $\mathrm{HBr}, 2006,111$ folhas, Dissertação de Mestrado, Instituto Tecnológico de Aeronáutico, São José dos Campos.

16 DONDEO, F. R., OLIVEIRA, R. F., et. al., Padrões de rugosidade produzidos em vidros, metais e materiais carbonosos com laser de $\mathrm{CO}_{2}$ e $\mathrm{Cu}$-HBR para aplicações em metrologia, In: 4ํ Congresso Brasileiro de Engenharia de Fabricação, 2007, Águas de São Pedro.

17 PHILLIPS, A. L., Welding Handbook, v. 4 - Metals and their weldability, $5^{\mathrm{a}}$ ed., Ed. Macmillan, Londres, 1966.

18 DAWES, C., Laser Welding - A practical guide, Abington Publishing, Cambridge, 1992.

19 ASW Handbook - WELDING, BRAZING AND SOLDERING.

20 BERRETTA, J. R., Solda Laser em Materiais Dissimilares com Laser de Nd:YAG Pulsado, 2005, 120 páginas, Tese de Doutorado, Universidade de São Paulo, São Paulo.

21 HO, C. Y., WEN, M. Y., Distribution of the intensity absorved by the keyhole wall in laser processing, Journal of Materials Processing Technology, 145, p. $303-310,2004$.

22 TZENG, Y., Parametric analysis of the pulsed Nd:YAG laser seamwelding process, Journal of Materials Processing Technology, v. 102, p. 40-47, out. 2000.

23 NIPPES, E. F. (ed), Metals Handbook, 9a ed., vol.6, Welding, Brazing and soldering, American Society for Metals, p.647-671, Ohio, 1983.

$24 \mathrm{LEE}$, J., KO, S. H., et al, Mechanism of keyhole formation and stability in stationary laser welding, Journal of Physics D: Applied Physics, v. 35, p. $1570-$ 1576, 2002.

25 BEYER, E., et. al., Proceedings of the Fifth International Conference on Lasers in Manufacturing, vols. 13-14, p. $233-240,1988$. 
26 L. MARA, et. al., Penetration mechanisms of electron beam welding and the spiking phenomenon, WELD. J., VOL 53, 1974, P 246S-251S

27 H. TONG AND W.H. GIEDT, A dynamic interpretation of electron beam welding, Welding Journal, VOL 49, 1970, P 259S-266S

28 GREVEY, D., et. al., Gas protection optimization during Nd:YAG laser welding, Optics \& Laser Technology, v. 37, p. 647-651, 2005.

29 ABBOTT, D. H., ALBRIGHT, C. E., CO2 shielding gas effects in laser welding mild steel, Journal of Laser Applications, v.6, p. 69-80, 1994.

30 TESKE. M., ALLENSTEIN, C. L. M., MARTINS, F., Influência da composição do gás de proteção na resistência ao impacto do aço ASTM A516 Grau 70 soldado pelo processo GMAW, In: 4ํㅡㄹ Congresso Brasileiro de Engenharia de Fabricação, 2007, Águas de São Pedro.

31 FERREIRA FILHO, D., BÁlSAMO, P. S. S., FERRARESI, V. A., Influência do tipo de gás de proteção na soldagem MIG/MAG na qualidade do cordão de aço inoxidável, In: 4ํㅡ Congresso Brasileiro de Engenharia de Fabricação, 2007, Águas de São Pedro.

32 GOTTARDO, I. A., FISCHER, C., DE PARIS, A. A. F., A influência de gases de proteção na soldagem de aço inox 304 com arame tubular, In: 4ํㅜำ Congresso Brasileiro de Engenharia de Fabricação, 2007, Águas de São Pedro.

33 SIBILlANO, T., ANCONA, A., et. Al., A study of the shielding gás influence on the laser beam welding of AA5083 aluminium alloys by in-process spectroscopic investigation, Optics and Lasers in Engineering, v. 44, p. 1039 $1051,2006$.

34 GLOWACKI, M. H., The effects of the use of different shielding gas mixtures in laser welding of metals, Journal of Physics D: Applied Physics, v. 28, p. $2051-2059,2005$.

35 NOVOPASHIN, S.A., MURIEL, A. Anomalous transition to turbulence in inert gases, JETP Letters, v. 68, n. 7, p. 582 - 584, 1998.

36 ASM HANDBOOK (REVISED VOL. 6) METALS HANDBOOK. VOLS. 12

37 HOLMAN, J. P., Heat Transfer, Nova lorque, McGraw-Hill, 1981. 
38 OLIVEIRA, V.M., Liga de Ti-35Nb-5Ta-7Zr: microestrutura e propriedades mecânicas e de corrosão. 2004. 85f. Tese Doutorado em Ciências Universidade Estadual de Campinas, Campinas.

39 BETNER, D. R., et. Al., Introduction to Titanium and its Alloys. 9th Edition. Ohio: Metals Handbook, American Society for Metals, v.3, p. $353-360$, 1985.

40 COLLINGS, E. W., The Physical Metallurgy of Titanium Alloys. Ohio: American Society for Metals. Metals Park, 261p., 1984.

41 BENTO, C. A. S., Estudo da interface Ti6Al4V/TiO2 por microscopia eletrônica de varredura. 2000. 83f. Dissertação de mestrado - Universidade Federal de São Carlos, São Carlos.

42 ROCHA MELO, G. M., Transformações de fases e características microestruturais de ligas Ti-Al e Ti-Nb. 2000. 99f. Dissertação de Mestrado Universidade Estadual de Campinas, Campinas.

43 ROLINSKI, E., lon nitriding of titanium alpha plus beta alloy for fusion reactor applications, Journal of Nuclear Materials, n. 256, p. 200-208, 1998.

44 VIEIRA, A. K., Corrosão de ligas de titânio recobertas com filmes de carbono tipo diamante (DLC) em meio contendo cloreto. 2003. 107f., Tese de Doutorado - Instituto Tecnológico da Aeronáutica, São José dos Campos.

45 WEISS, I., Advances in the Science and Technology of titanium Alloy Processing, A Publication of the Minerals, Metals \& Materials Society, Warrendale, Pennsylvania, USA; 1996.

46 FLOWER, H. M., Microstructural Development in Relation to Hot Working of Titanium Alloys, Materials Science and Technology, v. 6, p. 1082, 1990.

47 SAULINER, A., DEVELAY, R., Structures et propriétes caractéristiques de quelques alliages de titane, Publications Scientifiques et techniques Du Ministére de L'air, 1961.

48 KRÝSA, J., MRÁZ, R., ROUSAR, I., Corrosion rate of titanium in $\mathrm{H}_{2} \mathrm{SO}_{4}$, Materials Chemistry and Physics, v. 48 (1), p. 63 - 67, 1997. 
49 GONZÁLEZ, J. E. G., MIRZA-ROSCA, J. C., Study of the corrosion behavior of titanium and some of its alloys for biomedical and dental implant applications, Journal fo Electroanalytical Chemistry, v. 471, p. $109-115,1999$.

50 BARBIERI, F. C., Modificações das propriedades superficiais da liga Ti6Al4V por processo de nitretação de plasma. 2001.153f., Dissertação de Mestrado - Instituto Tecnológico da Aeronáutica, São José dos Campos.

51 MatWeb, The Online Materials Database. Disponível em <http://www.matweb.com/search/SpecificMaterial.asp?bassnum=MTP641>. Acesso em: 30/07/2007.

52 Metals handbook - 9th Editon - vol. 9, Metallography and microstructures

53 JAFEE, R. I., Titanium Science and Technology, vol. 3, Plenum Press, Nova lorque - Londres, 1973.

54 Spreadsheet Aplications for Materials Science. Diffusion of Oxygen into Titanium. Disponível em http://www.matsci.ucdavis.edu/meier/sams/Modules/Kinetics/Oxidation.htm Acesso em: 04/02/2007.

55 SHEWMON, P. G., Transformations in metals, McGraw-Hill Book Company, New York, 1969.

56 KORNILOV, I.I., Titanium and titanium alloys, publication n. 10, 1963.

$57 \mathrm{LI}, \mathrm{X}$., XIE, J., ZHOU, Y., Effects of oxygen contamination in the argon shielding gas in laser welding of commercially pure titanium thin sheet, Journal of Materials Science, v. 40 (13), p. 3437 - 3443, 2005.

58 REALUM - Indústria e comércio de metais puros e ligas Itda. Disponível em: <http://www.realum.com.br/titanio3.htm> Acesso em: 15 fevereiro 2008

59 ZHANG, L., GOBBI, S. L., NORRIS, I., ZOLOTOVSKY, S., RICHTER, K. $\mathrm{H}$. , Laser welding techniques for titanium alloy sheet, Journal of Materials Processing Technology, v. 65, p. 203-208, ago, 1997. 
60 MEHL, R. F. (ed), Metals Handbook, 8 ${ }^{\text {a }}$ ed., vol.6, Atlas of microstructures of industrial alloys, American Society for Metals, p.321-334, Ohio, 1972.

61 Metals handbook - 9th Editon - vol. 9, Metallography and microstructures.

62 BARTIKOWIAK, K., et. al., 2D laser forming comparative study on $\mathrm{Nd}$ :YAG of titanium alloy Ti6Al4V, In: 23rd International Congress on Laser Applications and Electro-Optics (ICALEO 2004), 2004, São Francisco, Califórnia

63 SARESH, N., PILLAI, M. G., MATHEW, J., Investigations into the effects of electron beam welding on thick TiAl4V titanium alloy, Journal of Materials Processing Technology, v. 192-193, p. 83 - 88, 2007.

64 Steen, W. M., Laser Material Processing, 3 ed., Springer - Verlag London Limited, 2003.

65 ANTONY, J., ANTONY, F. J., Teaching the Taguchi method to industrial engineers, Work Study, vol. 50, n. 4, p. 141 - 149, 2001

66 INTRODUCTION TO TAGUCHI METHOD. Disponível em http://www.ee.iitb.ac.in/ apte/CV_PRA_TAGUCHI_INTRO.htm. Acesso em 04 de abril de 2008.

67 RICHTER, K., BEHR, W., REISGEN, U., Low heat welding of titanium materials with a pulsed Nd:YAG laser, Mat.-wiss. U. Werkstofftech, 38, n. 1, 2007. 